Aus der Arbeitsgruppe Endokrinologie

(Prof. Dr. med. W. Wuttke)

der Medizinischen Fakultät der Universität Göttingen

\title{
Die Auswirkung von DHT, Östradiol und den Phytoöstrogenen Genistein und Equol auf das muskuloskelettale System sowie die Prostata unter Einfluss von Vibrationstherapie bei orchidektomierten Ratten
}

\author{
INAUGURAL-DISSERTATION \\ zur Erlangung des Doktorgrades \\ der Medizinischen Fakultät \\ der Georg-August-Universität zu Göttingen
}

vorgelegt von

Verena Henker

aus

Freudenstadt

Göttingen 2011 
Dekan:

1. Berichterstatter:

2. Berichterstatter/in:

3. Berichterstatter/in:

Tag der mündlichen Prüfung:
Prof. Dr. med. C. Frömmel

Prof. Dr. med. W. Wuttke 


\section{Inhaltsverzeichnis}

\section{$\underline{\text { Abkürzungsverzeichnis }}$}

1Einleitung.............................................................1

1.1 Allgemein 1

1.2 Steroide 3

1.2.1 Sexualhormone 3

1.2.2 Der Steroidrezeptor 4

1.2.3 Hormontherapie 5

1.2.4 SERMs und SARMs 6

1.3 Phytoöstrogene $\quad 7$

1.3.1 Genistein 8

1.3.2 Equol 9

$\begin{array}{ll}1.4 \text { Das muskuloskelettale System } & 10\end{array}$

$\begin{array}{lll}\text { 1.4.1 Sarkopenie } & 10\end{array}$

$\begin{array}{lll}\text { 1.4.2 Osteoporose } & 12\end{array}$

$\begin{array}{lll}\text { 1.4.3 Vibrationstherapie } & 13\end{array}$

$\begin{array}{lll}1.5 \text { Die Prostata } & 15\end{array}$

1.6 Ziel der Untersuchung $\quad 18$

2 Material und Methoden...................................................19

$\begin{array}{lll}2.1 \text { Tierexperiment } & 19\end{array}$

2.1.1 Versuchstiere und deren Haltung 19

$\begin{array}{ll}2.1 .2 \text { Versuchsablauf } & 19\end{array}$

$\begin{array}{ll}2.1 .3 \text { Orchidektomie } & 20\end{array}$

2.1.4 Durchführung der Vibrationstherapie 21

2.1.5 Gruppeneinteilung und Testsubstanzen 21

2.2 Histologische Aufarbeitung 22

2.2.1 Die Hämatoxylin- und Eosinfärbung 22 
2.3 Datenerhebung 23

$\begin{array}{lll}2.3 .1 & \text { M. gastrocnemius } & 23\end{array}$

2.3.2 Prostata 24

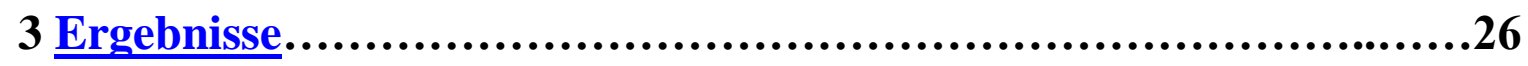

3.1 M. gastrocnemius 26

3.1.1 Der Effekt von DHT, E2, Genistein und Equol zwei Wochen 26 $\underline{\text { nach Futterumstellung auf die Muskelfaserfläche des M. gastrocnemius }}$

3.1.2 Der Effekt von DHT, E2, Genistein und Equol drei Wochen $\quad 27$ nach Futterumstellung auf die Muskelfaserfläche des M. gastrocnemius

3.1.3 Der Effekt von DHT, E2, Genistein und Equol acht Wochen 28 nach Futterumstellung auf die Muskelfaserfläche des M. gastrocnemius bei nicht vibrierten Tieren

3.1.4 Der Effekt von DHT, E2, Genistein und Equol acht Wochen 29 nach Futterumstellung auf die Muskelfaserfläche des M. gastrocnemius nach Vibrationstherapie für 10 Tage

3.1.5 Der Effekt von Vibrationstherapie vs. nicht Vibrationstherapie $\quad 30$ acht Wochen nach Futterumstellung

3.1.6 Der Verlauf der Größe der Muskelfaserfläche des M. gastrocnemius $\quad 31$ der sojafreien Kontrollgruppe über einen Zeitraum von 8 Wochen

3.1.7 Der Verlauf der Größe der Muskelfaserfläche des M. gastrocnemius $\quad 32$ der Genistein-Gruppe über einen Zeitraum von 8 Wochen

3.1.8 Der Verlauf der Größe der Muskelfaserfläche des M. gastrocnemius $\quad 33$ der Equol-Gruppe über einen Zeitraum von 8 Wochen

3.1.9 Der Verlauf der Größe der Muskelfaserfläche des M. gastrocnemius 34 der E2-Gruppe über einen Zeitraum von 8 Wochen

3.1.10 Der Verlauf der Größe der Muskelfaserfläche des M. gastrocnemius $\quad 35$ der DHT-Gruppe über einen Zeitraum von 8 Wochen

3.2 Prostata 36

3.2.1 Der Effekt von DHT, E2, Genistein, und Equol nach zwei Wochen 36 Futterumstellung auf die Epitheliumdicke der Prostata

3.2.2 Der Effekt von DHT, E2, Genistein, und Equol nach drei Wochen $\quad 37$ 
Futterumstellung auf die Epitheliumdicke der Prostata

3.2.3 Der Effekt von DHT, E2, Genistein, und Equol nach acht Wochen $\quad 38$ Futterumstellung auf die Epitheliumdicke der Prostata, in Schnittmitte gemessen

3.2.4 Der Effekt von DHT, E2, Genistein, und Equol nach acht Wochen 39 Futterumstellung auf die Epitheliumdicke der Prostata, am Schnittrand gemessen

3.2.5 Der Verlauf der Epitheliumdicke der Prostata der 40 sojafreien Kontrollgruppe über acht Wochen

3.2.6 Der Verlauf der Epitheliumdicke der Prostata der Genistein-Gruppe 41 über acht Wochen

3.2.7 Der Verlauf der Epitheliumdicke der Prostata der Equol-Gruppe 42 über acht Wochen

3.2.8 Der Verlauf der Epitheliumdicke der Prostata der E2-Gruppe 43 über acht Wochen

3.2.9 Der Verlauf der Epitheliumdicke der Prostata der DHT-Gruppe $\quad 44$ über acht Wochen

4 Diskussion. .45

5 Zusammenfassung............................................................53

6 Anhang...............................................................55

6.1 Histologische Abbildungen $\quad 55$

6.2 Standardprotokoll der Hämatoxylin- und Eosinfärbung 57

6.3 Lösungen 58

6.4 Gebrauchsgüter 59

6.5 Verzeichnis der Abbildungen und Tabellen $\quad 60$

$\begin{array}{lll}6.5 .1 & \text { Abbildungen } & 60\end{array}$

6.5.2 Tabellen $\quad 62$

$7 \quad$ Literatur......................................................63 


\section{Abkürzungsverzeichnis}

\begin{tabular}{|l|l|}
\hline AR & Androgenrezeptor \\
\hline BPH & Benigne Prostatahyperplasie \\
\hline DHEA & Dehydroepiandrosteron \\
\hline DHT & Dihydrotestosteron \\
\hline E2 & Östradiol \\
\hline ER & Östrogenrezeptor \\
\hline Hb & Hämoglobin \\
\hline HE & Hämatoxylin und Eosin \\
\hline HRT & Hormonersatztherapie \\
\hline IGF-1 & Insulin-like growth factor 1 \\
\hline LOH & Late-onset-Hypogonadismus \\
\hline ORX & orchidektomiert \\
\hline SARM & Selektiver Androgenrezeptor-Modulator \\
\hline SERM & Selektiver Östrogenrezeptor-Modulator \\
\hline sf & sojafrei \\
\hline T & Testosteron \\
\hline TNF- $\alpha$ & Tumor-Nekrose-Faktor $\alpha$ \\
\hline
\end{tabular}




\section{Einleitung}

\subsection{Allgemein}

Die Bevölkerung Deutschlands wird zunehmend älter. Heute sind bereits $20 \%$ der Bevölkerung 65 Jahre oder älter, im Jahre 2060 wird dieser Anteil auf 34\% ansteigen (statistisches Bundesamt 2009). Die heutige Lebenserwartung von Frauen beträgt 82 Jahre, die von Männern 77 Jahre. Im Jahre 2060 wird sich diese für Frauen auf 89 Jahre und für Männer auf 85 Jahre erhöhen, d.h. der Anteil der Bevölkerung über 65 Jahren steigt an und ebenso erhöht sich die generelle Lebenserwartung (statistisches Bundesamt 2009). Entsprechend erhöht sich auch die Anzahl der altersabhängigen Krankheiten und die damit verbundenen Folgeerkrankungen (Icks et al. 2008). Eine genaue Kenntnis der körperlichen Veränderungen des alternden Menschen ist daher unabdingbar, sowohl von bereits eingetretenen Erkrankungen, wie auch zu deren Prävention. So ist der altersbedingte Hormonabfall beim Mann schleichend und individuell unterschiedlich. Ab dem 40. Lebensjahr fällt der Serum-Testosteronspiegel des freien Testosterons um ca. 1\% pro Jahr ab und kann in der 5.-6. Lebensdekade klinisch manifest werden (Schill 2001).

Die klinischen Symptome werden in Kombination mit einem messbaren Absinken des Serum-Testosteronspiegels unter dem Begriff „late-onset hypogonadism“ (LOH) zusammengefasst (Weidner 2000; Zitzmann 2008; Vasan 2006). Es kann hierbei zu verschiedenen, individuell unterschiedlich ausgeprägten Symptomen kommen; aufgrund dieser Variabilität ist es oftmals schwierig, die Diagnose eines LOHs zu stellen (Morales 2004).

Neben Symptomen wie Reduktion der Libido, affektiven und kognitiven Veränderungen und Osteoporose kann es auch zu benignen und malignen Veränderungen der Prostata sowie zu einer Abnahme der Muskelmasse kommen (Hochreiter et al. 2005; Lenk 2005). Im Rahmen dieser Arbeit untersuchten wir anhand eines Tiermodells den Einfluss von Androgenen, Östrogen und Phytoöstrogenen auf die Prostata und den M. gastrocnemius von männlichen orchidektomierten Ratten.

Die Wirkung von Androgenen an der Prostata der Ratte konnte in einigen Studien nachgewiesen werden. So stellten Sandford et al. fest, dass unter Entzug von Androgenen die Apoptoserate der Prostata stieg und das Volumen sank (Sandford et al. 1984). Ein Grund dafür könnte die veränderte Durchblutung in Teilen der Prostata sein (Lekas et al. 1997; Shabsigh et al. 1998). Lekas et al. konnten nachweisen, dass sich nach der Kastration männlicher Ratten die Durchblutung in den ventralen Teilen der Prostata 
reduzierte. Dieser Effekt war kurz nach der Kastration durch Zugabe von Testosteron (T) wieder rückgängig zu machen. Die Wirkung von Östradiol (E2) auf die Prostata wurde erst kürzlich untersucht. Hierbei konnte eine direkte modulierende Wirkung von E2 über Östrogenrezeptoren $\alpha$ und $\beta$ (ER $\alpha$ und ER $\beta$ ) festgestellt werden (Ellem und Risbridger 2009a; McPherson et al. 2007; Prins et al. 2001). Kaushik et al. fanden heraus, dass eine langfristige Zugabe von E2 in der Prostata die Anzahl von Androgenrezeptoren senkt, was auf das Volumen der Prostata allerdings keinen Einfluss hat (Kaushik et al.2010).

Der zweite Aspekt dieser Arbeit widmete sich der Veränderung der Muskelmasse unter dem Einfluss von Sexualhormonen. Sarkopenie, der Verlust der Muskelmasse im Alter, kann zu allgemeiner Schwäche und Gebrechlichkeit mit Verminderung der Lebensqualität führen (Nikolic et al. 2005). Zwischen dem 25. und 80. Lebensjahr findet eine Reduktion der Muskelmasse um ca. 40\% (Adamo und Farrar 2006) statt, wobei sich diese ab dem 60. Lebensjahr stark beschleunigt. Ursächlich hierfür scheint ein Rückgang von E2 und T zu sein (Borst et al. 2007; Dieli-Conwright et al. 2009; Enns et al. 2008; Tiidus et al. 2005). Die anabole Wirkung von $\mathrm{T}$ auf den Muskel ist gut erforscht. Durch Applikation von supraphysiologischen Dosen von T konnte eine Zunahme der Muskelkraft, wie auch der Muskelmasse gezeigt werden (Bhasin et al. 2001; Borst et al. 2007), was nach Reduktion von $\mathrm{T}$ wieder reversibel war. Entsprechend bewirkt also ein Abfall von $\mathrm{T}$ eine Abnahme der Muskulatur.

Der Effekt von E2 auf den Muskel ist derzeit noch nicht vollständig erforscht und Gegenstand einiger Untersuchungen. Thomas et al. konnten zeigen, dass E2 die Aktivität von Myoblasten über ER $\alpha$ stimuliert und so nach einer Trainingseinheit zur Reparatur und Aufbau des Muskels beiträgt (Thomas et al. 2009).

Die erwünschten wie auch die unerwünschten Wirkungen der Sexualhormone auf die Muskulatur und die Prostata sollen nun in den folgenden Kapiteln anhand eines Modells an Ratten besprochen werden. 


\subsection{Steroide}

Steroide sind lipophile Hormone, die in ihren Zielzelle die Expression verschiedener Gene modulieren (Falkenstein et al. 2000).

Steroidhormone besitzen als strukturelle Grundlage ein Sterangerüst, das sich von Cholesterin ableitet. Die einzelnen Hormone unterscheiden sich in ihren funktionellen Gruppen an verschiedenen Positionen, was auch ihre unterschiedliche biologische Wirkung erklärt.

Man unterteilt die Steroidhormone in sechs unterschiedliche Gruppen; hierzu gehören auch die weiblichen und männlichen Sexualhormone.

\subsubsection{Sexualhormone}

Die wichtigsten Vertreter der weiblichen und männlichen Sexualhormone im menschlichen Körper sind Östrogene und T. T wird hauptsächlich in den Hoden und in geringen Mengen auch in der Nebennierenrinde synthetisiert.

Durch das Enzym Aromatase, das in peripheren Geweben wie Fett und Bindegewebe, sowie beim Mann und der männlichen Ratte in den Hoden und der Prostata zu finden ist, kann T zu E2 umgewandelt werden (Ellem und Risbridger 2006; Marts et al. 1987; Marks und Petrow 1983). Ein Mangel an Aromatase kann, durch den darausfolgenden Mangel an E2, beim Mann zu Knochenzubstanzverlust und Osteoporose führen.

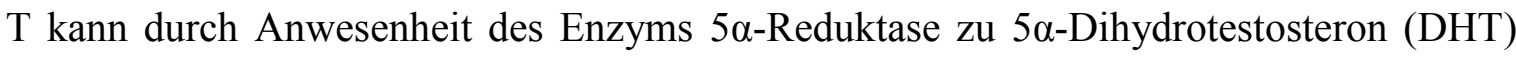
umgewandelt werden. DHT hat eine zweieinhalbfach stärkere biologische Wirkung als T (Zhu 2005).

Die Konversion zu DHT erfolgt innerhalb der Zielzelle selbst. Wie T übermittelt DHT seine Wirkung über die Bindung an den intrazellulären Androgen- Rezeptor. 5 $\alpha$ Reduktase ist nicht in allen androgenabhängigen Geweben zu finden, daher besteht für DHT eine enzymabhängige Gewebe-Spezifität. 


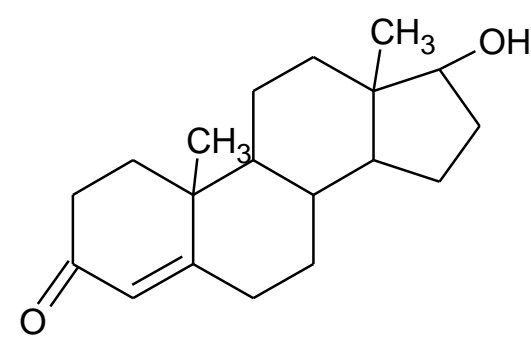

Testosteron

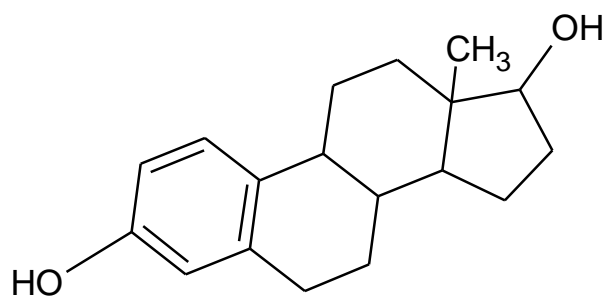

Östradiol

Abb.1: Strukturformeln von Testosteron und Östradiol

\subsubsection{Der Steroidrezeptor}

Durch Bindung an den intrazellulären Steroidrezeptor entfalten Steroidhormone ihre biologische Wirksamkeit. Der aktivierte Hormon-Rezeptor-Komplex gelangt nun in den Zellkern, wo er Gensequenzen abliest.

Aufgrund ihrer strukturellen Ähnlichkeit werden die einzelnen nukleären Rezeptoren zu einer Superfamilie der Steroidhormonrezeptoren zusammengefasst. Dazu gehören u.a. die beiden ER $\alpha$ und ER $\beta$ und der Androgenrezeptor (AR).

ER $\alpha$ und ER $\beta$ haben unterschiedliche und differenzierte biologische Funktionen, wobei ER $\alpha$ hauptsächlich für Wachstum und Proliferation verantwortlich ist, während ER $\beta$ hemmend und abschwächend wirkt (Muthyala et al. 2004; Weihua et al. 2000). Die beiden Östrogenrezeptoren werden gewebe- und zellabhängig exprimiert. Im Muskel beispielsweise sind beide Östrogenrezeptoren vorhanden. Eine Aktivierung des ER $\alpha$ stimuliert die sogenannten Satelliten-Zellen der Muskulatur. Diese liegen zwischen der Lamina basilaris und dem Sarkolemm des Muskelfaszikels und sind für die Proliferation und Regeneration der Muskulatur verantwortlich. Außerdem wird über die ER $\alpha$ Stimulation die Aufnahme von Glukose in den Muskel erhöht. Dieses erhöhte Angebot an Energie führt zu einem anabolen Muskelstoffwechsel (Glenmark et al. 2004). ER $\beta$ dagegen wirkt hemmend auf die beschriebene Muskelhomöostase (Glenmark et al. 2004). Androgene haben auf den Organismus eine vielfältige Wirkung. Durch Bindung an den AR können, wie auch bei den Östrogenrezeptoren, selektiv Gene abgelesen und in die entstprechenden Zielproteine umgesetzt werden. Auch hier spielen das Zielgewebe, gewebespezifische Cofaktoren sowie weitere Transkriptionsfaktoren eine modulierende Rolle auf die jeweilige Wirkung (Heinlein und Chang 2002). 


\begin{tabular}{|l|l|}
\hline Wirkung von Östrogenen auf & Wirkung von Androgenen auf \\
\hline ZNS: kognitive Funktionen, Emotionen, Libido & $\begin{array}{l}\text { Wachstum und Differenzierung der } \\
\text { Fortpflanzungsorgane }\end{array}$ \\
\hline $\begin{array}{l}\text { hypothalamische Funktion: Temperatur,Herz- } \\
\text { Kreislauf }\end{array}$ & sekundäre Geschlechtsmerkmale \\
\hline Skelett: antiosteoporotische Wirkung & Spermatogenese \\
\hline $\begin{array}{l}\text { Beeinflussung von Faktoren: IL-1,IL-6, TNF-a, } \\
\text { PGE }\end{array}$ & Stimulation von Erythropoetin \\
\hline hypophysär modulierende Funktion & ZNS: Libido, Emotion \\
\hline Fettstoffwechsel & Potenz \\
\hline & Muskulatur \\
\hline
\end{tabular}

Tab.1: Wirkung von Östrogenen und Androgenen beim Mann

\subsubsection{Hormontherapie}

Die sukzessive Abnahme des Gesamt-Testosteronspiegels beim Mann kann von klinischen Symptomen unterschiedlicher Schwere begleitet sein. Durch eine Hormontherapie mit $\mathrm{T}$ kann man versuchen, diesen Symptomen entgegenzuwirken (Weidner 2000; Zitzmann 2008; Vasan 2006). Entsprechend gibt es den therapeutischen Ansatz der Hormontherapie mit T, was jedoch die Gefahr von Nebenwirkungen birgt, da Hormone ubiquitär wirken und unterschiedliche Zielgewebe haben. Bei der Gabe von T kann es daher zu unerwünschten Wirkungen wie beispielsweise Thrombosen und Veränderungen der Prostata kommen (Hochreiter et al. 2005; Lenk 2005; Zitzmann 2008).

Der Verdacht, dass unter Gabe von $\mathrm{T}$ durch eine Überstimulation des Wachstums ein Prostatakarzinom entstehen kann, konnte bisher nicht abschließend geklärt werden (Drewa und Chlosta 2010).

Weitere Langzeitstudien sind nötig, um den Nutzen und das Risiko einer Hormonersatztherapie abwägen zu können (Page et al. 2005). Sie sollte nur in Betracht gezogen werden, wenn eine Beschwerdesymptomatik und ein objektivierbarer Hypogonadismus zusammen vorzufinden sind (Diemer et al. 2005). Um die Gefahr von ernsten Nebenwirkungen zu minimieren, sollte daher eine Organselektivität angestrebt werden. 


\subsubsection{SERMs und SARMs}

Hormone kommen ubiquitär im Körper vor und übermitteln ihre Wirkung in verschiedenen Gewebearten. Dies kann innerhalb einer Hormontherapie zu unerwünschten Wirkungen führen. Um das Risiko dieser Nebenwirkungen zu minimieren oder zu umgehen, werden „Selektive Östrogenrezeptor-Modulatoren“ (SERMs) eingesetzt. Sie binden an ER $\alpha$ und/oder an ER $\beta$ und entfalten gewebeabhängig ihre agonistische oder antagonistische Östrogen-ähnliche Wirkung. SERMs und seine Metabolite können des Weiteren an anderen Steroidrezeptoren wie Androgen- und Progesteronrezeptoren binden. Darüber hinaus können SERMs auch an andere Rezeptoren, zum Beispiel Membranrezeptoren, binden und so nicht-steroidale Wirkungen hervorrufen (Clarke und Khosla 2009).

Raloxifen beispielsweise bindet an beide Östrogenrezeptoren und wurde ursprünglich mit dem Ziel der Anwendung bei Brustkrebs erforscht. Es ist wirksam bei Hormonrezeptorpositiven Brustkrebsarten, indem es kompetitiv an den Hormonrezeptor bindet und somit ein Hormon-induziertes Tumorwachstum erschwert. Besonders effektiv ist es jedoch im Knochen durch seine partielle Östrogenwirkung und wird daher häufig bei Osteoporose eingesetzt (An et al. 2001; Clarke und Khosla 2009). Darüber hinaus hat Raloxifen auch eine positive Wirkung auf Muskelzellen. So konnte nachgewiesen werden, dass Raloxifen über ER $\alpha$ auf die Muskelzellen aktivierend wirkt (Dieli-Conwright et al. 2009).

Eine andere natürlich vorkommende Gruppe mit selektiver E2-Wirkung sind die Phytoöstrogene (Lund et al. 2004). Sie wirken ebenso rezeptor- und gewebespezifisch und entfalten so agonistische wie auch antagonistische Wirkungen. Auf die in unserem Versuch genutzten Phytoöstrogene Genistein und Equol wird im Kapitel Phytoöstrogene genauer eingegangen.

Das altersabhängige Absinken des Testosteronspiegels kann durch eine Hormonersatztherapie mit $\mathrm{T}$ verhindert und dadurch viele Symptome des LOHs gemildert werden. Allerdings können unerwünschte Wirkungen wie Thrombosen, Akne und Hirsutismus auftreten, ebenso wie Veränderungen der Prostata (Hochreiter et al. 2005; Lenk 2005; Zitzmann 2008). Selektive Androgenrezeptor-Modulatoren (SARM) könnten analog zu den SERMs eine gewebeabhängige agonistische oder antagonistische Wirkung hervorrufen. Erwünschte Einflüsse wie die anabole T-Wirkung auf die Muskulatur könnten so von unerwünschten Effekten getrennt werden.

Die Anforderungen an SARMs beschrieb Negro-Vilar (1999). So sollen sie eine hohe ARSpezifität, eine hohe orale Bioverfügbarkeit und eine gewebeabhängige pharmazeutische 
Wirkung haben (Negro-Vilar 1999). Nach diesem Konzept wurden Ende der 1990er Jahre die ersten nicht-steroidalen Androgen-Matrizen, die Propionamide und Quinolinone, entdeckt und bald darauf in einer präklinischen „proof-of-principle“ Studie auf die Muskel- und Knochenwirkung in vivo getestet (Mohler et al. 2009). Sie bildeten die Grundlage weiterer pharmakologischer Forschung. Gao et al. testeten DHT und S-3-(4acetylamino-phenoxy)-2-hydoxy-2-methyl-N-(4-nitro-3-trifluoromethyl-phenyl)propionamid (S-4) an orchidektomierten Ratten. Den Tieren wurde zwölf Wochen nach Orchidektomie acht Wochen lang entweder S-4 oder DHT gegeben und anhand der Muskelmasse und -kraft des M. soleus und des M. levator ani die Veränderung im Vergleich zu nicht orchidektomierten Tieren gemessen. Der Muskelschwund, der durch die Orchidektomie verursacht wurde, konnte durch S-4 und DHT vollständig wieder aufgehoben werden und die Muskelkraft wiederhergestellt werden. Der genaue molekulare Mechanismus bleibt hierbei jedoch im Dunkeln. Diskutiert wird u.a. ein „remodeling“ der neuromuskularen Verknüpfungen. Neben den anabolen Aktivitäten hat S-4 auch eine dosisabhängige schwache Androgenwirkung auf die Prostata (Gao et al. 2005). DHT dagegen hat eine zweieinhalbfach stärkere biologische Wirkung als $\mathrm{T}$ und wirkt nicht selektiv, d.h. erwünschte wie unerwünschte Wirkungen sind zu erwarten. Die in der Studie beobachteten anabolen Veränderungen an der Muskulatur der Tiere und die schwache Wirkung auf die Prostata sprechen für eine selektive Wirkung von S-4.

Diese Studie zeigt also, dass das Prinzip der selektiven Androgenrezeptor-Modulatoren an Ratten möglich ist und die gewünschten Ergebnisse bringen kann.

Derzeit befindet sich die Entwicklung der SARM`s noch in der Überprüfung des Therapiekonzeptes. Die präklinischen Daten sind vielversprechend, müssen aber noch in weiteren klinischen Studien überprüft werden (Bhasin und Jasuja 2009; Mohler et al. 2009).

\subsection{Phytoöstrogene}

Eine Vielzahl von Pflanzen enthält Substanzen mit schwach Östrogen- oder Antiöstrogenähnlicher Wirkung, die man Phytoöstrogene nennt. Die Wirkung dieser Phytoöstrogene wird hauptsächlich auf die strukturelle Ähnlichkeit mit Östradiol zurückgeführt; beide Substanzen besitzen einen Phenolring. Zu den wichtigsten Phytoöstrogenen gehören die Lignane und die Gruppe der Isoflavone (Dixon 2004), zu denen Genistein und Equol gehören. Diese werden im weiteren Verlauf noch näher besprochen. 
Die hormonelle Wirkung der aus der Nahrung aufgenommenen Isoflavone wurde erstmals 1940 entdeckt, als eine Unfruchtbarkeit bei Schafen festgestellt wurde, die auf Weiden grasten, auf denen Klee wuchs. Klee enthält Isoflavone, die in das Hormonsystem der Schafe eingriffen und ihre Fruchtbarkeit reduzierten (Setchell et al. 2001).

Neben der bereits erwähnten Wirkung auf die Gonadenfunktion haben Phytoöstrogene noch weitere Effekte auf verschiedene Organsysteme. Eine kardioprotektive Wirkung kommt durch eine Senkung des LDL-, Cholesterin- und des Triglyceridspiegels sowie durch die Senkung des Blutdrucks zustande (Carlson et al. 2008; Orgaard und Jensen 2008; Setchell et al. 2001). Auf die Entstehung bestimmter Karzinome haben Phytoöstrogene ebenfalls Einfluss. So konnte nachgewiesen werden, dass durch Aufnahme von Sojaprodukten sich das Risiko, an einem Prostatakarzinom zu erkranken, verringert (Kim 2008; Travis et al. 2009).

\subsubsection{Genistein}

Genistein findet sich hauptsächlich in Sojabohnen und Rotklee und ist das am häufigsten vorkommende Isoflavon.

Genistein bindet bevorzugt an ER $\beta$ durch eine 30-fach stärkere Bindungsaffinität als an ER $\alpha$ (An et al. 2001; Orgaard und Jensen 2008; Taylor et al. 2009). Überdies aktiviert Genistein auch Co-Regulatoren, die bei der Bindung an den Hormonrezeptor-Komplex die Transkriptionsfunktion von ER $\alpha$ hemmen. Außerdem vermittelt Genistein auf zellulärer Ebene einen antikanzerogenen Effekt über die Inhibition von Tyrosinkinasen und eine antioxidative Wirkung über das Abfangen von freien Radikalen. Eine weitere Wirkung ist die Hemmung des Enzyms 5 $\alpha$-Reduktase, das für die Umwandlung von Testosteron zu DHT verantwortlich ist (Sarkar und Li 2002).

In der Prostata wirkt Genistein hauptsächlich über die vorhandenen $\beta$-Rezeptoren. In Studien wurde festgestellt, dass eine mangelnde Aktivierung des ER $\beta$ zu einer benignen Prostatahyperplasie (BPH) führt (Brossner et al. 2004; McPherson et al. 2007). Es konnte nachgewiesen werden, dass eine lebenslange Aufnahme von Genistein das Risiko für Prostatakarzinome bis zu 54\% senkt. Schon die Aufnahme von Genistein über 3-11 Monate führt zu einer signifikanten Reduktion des Prostatakarzinom-Risikos (Wang et al. 2009). 


\subsubsection{Equol}

Equol wurde erstmals 1932 aus dem Urin trächtiger Stuten isoliert. Der Umstand, dass die unbekannte Substanz anschließend auch bei nichtträchtigen Stuten und Hengsten isoliert wurde, ließ den Schluss zu, dass es sich nicht um eine schwangerschaftsbedingte Substanz handeln musste (Marrian und Haslewood 1932). In Anlehnung an den tierischen Ursprung nannte man die Substanz Equol (Equus = lat. Pferd).

Equol wird nicht direkt aus Pflanzen aufgenommen, sondern im Darm aus der Vorstufe Daidzein, das in Sojabohnen vorkommt, verstoffwechselt (Setchell et al. 2002). Hierzu sind verschiedene Bakterien der Darmflora notwendig, die nicht bei allen Menschen gleichermaßen vorkommen (Muthyala et al. 2004; Setchell und Cole 2006). Nur ca. 30 \% gehören zu den sogenannten „Respondern“, d.h. Trägern dieser Bakterienflora. Maßgeblich für diese Equol-produzierende bakterielle Mischkultur im Darm ist eine fettarme und vegetarische Ernährung, ebenso wie eine kohlenhydratreiche Kost (Hedlund et al. 2003; Lampe et al. 1998; Muthyala et al. 2004; Rafii et al. 2003).

Die Wirkung von Equol an ER $\alpha$ und ER $\beta$ ist um ein vielfaches höher als die Wirkung von Daidzein, der Vorstufe von Equol. Daher ist es für den biologischen Effekt von aufgenommenen Isoflavonen wichtig, ob es sich bei dem Individuum um einen „EquolResponder" handelt oder nicht.

Eine antikanzerogene Wirkung hat Equol durch seine im Vergleich $\mathrm{zu}$ anderen Isoflavonen höchste antioxidative Wirkung (Setchell et al. 2002), besonders in der Zelle als Radikalfänger.

Equol hat außerdem eine starke Wirkung auf die Prostatagröße und deren Gewicht. In der Prostata bindet Equol an ER $\beta$ und hat damit einen Östrogen-ähnlich hemmenden Effekt. Darüber hinaus bindet Equol spezifisch an DHT und wirkt so noch als Antiandrogen (Lund et al. 2004; Setchell und Cole 2006). Equol bindet jedoch nicht an AR oder T, wodurch andere T-sensible Organe wie beispielsweise die Hoden durch das Phytoöstrogen nicht beeinflusst werden (Lund et al. 2004). 
<smiles>Oc1ccc(C2COc3cc(O)ccc3C2)cc1</smiles>

Equol<smiles>O=c1c(-c2ccc(O)cc2)coc2cc(O)cc(O)c12</smiles>

Genistein

Abb.2: Strukturformeln von Equol und Genistein

\subsection{Das muskuloskelettale System}

\subsubsection{Sarkopenie}

Bis zum 25. Lebensjahr nimmt die Muskelmasse zu, bis sie ihren „peak“ erreicht und langsam in der 2. Lebenshälfte abnimmt. Zwischen dem 25. und 80. Lebensjahr findet eine Reduktion um ca. 40\% (Adamo und Farrar 2006) statt, wobei sich diese ab dem 60. Lebensjahr stark beschleunigt. Diesen altersabhängigen Verlust von Muskelmasse nennt man Sarkopenie. Die klinischen Symptome sind eine herabgesetzte Muskelstärke, eingeschränkte Mobilität und Funktion der Muskeln, eine deutlich erhöhte Muskelermüdung bei Anstrengung, sowie ein erhöhtes Risiko für Knochenbrüche (Lang et al. 2009).

Der Muskel setzt sich aus Muskelfasern zusammen, die in ihrer kleinsten Einheit aus den kontraktilen Proteinfilamenten Myosin und Aktin bestehen. Diese Filamente schieben sich während einer Kontraktion ineinander und verkürzen so die Muskelfaser. Innerviert werden die Muskelfasern von Motorneuronen, die je nach Muskel eine unterschiedliche Anzahl von Muskelfasern aktivieren. Dabei gilt, je weniger Muskelfasern von einem Motoneuron innerviert werden, desto differenzierter ist die Muskelantwort. Es gibt drei verschiedene Arten von Muskelfasern (Silbernagel und Klinke 2003).

1. langsame Muskelfasern (Typ I): Sie sind hauptsächlich für Haltefunktionen erforderlich

2. schnelle Muskelfasern (Typ II): Sie haben eine hohe Kontraktionskraft, erschlaffen allerdings sehr schnell und sind für die Schnellkraft verantwortlich. In unserem Versuch 
wurde der M. gastrocnemius der Ratte untersucht, der bei Mensch und bei Ratte überwiegend aus Muskelfasern Typ II besteht.

3. intermediäre Muskelfasern (Typ III): Sie sind eine Mischung aus Typ I und Typ II und kommen praktisch in jedem Muskel vor.

Der altersabhängige Muskelverlust betrifft beide Muskelfasertypen (Typ I und Typ II), überwiegend jedoch die schnellen Muskelfasern (Typ II). Außerdem können die schnellen Muskelfasern (Typ II) auch in langsame Muskelfasern umgewandelt werden (Lang et al. 2009). Darüber hinaus degenerieren Motoneurone, sodass noch bestehende Motoneurone eine größere Anzahl an Muskelfasern innervieren müssen (Adamo und Farrar 2006; Jones et al. 2009; Lang et al. 2009). Der Verlust von schnellen Muskelfasern führt zu Problemen wie beispielsweise das erschwerte Treppensteigen oder das Aufstehen von einem Stuhl, was durch die Vergröberung der Bewegungen durch den Verlust der Motoneurone noch verstärkt wird.

Die Fähigkeit des Muskels, sich beispielsweise nach Muskelabbau oder Verletzungen zu regenerieren, hängt von der Aktivierung und Proliferation von randständigen Zellen, den Satellitenzellen, ab (Nikolic et al. 2005). Es konnte gezeigt werden, dass Satellitenzellen mit dem Alter abnehmen (Sadeh 1988) und so für die Entstehung einer Sarkopenie mitverantwortlich sind. Die Aktivierung und Proliferation von Satellitenzellen wird von vielen Faktoren gesteuert, u.a. auch von der Anwesenheit von E2. In einer Studie konnte gezeigt werden, dass sich bei männlichen Ratten nach Zusatz von E2 die Anzahl von Satellitenzellen in der Skelettmuskulatur nach einem einzigen körperlichen Training („downhill running“) vergrößerte (Tiidus et al. 2005). Dieser Effekt wird direkt über in Satellitenzellen befindliche ERs übermittelt (Enns et al. 2008).

Östrogenrezeptoren sind überall in der Skelettmuskulatur vorhanden, dennoch sind nicht alle Funktionen und Wirkungen komplett erforscht und verstanden. Dieli-Conwright et al. konnten auf zellulärer Ebene zeigen, dass E2 den Muskelzellstoffwechsel durch Einbau von Glukosetransportern anregt und zur Differenzierung der Satellitenzellen beiträgt (Dieli-Conwright et al. 2009).

Bei Ratten wirkt $\mathrm{T}$ direkt in der Muskelzelle an dort befindlichen ARs und führt so zu einem anabolen Stoffwechsel (Michel und Baulieu 1976). Es konnte an orchidektomierten Ratten gezeigt werden, dass die Konzentration von ARs in der Muskulatur nach der Orchidektomie sank und sich nach der Zugabe von externem DHT signifikant erhöhte (Antonio et al. 1999; Michel und Baulieu 1980). Die Applikation von supraphysiologischen Dosen von T bei älteren Männern bewirkte folglich eine Zunahme 
der Muskelkraft, sowie der Muskelmasse (Borst et al. 2007). Allerdings traten auch unerwünschte Wirkungen wie aggressives Verhalten, thromboembolische Ereignisse und periphere Ödeme vermehrt auf (Jones et al. 2009). Der genaue molekulare Mechanismus, wie $\mathrm{T}$ auf den Muskel wirkt, ist nach wie vor nicht vollständig geklärt. Es werden ARvermittelte Wege, wie auch AR-unabhängige Wege diskutiert (Herbst und Bhasin 2004). Einige Studien weisen daraufhin, dass der anabole Effekt auf eine vermehrte Proteinsynthese zurückzuführen ist (Bhasin et al. 2001), ebenso vergrößert sich die Anzahl der Motoneurone unter Einfluss von T (Herbst und Bhasin 2004).

Unklar ist überdies, ob T seine Wirkung über den AR vermittelt, oder ob dies durch ARunabhängige Wege geschieht (Bhasin et al. 2001).

Einen positiven Effekt auf die Muskulatur haben regelmäßiges Muskeltraining und körperliche Aktivität. So verbessert sich die Muskelstärke, die Schnelligkeit und bei gezieltem Training auch die Muskelmasse (Frontera et al. 1988). Darüber hinaus hat körperliche Aktivität noch weitere wichtige Vorteile: über den erhöhten Fitnessgrad wird auch ein besseres Körpergefühl vermittelt, was sich in einem reduzierten Risiko zu stürzen zeigt. Die Belastungen, die über das Muskeltraining auf den Knochen wirken, verändern auch die Knochenstruktur. So passt sich der Knochen dynamisch den Muskelanforderungen an (Warden et al. 2005). Auf die Knochenmasse sowie die Knochendichte hat Bewegungstraining nur eine eingeschränkte, jedoch positive Wirkung. Ein intensives und regelmäßiges Training kann so einen positiven Effekt auf die Knochendichte von Wirbelkörpern und Hüfte haben (Lang et al. 2009).

\subsubsection{Osteoporose}

In Deutschland sind schätzungsweise $90 \%$ aller Schenkelhalsfrakturen auf eine bestehende Osteoporose zurückzuführen (Bartl 2008). Durch die Überalterung der Bevölkerung werden die Zahlen voraussichtlich in den nächsten Jahren weiter steigen. Osteoporose führt durch eine erniedrigte Knochendichte zu einer erhöhten Neigung für Knochenbrüche und ist außerdem auch für starke Schmerzen und den Verlust von Mobilität verantwortlich. Eine manifeste Osteoporose ist mit einer erhöhten Morbidität gekoppelt. In einem Zeitraum von 3-6 Monaten nach einer Hüftfraktur sterben immer noch 20-30\% der Patienten (Bartl 2008). Dabei ist die Todesfolge direkt oder indirekt über Komorbiditäten auf die Osteoporose zurückzuführen (Kanis et al. 2003). 
Osteoporose entsteht hauptsächlich durch die Reduktion der Produktion von Sexualhormonen im alternden Menschen (Holzbeierlein et al. 2004). Östrogene erhalten die Knochenmasse und regulieren den Knochenstoffwechsel, indem die Lebensspanne der knochenabbauenden Osteoklasten durch Induktion von Apoptose verkleinert wird. Die Lebensspanne der knochenregenerierenden Osteoblasten jedoch verlängert sich (Riggs et al. 2002). Androgene zeigen im Knochen eine ähnliche Wirkung. T kann über Aromatase in E2 umgewandelt werden und vermittelt überwiegend so eine knochenprotektive Wirkung. Allerdings hat $\mathrm{T}$ auch einen geringen direkten Effekt auf die Knochen. $\mathrm{T}$ wirkt leicht proliferativ auf Osteoblasten und greift an unterschiedlichen Stellen in deren Differenzierung ein (Riggs et al. 2002).

Knochendichte und Serum-Östrogenspiegel korrelieren miteinander und eignen sich daher gut, um bei älteren Menschen die Knochendichte abzuschätzen und deren Verlauf zu ermitteln (Ohlsson und Vandenput 2009). Es wurde eine Wirkungsschwelle für E2 ermittelt (31 pg/ml), unter der der Beginn des Knochenverlusts deutlich in Zusammenhang mit dem Serum-Östrogenspiegel steht (Ohlsson und Vandenput 2009).Durch die schleichende Minderung der T-Produktion bei Männern fällt auch der Östrogenspiegel sukzessive ab. Deshalb macht sich der Knochenverlust bei Männern erst deutlich später bemerkbar. In jedem Stadium der Osteoporose wie auch in der Prävention werden körperliche Aktivität und die Gabe von Calcium und Vitamin D zur Stärkung der Knochen empfohlen.

\subsubsection{Vibrationstherapie}

Um die Gefahr der Sarkopenie bei älteren Patienten zu reduzieren, ist es wichtig körperlich aktiv zu sein (Preisinger 2009). Das regelmäßige körperliche Training ist aber häufig mit einer geringen Compliance verbunden (Russo et al. 2003; Verschueren et al. 2004), sodass man bei der Suche nach effektiven und attraktiven Alternativen auf die Ganzkörper- Vibrationstherapie kam.

Die Ganzkörper-Vibrationstherapie ist eine Trainingsmethode, die als langfristiges Ziel die Stärkung der Muskelkraft, sowie eine Erhöhung der Knochendichte hat. Schon Jankovich konnte 1972 an einem Rattenmodell zeigen, dass eine mechanische Vibration von 20-25 Hz täglich ausreicht, um die Knochendichte zu erhöhen (Jankovich 1972). In Versuchen an ovariektomierten Ratten konnte ebenfalls eine positive Wirkung auf die Knochendichte festgestellt werden. So können regelmäßige Vibrationseinheiten eine 
frühzeitige Abnahme der Knochensubstanz verhindern (Flieger et al. 1998; Oxlund et al. 2003). Xie et al. untersuchten den M. soleus von Mäusen nach 6 Wochen GanzkörperVibrationstherapie (45 Hz für 15 min. täglich) (Xie et al. 2008). Sie konnten zeigen, dass sich die Anzahl der Muskelfasern beider Typen (I und II) vergrößerte ebenso wie auch der Querschnitt des Muskels. Die genauen Mechanismen, wie es durch die mechanische Vibration zu einer quantitativen und qualitativen Zunahme der Muskulatur kommt, sind nach wie vor unbekannt. Es werden jedoch oszillatorisch sensible Einheiten wie z.B. Muskelspindeln, Sehnenspindeln oder somatosensorische Rezeptoren als mögliche Auslöser diskutiert (Fallon und Macefield 2007). Darüber hinaus werden auch die Muskelsehnen durch die Ganzkörper-Vibrationstherapie gestärkt (Sandhu et al. 2011).

Der Patient stellt sich hierbei auf eine Platte, zumeist in einer statischen Position, oder führt langsame dynamische Bewegungen aus, während diese vibriert. Variabel sind bei der Einstellung der Vibration drei verschiedene Größen (Rauch 2009):

1. Frequenz: Die Anzahl der Vibrationsbewegung pro Minute [Hz]. Sie variiert zwischen 10 und $50 \mathrm{~Hz}$.

2. Amplitude: Die Größe des Ausschlages der Vibrationsbewegung [mm]. Sie variiert zwischen einigen Mikrometern und wenigen Milimetern.

3. Die grundsätzliche Bewegung der Vibrationsplatte. So kann sich die Platte parallel zum Boden bewegen, sodass sich beide Füße auf einer Ebene befinden, oder eine Kippung haben, sodass ein Fuß eine Aufwärtsbewegung macht, während der andere eine Abwärtsbewegung ausführt.

Die Trainingsintensität wird dabei von der Frequenz und der Amplitude bestimmt. Je höher Frequenz und Amplitude sind, desto höher ist auch der Trainingseffekt.

Man kann kurzfristige von langfristigen Effekten der Vibrationstherapie unterscheiden. Während eines Vibrationstrainings wird kurzfristig der Sauerstoffverbrauch erhöht. Dabei gilt, je intensiver das Training, desto höher der Sauerstoffverbrauch. Dazu steigt die Temperatur der Muskulatur an, die Hautdurchblutung wird gesteigert und die Herzfrequenz erhöht sich (Cochrane et al. 2008; Rauch 2009). Aufgrund der erhöhten Hautdurchblutung kann es nach dem Training zu leichten petechialen Einblutungen in den unteren Extremitäten kommen, die aber ungefährlich sind (Rauch 2009). Ansonsten wird die Ganzkörper-Vibrationstherapie gut vertragen (Cardinale et al. 2008; Rauch 2009; Russo et al. 2003; Verschueren et al. 2004).

Langfristige Wirkungen der Vibrationstherapie sind eine verbesserte Balance, Reduktion des Körperfetts, eine gesteigerte Muskelkraft sowie eine erhöhte Knochendichte 
(Cochrane et al. 2008; Maddalozzo et al. 2008; Rauch 2009; Verschueren et al. 2004). In einer Studie wurde die Vibrationsplatte über sechs Monate mit 29 postmenopausalen Frauen auf die Wirkung auf Muskulatur und Knochen untersucht (Russo et al. 2003). Dabei wurde festgestellt, dass sich die Muskelstärke und Schnelligkeit bei den Frauen mit Vibrationstherapie im Gegensatz zu den Frauen ohne Therapie um 5\% verbesserte. Auch die Knochendichte baute sich bei Frauen mit Vibrationstherapie weniger stark ab, als bei Frauen ohne Vibrationstherapie.

Eine langfristige arbeitsbedingte Exposition von Ganzkörper-Vibrationen (3-5 Hz) kann durch Wirbelsäulendegeneration zu chronischen lumbosakralen Rückenschmerzen führen (Leitlinien Arbeitsmedizin 2003). Die verstärkte Belastung der Wirbelkörper durch die anhaltenden Schwingungszustände und die verminderte Versorgung führen zu einer $\mathrm{pH}$ Senkung des Gewebes und damit zur Degeneration. Hiervon betroffen sind u.a. Gabelstablerfahrer, Traktorfahrer und Piloten. Das Auftreten von Rückenschmerzen aufgrund einer Vibrationstherapie konnte jedoch nicht festgestellt werden, da sich die Vibrationsdosen und -intervalle, sowie die Schwingungsfrequenz grundsätzlich unterscheiden. Dennoch fehlen bisher langfristig angelegte Studien, um die Gefahr von Schäden durch die Ganzkörper-Vibrationstherapie vollständig auszuschließen.

\subsection{Die Prostata}

Die Prostata ist ein Sexualhormon-abhängiges Organ. In der Prostata wird das in den Hoden produzierte $\mathrm{T}$ zu DHT umgewandelt, was durch das Enzyms 5a-Reduktase geschieht (Zhu 2005). DHT ist ein potenteres Androgen als T und ist in der Prostata der hauptsächliche Androgen-vermittelnde Faktor. Beide Androgene, DHT wie T, können am AR der Prostata binden. Sie rufen dabei unterschiedliche Aktivitäten hervor, die auf unterschiedlichem Bindungsverhalten und verschiedenen DNA-Interaktionen beruhen (Zhu 2005).

Über Jahrzehnte wurde angenommen, dass ein erhöhter T-Spiegel mit einem erhöhten Risiko für ein Prostatakarzinom zusammenhängt. Diese Annahme wurde zuletzt in Frage gestellt und ein differenzierteres Zusammenspiel von Androgenen und der Prostata hergestellt.

Das Sättingungsmodell geht von einer begrenzten Anzahl von ARs in der Prostata aus. Bei niedrigen Androgenwerten reagiert die Prostata sensibel auf schon geringe Schwankungen von T. Ist aber die Sättigung der ARs durch einen Anstieg von T erreicht, 
reagiert die Prostata nicht mehr auf weitere Veränderungen des T-Wertes (Morgentaler 2009). Das bedeutet: für hohe T-Werte ist das Risiko für Prostata-Karzinome nicht erhöht. In einer Studie konnte gezeigt werden, dass sich trotz mittelfristiger T-Gabe die intraprostatische T- und DHT-Konzentration nicht erhöht hat (Marks et al. 2006). Dies weist daraufhin, dass die Prostata sich ihr eigenes Hormonmilieu schafft, das unabhängig von der Serumkonzentration ist (Marks et al. 2006). Im Gegensatz dazu stehen niedrige TWerte im Zusammenhang mit malignen Prostatakarzinomen (Schatzl et al. 2001). In einer Studie mit Prostatakarzinom-Patienten wurde das freie T verglichen: 56\% der Patienten hatten einen erniedrigten T-Spiegel (15 ng/ml oder weniger) und davon $8 \%$ einen hohen „Gleason score“ (8 oder höher). Der „Gleason score“ (1-10) gibt den Differenzierungsgrad des prostatischen Gewebes in der Histologie an. Dabei ist 1 hochdifferenziert und 10 anaplastisch. Verglichen dazu hatten 44\% einen erhöhten TSpiegel (15 ng/ml oder höher), deren „Gleason score“ jedoch geringer war (7 oder kleiner) (Hoffman et al. 2000). Die Studie zeigte also, dass ein erniedrigter T-Spiegel häufig mit einem aggressiven Karzinom assoziiert ist.

Bei männlichen Ratten wird E2 unter anderem in der Prostata aus T mithilfe des Enzyms Aromatase hergestellt (Marts et al. 1987; Marks und Petrow 1983; Ellem und Risbridger 2006). Sie befindet sich in der gesunden Prostata im Stroma und sorgt für eine Balance zwischen E2 und T. Bei einer Abnahme von T und gleichbleibenden oder gesteigerten E2Levels kann es zu einem Ungleichgewicht kommen und die Gefahr von benignen und malignen Entartungen kann ansteigen (Ellem und Risbridger 2009a). E2 hat in der Prostata direkte Effekte (Pelletier 2002), die über die Rezeptoren ER $\alpha$ und ER $\beta$ vermittelt werden. Dabei haben ER $\alpha$ und ER $\beta$ unterschiedliche Funktionen.

ER $\alpha$ übermittelt zwei verschiedene Wirkungen:

1. Zellproliferation. Diese Zellproliferation ist unterschiedlich zu der der Androgene und betrifft die epitheliale Basalschicht. Bei epithelialer und stromaler Expression von ER $\alpha$ kann es zu einer Metaplasie kommen (Ellem und Risbridger 2009a; Prins et al. 2001).

2. Entzündung. Durch die Anwesenheit von E2 und ER $\alpha$ kann eine entzündliche Reaktion ausgelöst werden (Royuela et al. 2001). Dies konnte gezeigt werden durch einen Versuch mit „knock-out“-Tieren. Bei einer Gruppe von Mäusen wurde das Gen für ER $\alpha$ ausgeschaltet, bei einer anderen Gruppe das Gen für ER $\beta$. Zusammen mit einer Kontrollgruppe wurde nun den beiden Gruppen E2 gegeben. Es konnte gezeigt werden, dass eine Entzündungsreaktion bei Tieren auftrat, die ER $\alpha$ exprimierten, wohingegen bei ER $\beta$-exprimierenden Tieren keine derartige Reaktion zu sehen war (Prins et al. 2001). 
Durch diese zwei genannten Wirkungen kann es dann im Folgenden zu einer Entwicklung von Prostatakarzinomen kommen. In intraepithelialen Neoplasien konnte eine vermehrte Expression von ER $\alpha$ festgestellt werden (Bonkhoff et al. 1999). Bei vorhandenem Karzinom wurde eine stadienabhängige Expression von ER $\alpha$ gefunden, d.h. das Ausmaß der Expression korrelierte mit dem Stadium des Tumors. Darüber hinaus wurde in Lymphknoten und Metastasen ER $\alpha$ gefunden (Bonkhoff et al. 1999).

ER $\beta$ wird hauptsächlich in epithelialem Gewebe exprimiert (Lau et al. 2000; McPherson et al. 2007). Im Gegensatz zu ER $\alpha$ hat ER $\beta$ einen hemmenden Effekt auf die Prostata. Es wirkt

1. Anti-proliferativ: Es konnte gezeigt werden, dass ER $\beta$ nach spezifischer Stimulation einen anti-proliferativen Effekt auf die Prostata hat (McPherson et al. 2007).

2. Anti-inflammatorisch: ER $\beta$ wirkt immunmodulatorisch und hemmt so Entzündungsreaktionen (Ellem und Risbridger 2009a).

3. Anti-karzinogen: die genaue anti-karzinogene Wirkung von ER $\beta$ ist nicht vollständig geklärt. Allerdings gelangte man durch den anit-proliferativen sowie den antiinflammatorischen Effekt zu der Annahme, dass eine Stimulation von ER $\beta$ eine protektive Wirkung auf die Prostata hat (Ellem und Risbridger 2009a). Weiterhin konnte gezeigt werden, dass in Krebszellen kein ER $\beta$ exprimiert wird (Ellem und Risbridger 2009b).

Ein Zuviel an E2 kann zu einer abnormen Zellproliferation führen, sowie über ER $\alpha$ eine entzündliche Reaktion hervorrufen. Das kann zu einer Hypertrophie mit Gefahr der malignen Entartung führen. Ein Zuwenig an E2 kann allerdings auch durch die mangelnde Hemmung der Androgene zu einer Hypertrophie durch Proliferation führen (Ellem und Risbridger 2009b).

Es konnte gezeigt werden, dass bei orchidektomieren Ratten rasch die Prostata atrophierte. Da die Hoden fast ausschließlich $\mathrm{T}$ produzieren, sank der T-Spiegel der orchidektomierten Ratten stark ab und verursachte einen Androgenmangel, der sich u.a. durch die beschriebene Atrophie der Prostata bemerkbar machte (Kerr und Searle 1973). Bei nicht-orchidektomierten Ratten, die mit E2 behandelt wurden, konnte eine Erhöhung der Apoptoserate festgestellt werden, was mit einer Hemmung der Prostatawachstums einhergeht (Kerr und Searle 1973).

Hier setzen auch die Phytotherapeutika, im Speziellen Phytoöstrogene an. Sie können durch E2-Wirkung direkt oder indirekt die Androgenwirkung modulieren und haben somit ebenso eine positive Wirkung auf die Prostata (Ellem und Risbridger 2009b). Hauptsächlich wird dies durch die Bindung an ER $\beta$ verursacht, was zur Hemmung der 
Proliferation führt. Über Coregulatoren und Induktion von Transkriptionsfaktoren sowie die Bindung an nicht-steroidale Rezeptoren kann die Hormonantwort weiter moduliert werden.

\subsection{Ziel der Untersuchung}

Ziel unserer tierexperimentellen Studie war es, die Auswirkung der Sexualhormone DHT und E2 sowie der Phytoöstrogene Equol und Genistein auf das muskuloskelettale System und auf die Prostata von Ratten $\mathrm{zu}$ untersuchen. Es folgte eine Ausschaltung der körpereigenen Sexualhormone durch Orchidektomie, um die gegebenen Substanzen isoliert untersuchen $\mathrm{zu}$ können. Dabei wurde die Wirkung von E2 und den Phytoöstrogenen Equol und Genistein mit der von DHT verglichen.

Des Weiteren untersuchten wir die Auswirkung von Bewegung auf die Skelettmuskulatur unter Einfluss von Equol, Genistein, E2 und DHT. Dazu nutzten wir die Methode der Ganzkörper-Vibrationstherapie und verglichen diese Tiere mit nicht vibrierten. Um eine mögliche Metabolisierung von T zu DHT mithilfe des Enzyms 5 $\alpha$-Reduktase zu verhindern und somit einen reinen T-Effekt auf Muskulatur und Prostata zu erlangen, verwendeten wir DHT, das an AR`s bindet und nicht weiter verstoffwechselt werden kann. 


\section{Material und Methoden}

\subsection{Tierexperiment}

Die vorliegende Arbeit bearbeitet eine Fragestellung eines weiterreichenden Tierexperiments. Der Vollständigkeit halber ist der ganze, für die Arbeit relevante Versuchsablauf beschrieben. Im Rahmen dieser Arbeit wurden die Punkte 2.2 und 2.3 durchgeführt.

\subsubsection{Versuchstiere und deren Haltung}

$\mathrm{Zu}$ Beginn des Versuchs lag die Genehmigung des Niedersächsischen Landesamtes für Verbraucherschutz und Lebensmittelsicherheit (LAVES; AZ: G 43.08) vor. Es wurden 180 männliche Sprague-Dawley-Ratten (SD-Ratten) verwendet, die vorerst in Gruppen von jeweils vier Tieren pro Käfig eingeteilt wurden. Bei den Käfigen handelte es sich um Makrolonkäfige (Typ IV, Fa. Techniplast Deutschland GmbH, Hohenpreißenberg). Die Tiere wurden bei einer Raumtemperatur von 22-24 $\mathrm{C}$ und einer Relativen Luftfeuchtigkeit von 50-55\% gehalten. Die Beleuchtung des Raumes erfolgte im 12Stunden-Rhythmus von 6-18 Uhr. Wasser und Futter standen den Tieren zur freien Verfügung, wobei sie sojafreie Futterpellets (sf.) (V 1354-000 ssniff R-Z, 10 mm, Phytoestrogen-arm, Maus/Ratte (mit 21,7\% Rohprotein)) zu fressen bekamen. Die Ratten waren bei Versuchsbeginn ca. 3 Monate alt und hatten ein Gewicht von durchschnittlich $357 \mathrm{~g}$.

\subsubsection{Versuchsablauf}

Nach einer Eingewöhnungszeit von drei Wochen erfolgte die Orchidektomie (Orx) aller Ratten gefolgt von einer Erholungszeit von drei Tagen. Anschließend begann für alle Ratten, außer der Kontrollgruppe (acht Tiere), die Vibrationstherapie. Sie fand an fünf Tagen der Woche statt und dauerte insgesamt vier Wochen.

Die Tiere wurden nun dem Gewicht nach in Gruppen von 30 Tieren eingeteilt und zu dritt oder zu viert in Käfige gesetzt. Das Futter wurde umgestellt und nur eine Gruppe (Kontrollgruppe) bekam weiterhin sojafreie Pellets. Dem Futter der anderen Gruppen wurde E2, Genistein, Equol oder DHT beigemischt. Zwei Wochen nach der Futterumstellung wurden die ersten Tiere obduziert, genaue Anzahl siehe Tab. 3. Eine Woche später, also in der dritten Woche erfolgte eine zweite Obduktion. Sechs Wochen 
nach der Futterumstellung wurde die Hälfte der verbleibenden Tiere, die die Futterzusätze E2, DHT, Genistein oder Equol bekommen hatten, erneut vibriert. Die Vibrationstherapie erfolgte zwei Wochen lang an fünf Tagen der Woche. Die andere Hälfte der Tiere wurde nicht vibriert.

Die Tötung der Tiere erfolgte durch eine $\mathrm{CO}_{2}$-Narkose und anschließender Dekapitation. Im Anschluss folgte die histologische Aufarbeitung.

\begin{tabular}{|l|l|l|l|}
\hline Zusätze & $\begin{array}{l}\text { durchschnittliche } \\
\text { Futteraufnahme in } \\
\text { g/Tag }\end{array}$ & Futterzusatz & $\begin{array}{l}\text { tatsächliche } \\
\text { Futterzusatzaufnahme } \\
\text { in mg/Tag }\end{array}$ \\
\hline E2 & 17,2 & $10 \mathrm{mg} / \mathrm{kg}$ & 0,17 \\
\hline DHT & 21,2 & $1 \mathrm{~g} / \mathrm{kg}$ & 21,2 \\
\hline Equol & 20,5 & $400 \mathrm{mg} / \mathrm{kg}$ & 8,2 \\
\hline Genistein & 20,7 & $1 \mathrm{~g} / \mathrm{kg}$ & 20,7 \\
\hline
\end{tabular}

Tab. 2: Futteraufnahme der Ratten

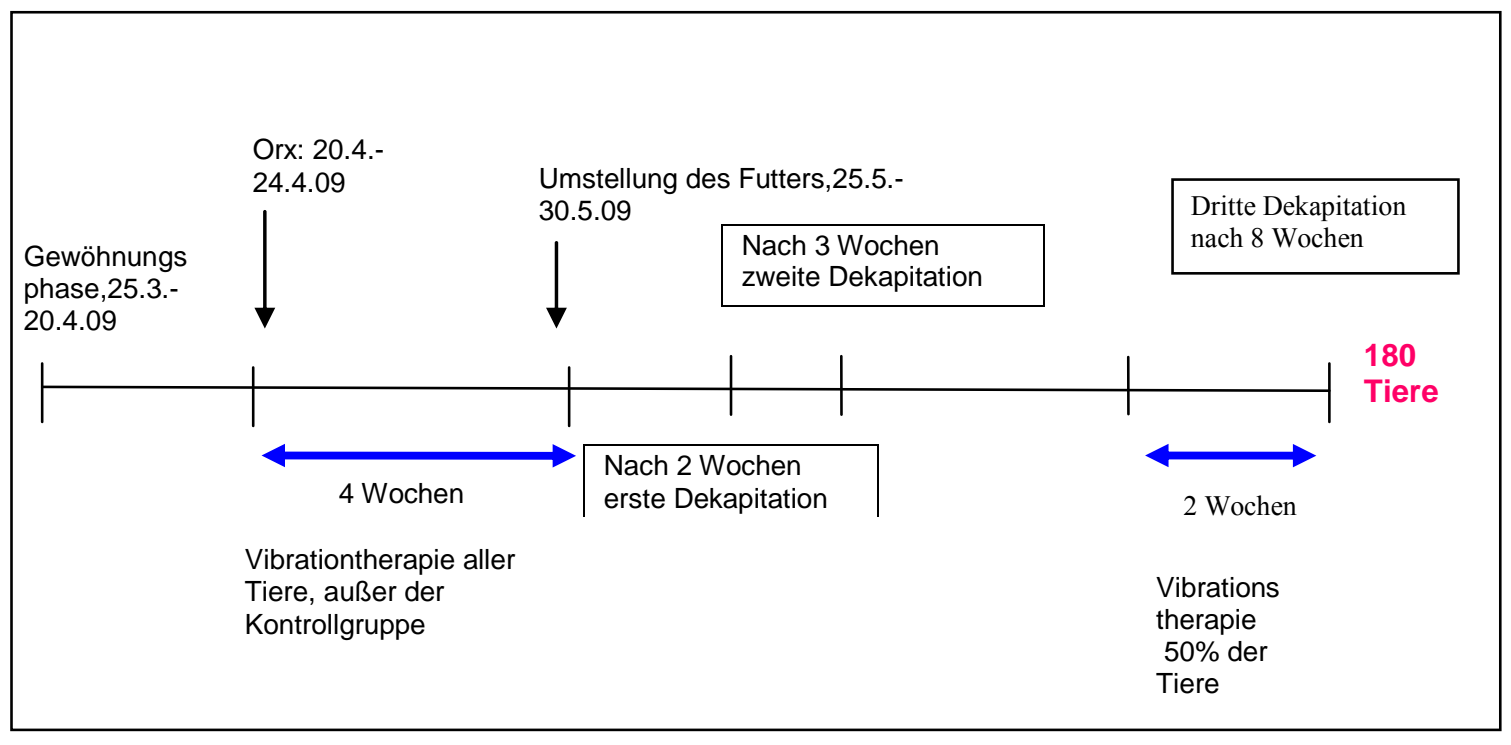

Abb.3: Versuchsverlauf Ansicht

\subsubsection{Orchidektomie (Orx)}

Die Operation der Tiere fand in Allgemeinanästhesie statt. Hierzu wurde über eine Inhalationsmaske Isofluran gegeben, die an ein Flowmeter (SF3, UNO ROESVASTSTAAL BV, Zevenaar, Holland) und ein Kleintiernarkosegerät (Penlon Sigma Delta, Penlon Limited Abington, Oxon, Großbritannien) angeschlossen war. 
Beatmet wurde mit einem Flow von 0,45 1/min O2 und 0,3 1/min Air. Anhand des Relaxationsgrades der Muskulatur wurde die Narkosetiefe ermittelt und kontrolliert. Nach dem Rasieren der Tiere mit einem Fellschneider (Arco, Fa. Moser GmbH, Unterkirnach) wurden die Hoden palpiert. Es folgte die chirurgische Desinfektion mit Braunol (Wirkstoff: Povidon-Iod, B. Braun AG, Melsungen) und die Freipräparation des Hodens. Der Ductus epidymidis sowie die versorgenden Blutgefäße wurden ligiert und entfernt. Nach Ausschluss von Blutungen wurde das Operationsfeld in Einzelknopf-Nahttechnik verschlossen. Zur Entzündungshemmung und Schmerzstillung wurde den Tieren 0,1 mg Metacam ${ }^{\circledR}$ (Wirkstoff: Meloxicam, Boehringer Ingelheim Vetmedica GmbH, Ingelheim/Rhein) subkutan appliziert.

\subsubsection{Durchführung der Vibrationstherapie}

Die Vibrationstherapie erfolgte mit dem SwingVibe ${ }^{\circledR}$ GanzkörperVibrationstrainingsgerät. Ohne Einstreu, Wasser und Futter wurden jeweils zwei Käfige auf die Vibrationsplatte gestellt. Es wurde der Modus „Monoswing“ gewählt, da hier die vertikal verlaufenden Schwingungen an jeder Stelle der Vibrationsplatte gleich stark sind. Die Käfige wurden auf der Platte mit Nylon-Gurten fixiert und die Tiere zunächst mit 25 $\mathrm{Hz}$ für 5 Minuten, dann mit $30 \mathrm{~Hz}$ für 2x5 Minuten mit der horizontalen Amplitude 4mm trainiert.

\subsubsection{Gruppeneinteilung und Testsubstanzen}

\begin{tabular}{|c|c|c|c|c|}
\hline Futterzusatz & 1.Obduktion & 2.Obduktion & $\begin{array}{l}\text { 3.Obduktion, } \\
\text { vibriert }\end{array}$ & $\begin{array}{l}\text { 3.Obduktion, } \\
\text { nicht vibriert }\end{array}$ \\
\hline $\begin{array}{l}\text { Kontrollgruppe } \\
\text { Sojafreie Pellets }\end{array}$ & 4 & 4 & 4 & 4 \\
\hline Genistein & 4 & 4 & 3 & 3 \\
\hline Equol & 4 & 4 & 4 & 4 \\
\hline Dihydrotestosteron & 4 & 4 & 3 & 4 \\
\hline Östrogen & 4 & 4 & 4 & 4 \\
\hline $\begin{array}{l}\text { Kontrollgruppe, nicht } \\
\text { vibriert, sf Futter }\end{array}$ & 4 & & & \\
\hline
\end{tabular}

Tab.3: Gesamtübersicht der geschnittenen und ausgewerteten Tiere für je Muskel und Prostata 


\subsection{Histologische Aufarbeitung}

Die gewonnen Prostata- und Muskelpräparate wurden in einem Entwässerungsautomaten (Leica TP 1020, Leica Mikrosysteme Vertrieb GmbH, Wetzlar) über 15 Stunden bearbeitet. Zunächst wurden sie in einer aufsteigenden Alkoholreihe mit 50\%, 75\%, 96\% und 100\% Ethanol entwässert und anschließend mit Xylol behandelt und in Paraffin aufbewahrt. Im nächsten Schritt wurden die Präparate in der Einbettmaschine (Leica EG 1140 H, Leica Mikrosysteme Vertrieb GmbH, Wetzlar) eingebettet. Die Muskelpräparate wurden vor dem Einbetten in Paraffin einmal quer durchgeschnitten und mit der Schnittfläche zum Anschnitt eingebettet.

Die histologischen Präparate wurden am Rotationsmikrotom (RM 2135, Fa. Leica Mikrosysteme Vertrieb GmbH, Wetzlar) geschnitten. Nach Einspannen des Paraffinblocks wurde dieser zuerst mit $30 \mu \mathrm{m}$ Schichtdicke angeschnitten, um zum Gewebe vorzudringen. Die im Anschluss hergestellten Schnitte hatten eine Dicke von 3 $\mu \mathrm{m}$. Die gewonnenen Schnitte wurden in kaltes, kalkfreies Wasser gelegt und von dort aus zur Streckung in ein warmes Paraffinstreckbad mit ebenfalls kalkfreien Wasser gebracht. Als Nächstes wurden die Schnitte auf einen Objektträger (SuperFrost ${ }^{\circledR}$ Plus 26x76x1mm, Fa. Menzel-Gläser $\mathrm{GmbH}$ \& Co KG, Braunschweig, Bestell-Nr.: J1800AMNZ) gebracht und zum Fixieren und Antrocknen auf eine Wärmeplatte gelegt. Nachfolgend kamen die Schnitte zur vollständigen Trocknung und Fixierung für mindestens 12 Stunden bei $37^{\circ} \mathrm{C}$ in einen Trockenschrank (Heraeus Holding GmbH, Hanau).

\subsubsection{Die Hämatoxylin- und Eosinfärbung}

Die Hämatoxylin- und Eosinfärbung ist ein Färbeverfahren mit dem verschiedene Gewebestrukturen anhand zweier Einzelfärbungen unterschieden werden können. Sie wird als Übersichtsfärbung benutzt.

Hämatoxylin ist ein Naturfarbstoff, der aus dem in Mittelamerika stammenden Campechebaum gewonnen wird. Der wirksame Farbstoff ist nicht das Hämatoxylin selbst, sondern sein Oxidationsprodukt Hämatein. Bei der Färbung nach Mayer wird zur Oxidation $\mathrm{NaJO}_{3}$ verwendet. Durch Zusatz von Alaunsalzen, hier Kalialaun, entsteht eine stark positiv geladene Hämatoxylinlacke, die an negativ geladene bzw. saure Strukturen in 
der Zelle bindet. Dazu gehören vor allem die Phosphatgruppen der Nukleinsäure, sowie das endoplasmatische Retikulum. Nach dem Färben werden die Präparate unter fließendem Leitungswasser gespült (gebläut), wodurch die Färbung durch Anhebung des pH-Wertes auf 3 fixiert wird und die Präparate blau erscheinen.

Als Gegenfärbung wird Eosin verwendet, welches an azidophile Strukturen, wie zum Beispiel Eiweiße, bindet und diese rot färbt. Der Farbstoff muss nach dem Färben zum Teil wieder entfärbt werden, was mit einer aufsteigenden Alkoholreihe geschieht.

\subsection{Datenerhebung}

\subsubsection{M. gastrocnemius}

Die Auswertung der Muskelschnitte erfolgte am Lichtmikroskop (Zeiss Axiophot ${ }^{\circledR}$ Fotomikroskop, Fa. Zeiss, Carl Zeiss AG, Oberkochen) mit einer Vergrößerung von 20x (2x10) für alle Präparate. Zunächst wurde das Präparat in der Übersicht betrachtet und dann in der Mitte des Präparates eingestellt. Dann erfolgte das Foto des zu messenden Bereichs (ColorView, Soft Imaging System, Olympus Soft Imaging Solutions GmbH, Münster). Hiernach wurden die einzelnen Muskelfasern mit dem Programm AnalySIS ${ }^{\circledR}$ (analySIS ${ }^{\circledR}$, Soft Imaging System, Olympus Soft Imaging Solutions, Münster) umfahren und damit die Fläche gemessen. Es wurden pro Präparat 10 Messungen durchgeführt. Die gesammelten Ergebnisse wurden anschließend mit der Software GraphPad Prism ${ }^{\circledR}$ (GraphPad Prism 4® Software, Fa. GraphPad Software, Inc. San Diego, USA) graphisch und statistisch ausgewertet. 


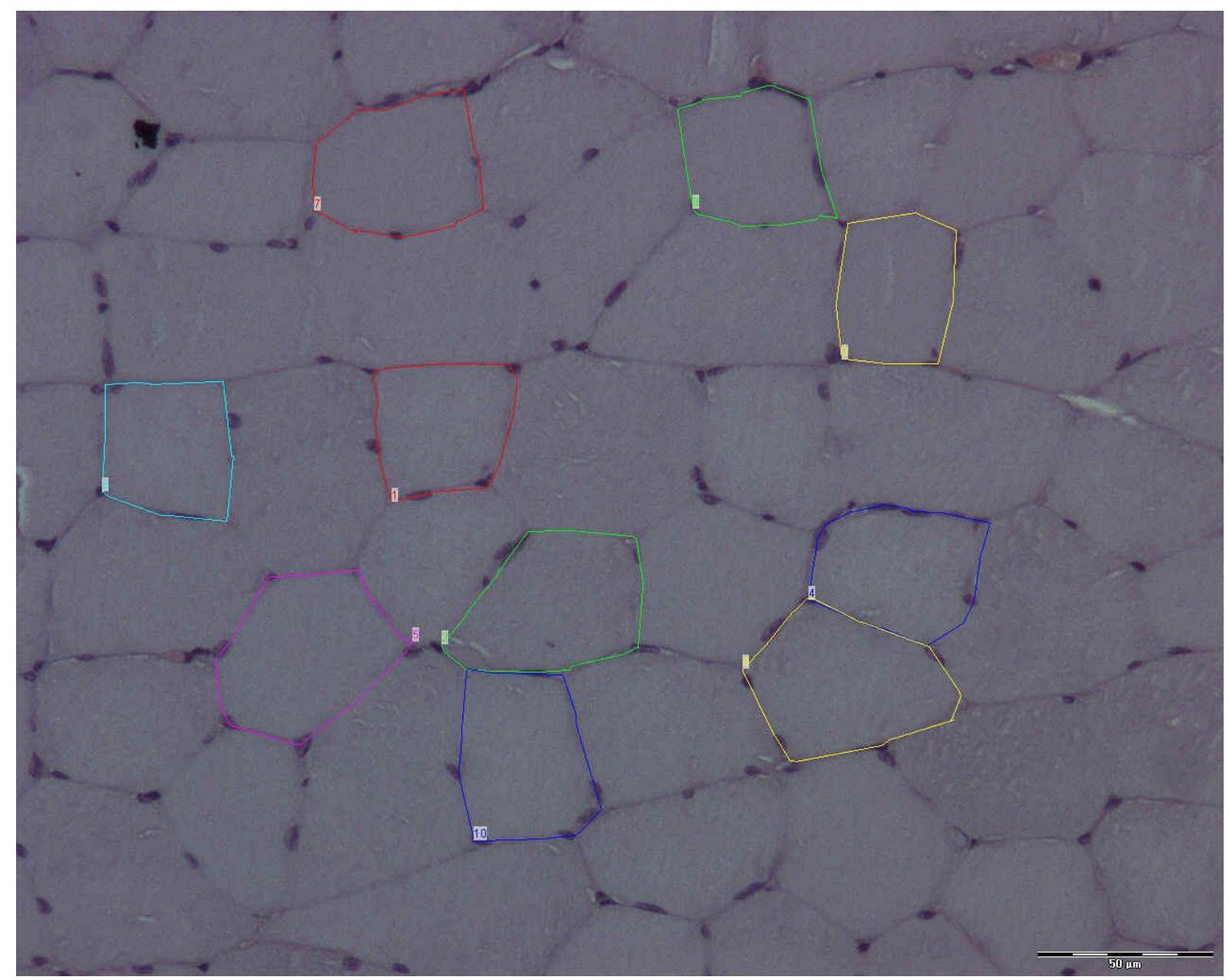

Abb.4: Muskel, HE-Färbung, 20-fach, methodisches Vorgehen zur Auswertung durch Umfahrung der einzelnen Muskelfasern

\subsubsection{Prostata}

Die HE gefärbten Schnitte wurden am Lichtmikroskop (Zeiss Axiophot ${ }^{\circledR}$ Fotomikroskop, Fa. Zeiss, Carl Zeiss AG, Oberkochen) ausgewertet. Dabei wurde eine Vergrößerung von 12,5x (10 x 1,25) für alle Präparate gewählt, um die Vergleichbarkeit zu gewährleisten. Zunächst wurde die Prostata eingestellt und nach einem Überblick über das Präparat der auszumessende Teil eingestellt. Dabei wurde in der Mitte des Präparates gemessen, um vergleichbare Daten zu erlangen. Unter Einfluss von DHT vergrößerte sich die Prostata durch Flüssigkeitseinlagerung und Zellproliferation massiv. Es ist möglich, dass die Ductuli durch dieses Wachstum in der Präparatmitte zusammengedrängt wurden und am Rand der Präparate mehr Raum hatten sich zu entfalten. Aufgrund dieser Diskrepanz wurden zwei Messungen vorgenommen; einmal in der Mitte der Präparate sowie an deren Rand(siehe dazu 6.1 histologische Abbildung). Hiernach wurde der eingestellte Bereich 
fotografiert (ColorView, Soft Imaging System, Olympus Soft Imaging Solutions GmbH, Münster) und mit der Software AnalySIS ${ }^{\circledR}$ (analySIS®, Soft Imaging System, Olympus Soft Imaging Solutions, Münster) ausgemessen. Dabei wurde die Breite des Epithels der einzelnen Ductuli an verschiedenen Stellen ausgemessen. Pro Präparat wurden 20 Messungen vorgenommen. Pro Futtergruppe vier Tiere à zwei Präparate.

Die gesammelten Ergebnisse wurden anschließend mit der Software GraphPad Prism ${ }^{\circledR}$ (GraphPad Prism 4® Software, Fa. GraphPad Software, Inc. San Diego, USA) graphisch und statistisch ausgewertet.

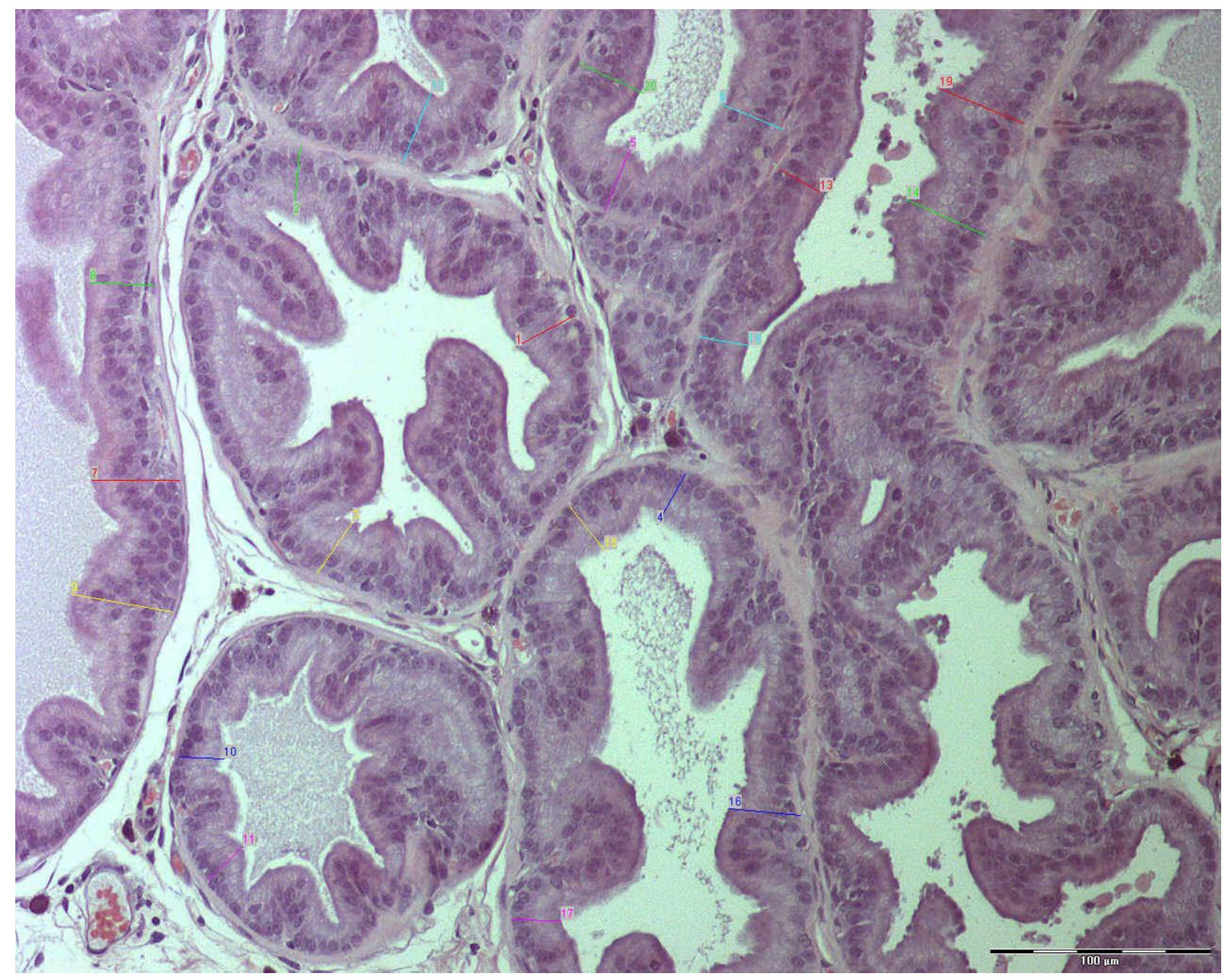

Abb.5: Prostata, HE-Färbung, 12,5-fach, Messung der Breite des Epithels der verschiedenen Ductuli 


\section{Ergebnisse}

\subsection{M. gastrocnemius}

Die quer angeschnittenen und HE gefärbten Schnitte des M. gastrocnemius wurden zunächst in der Übersicht eingestellt und angeschaut. Nach Vergrößerung auf 20x und Einstellung des gewünschten Areals wurden pro Präparat 10 Muskelfasern umfahren.

\subsubsection{Der Effekt von DHT, E2, Genistein und Equol zwei Wochen nach Futterumstellung auf die Muskelfaserfläche des $M$. gastrocnemius}

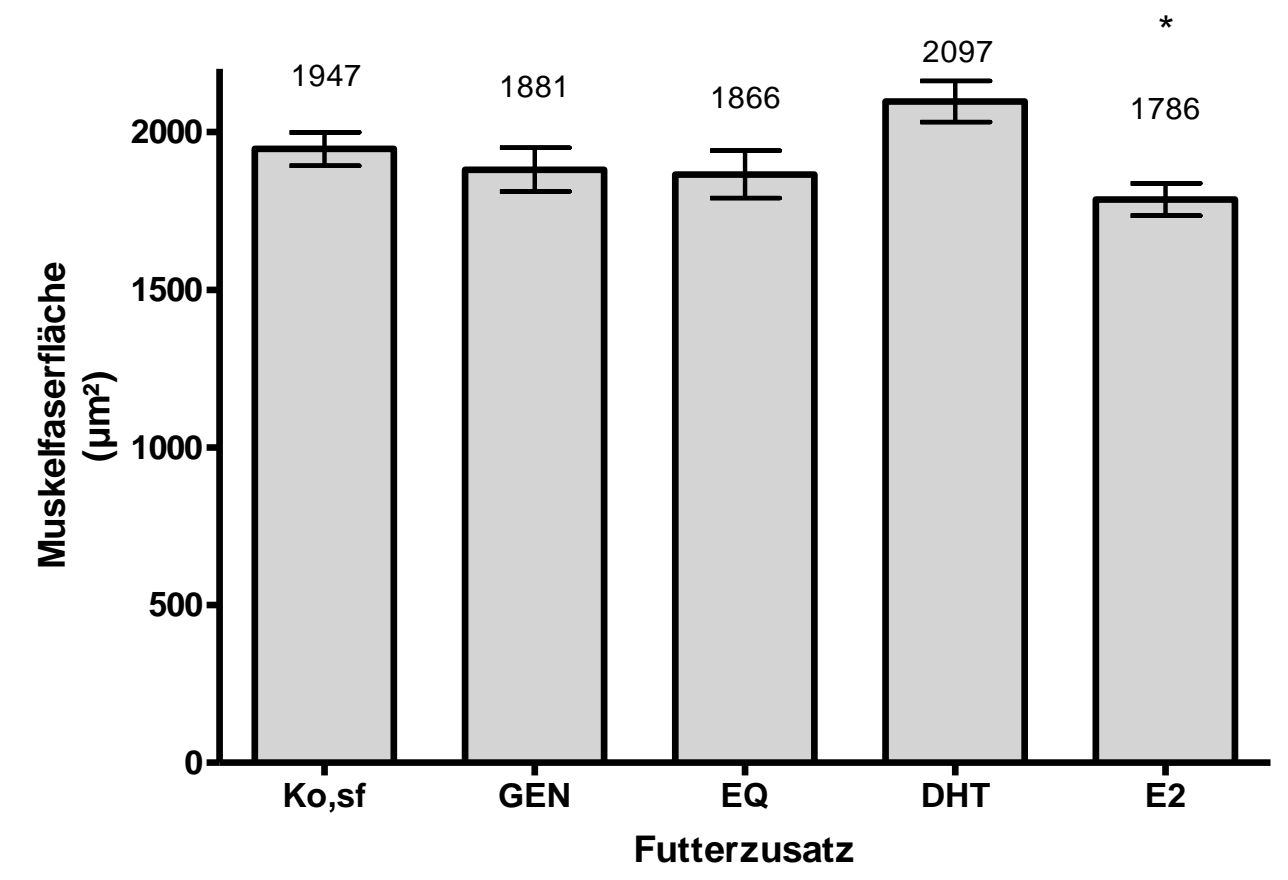

Abb.6: Der Effekt von DHT, E2, Genistein und Equol zwei Wochen nach Futterumstellung auf die Muskelfaserfläche des M. gastrocnemius; Ko: Kontrollgruppe; sf: sojafrei $* \mathrm{p}<0,05$ vs. sf Ko

Zwei Wochen nach Futterumstellung der orchidektomierten Tiere sank die durchschnittliche Muskelfaserfläche der mit Genistein, Equol und E2 substituierten Tiere 
im Vergleich zur sojafreien Kontrollgruppe ab. Am deutlichsten ist dies bei E2 mit einer Abnahme von $161 \mu \mathrm{m}$ zu sehen, die signifikant ist. Genistein und Equol sinken nicht signifikant um $66 \mu \mathrm{m}$ und $81 \mu \mathrm{m}$ gegenüber der Kontrollgruppe ab. Bei der DHT Gruppe findet eine nicht signifikante Zunahme der Faserfläche um $150 \mu \mathrm{m}$ statt.

\subsubsection{Der Effekt von DHT, E2, Genistein und Equol drei Wochen nach Futterumstellung auf die Muskelfaserfläche des $M$. gastrocnemius}

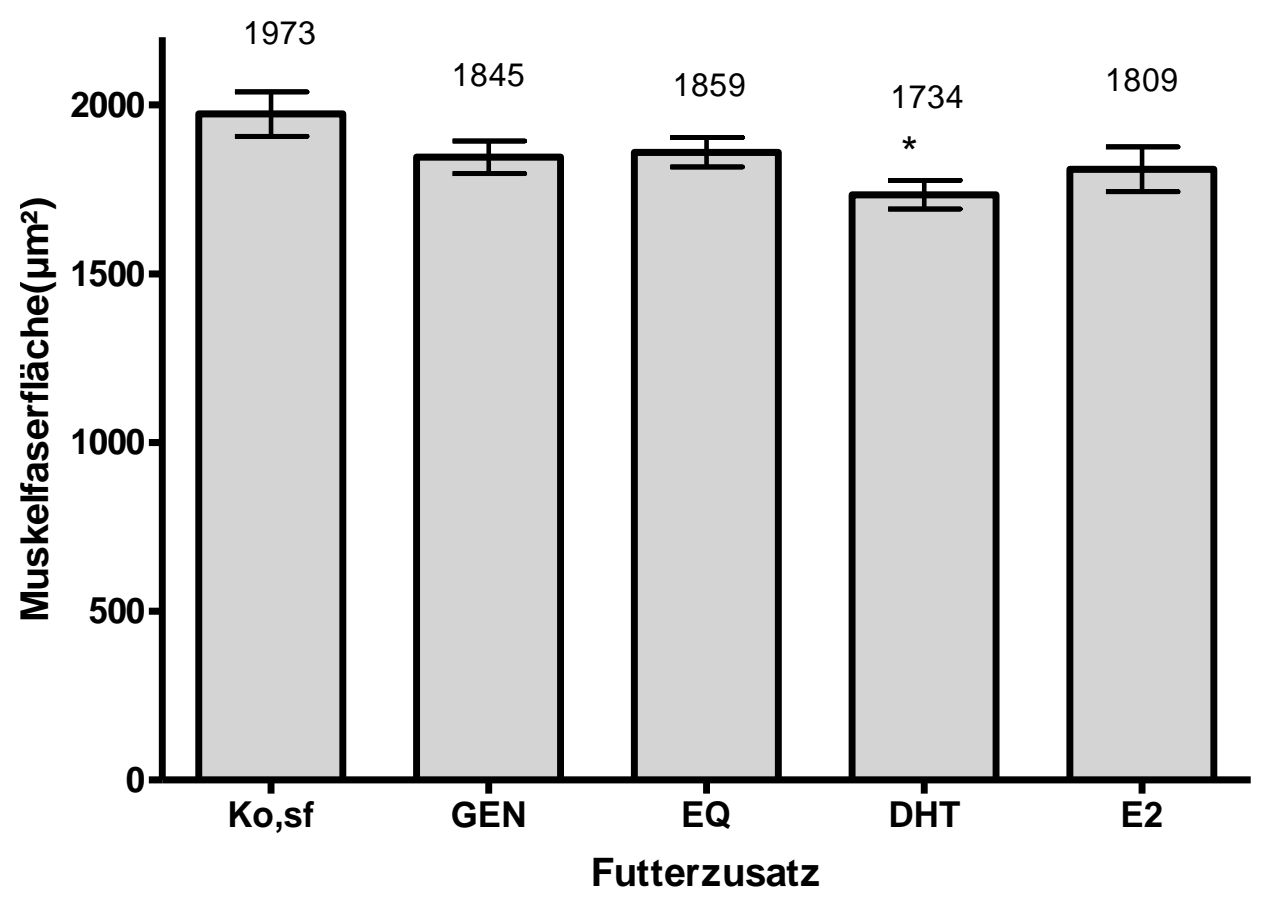

Abb.7: Der Effekt von DHT, E2, Genistein und Equol drei Wochen nach Futterumstellung auf die Faserfläche des M. gastrocnemius $* \mathrm{p}<0,05$ vs. sf Ko

Die Muskelfaserfläche der Kontrollgruppe der dritten Woche ist im Vergleich zur zweiten Woche in Abb. 6 um $26 \mu \mathrm{m}$ angestiegen. E2 ist ebenfalls angestiegen, von $1786 \mu \mathrm{m}$ auf $1809 \mu \mathrm{m}$. Die Genistein- und Equol-Werte sind im Vergleich zur zweiten Woche leicht abgefallen. Die Abnahme der DHT-Werte von der zweiten Woche zur dritten Woche war 
mit $363 \mu \mathrm{m}$ weit stärker und in der dritten Woche im Vergleich zur Kontrollgruppe signifikant.

\subsubsection{Der Effekt von DHT, E2, Genistein und Equol acht Wochen nach Futterumstellung auf die Muskelfaserfläche des $M$. gastrocnemius bei nicht vibrierten Tieren}

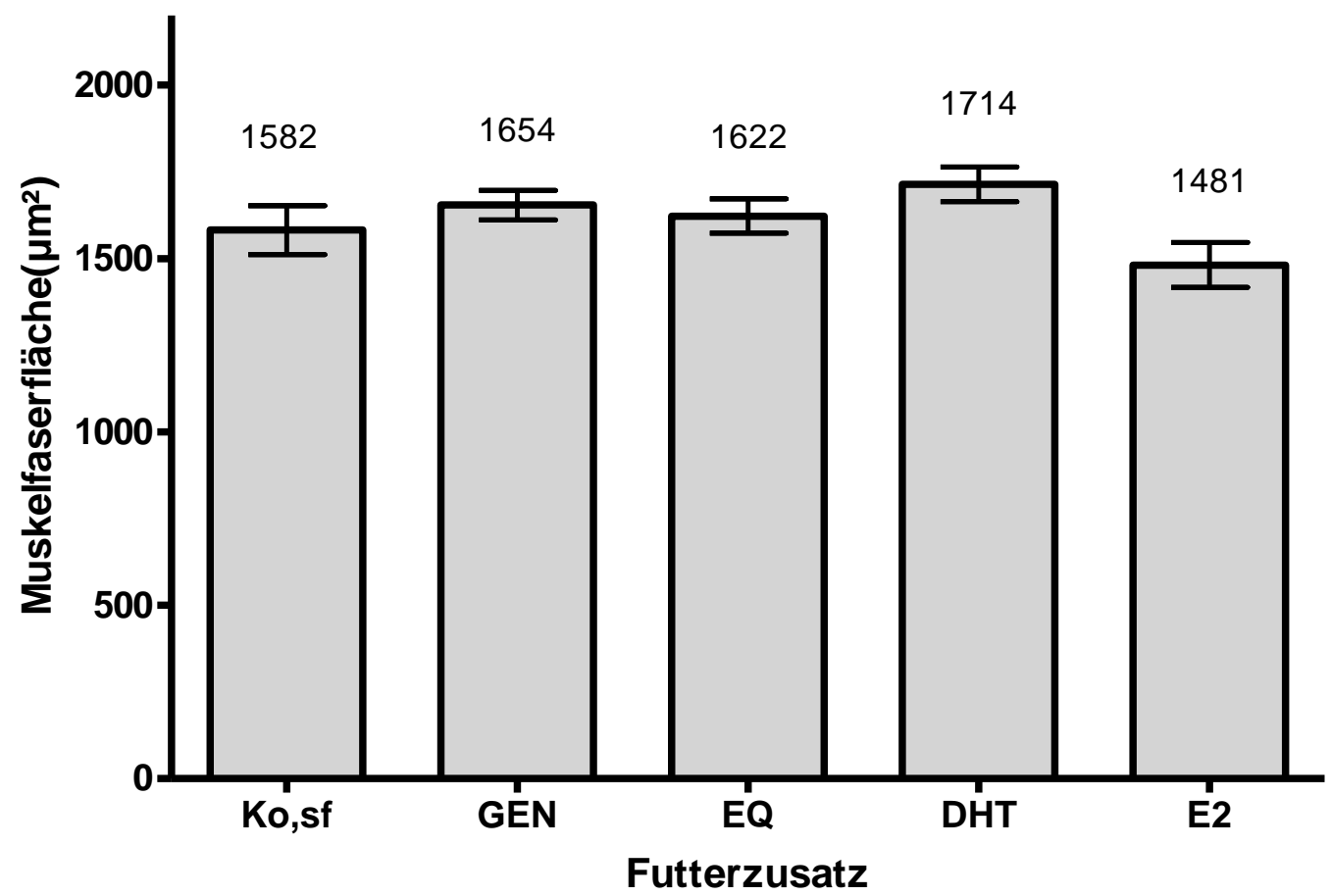

Abb. 8: Der Effekt von DHT, E2, Genistein und Equol nach 8 Wochen Futterumstellung auf die Faserfläche des M. gastrocnemius, nicht vibriert

In der Gruppe der Tiere, die keine Vibrationstherapie erhalten hatten konnten folgende Werte festgestellt werden: verglichen mit der sojafreien Kontrollgruppe bleiben die Werte von Genistein und Equol nahezu gleich. Eine nicht signifikante Abnahme um $101 \mu \mathrm{m}$ im Vergleich zur Kontrollgruppe fand bei E2 statt. Der Wert von DHT erhöhte sich, jedoch nicht signifikant um $132 \mu \mathrm{m}$ auf $1714 \mu \mathrm{m}$. 


\subsubsection{Der Effekt von DHT, E2, Genistein und Equol acht Wochen nach Futterumstellung auf die Muskelfaserfläche des $M$. gastrocnemius nach Vibrationstherapie für 10 Tage}

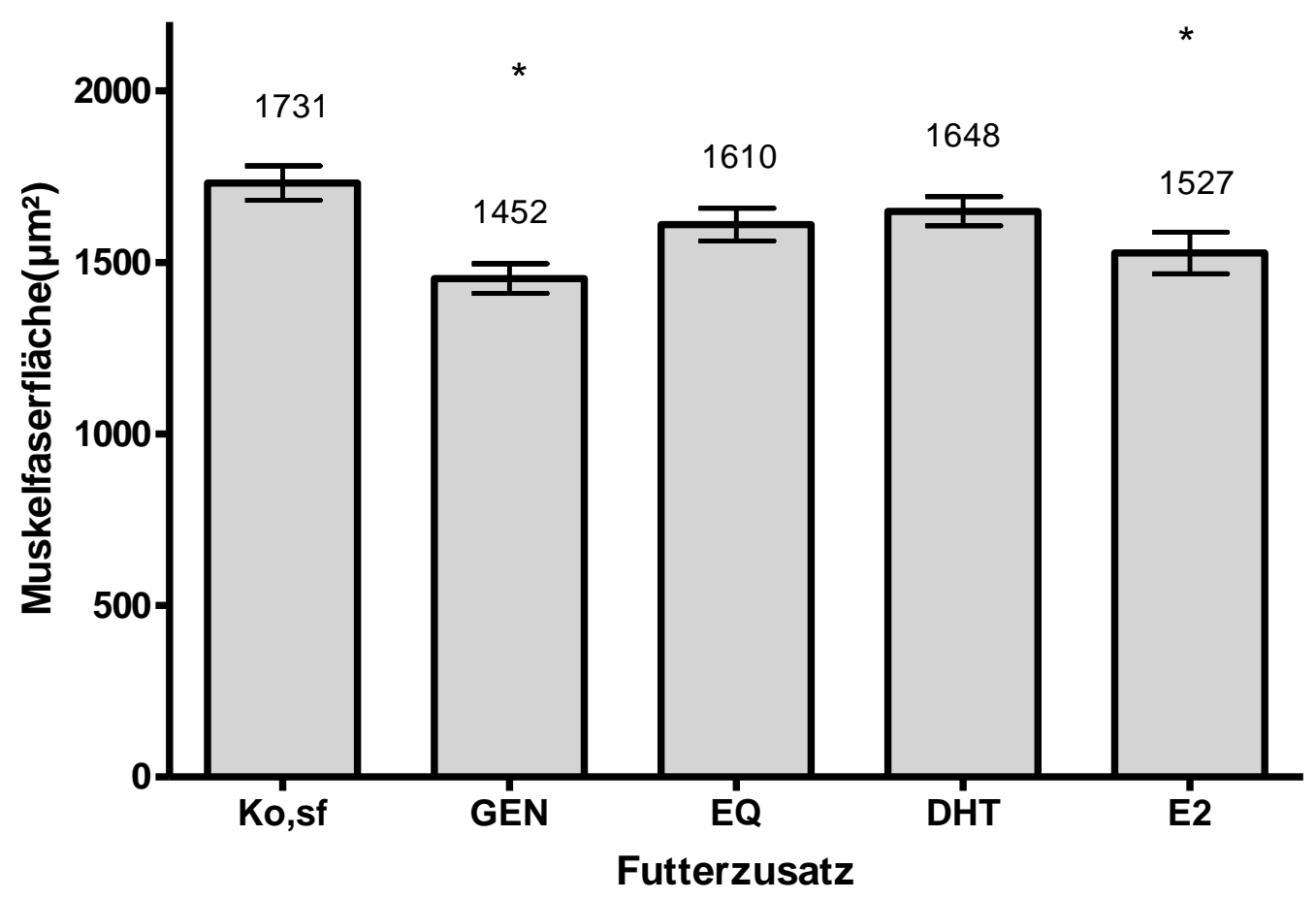

Abb.9: Der Effekt von DHT, E2, Genistein und Equol nach 8 Wochen Futterumstellung auf die Faserfläche des M. gastrocnemius, mit Vibrationstherapie für 10 Tage $* \mathrm{p}<0,05$ vs. sf Ko

Vergleicht man den Wert von Genistein mit dem Wert der Kontrollgruppe, so nimmt dieser signifikant um $16 \% \mathrm{ab}$. Die Muskelfaserfläche von E2 nimmt ebenso signifikant zur Kontrollgruppe ab, um 12 \%. Die Abnahmen von Equol und DHT sind weniger stark und nicht signifikant. Equol nimmt allerdings etwas stärker ab als DHT. 


\subsubsection{Der Effekt von Vibrationstherapie vs. nicht Vibrationstherapie acht Wochen nach Futterumstellung}

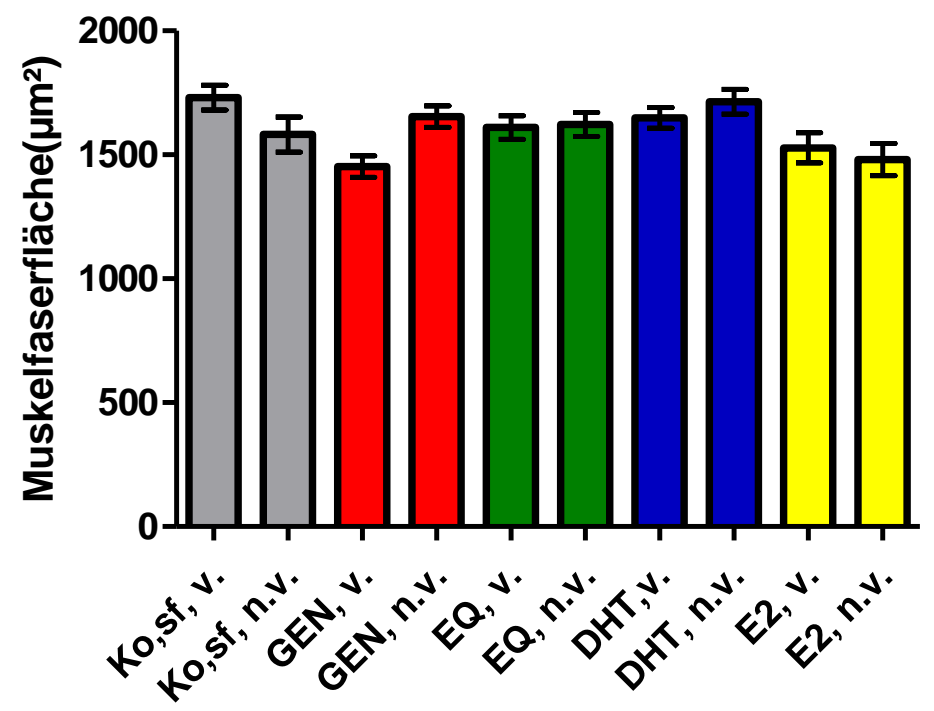

Futterzusatz

Abb.10: Der Effekt von Vibrationstherapie vs. nicht Vibrationstherapie acht Wochen nach Futterumstellung auf die Faserfläche des M. gastrocnemius; n.v.: nicht vibriert, v: vibriert

Die Abbildung 10 vergleicht die Werte von Genistein, Equol, DHT, E2 und der Kontrollgruppe acht Wochen nach der Futterumstellung und nach 10-tägiger Vibrationstherapie vs. Nicht-Vibrationstherapie miteinander. In der Kontrollgruppe steigt die Faserfläche der vibrierten Gruppe gegenüber der nicht vibrierten um $149 \mu \mathrm{m}$ an. Beide Equol-Gruppen zeigen keine Unterschiede. Die vibrierten Genistein-Tiere wie auch die beiden E2-Gruppen verbuchen den größten Muskelflächenverlust. Die geringste Verkleinerung ist bei den DHT-Tieren zu beobachten. 


\subsubsection{Der Verlauf der Größe der Muskelfaserfläche des $M$. gastrocnemius der sojafreien Kontrollgruppe über einen Zeitraum von 8 Wochen}

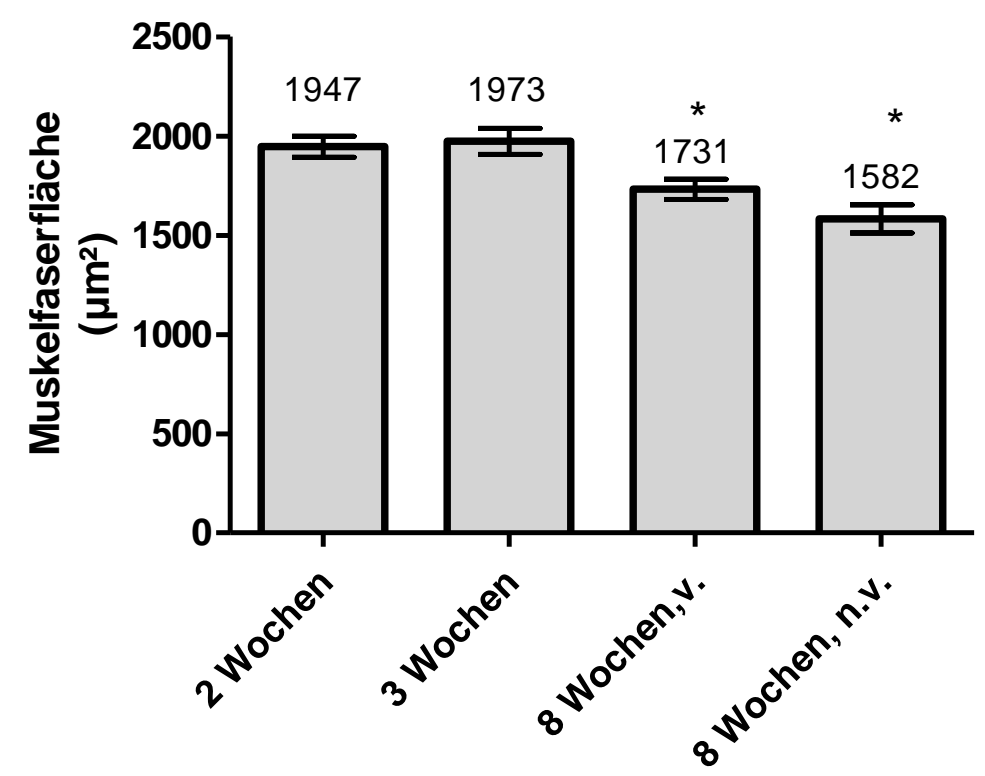

Abb.11: Verlauf der Größe der Muskelfaserfläche des M. gastrocnemius der Kontrollgruppe über acht Wochen v.: vibriert, n.v.: nicht vibriert $*$ p $<0,05$, vs. 2 Wochen

Die Muskelfläche des M. gastrocnemius nimmt über den gesamten gemessenen Zeitraum ab. Im Vergleich zu dem Ausgangswert in der zweiten Woche nimmt die Faserfläche in der achten Woche signifikant ab, in der Gruppe der nicht vibrierten Tiere am meisten mit $278 \mu \mathrm{m}^{2}$. Die zusätzliche Vibrationstherapie verhindert so einen Muskelverlust von 149 $\mu \mathrm{m}^{2}$. 


\subsubsection{Der Verlauf der Größe der Muskelfaserfläche des $M$. gastrocnemius der Genistein-Gruppe über einen Zeitraum von 8 Wochen}

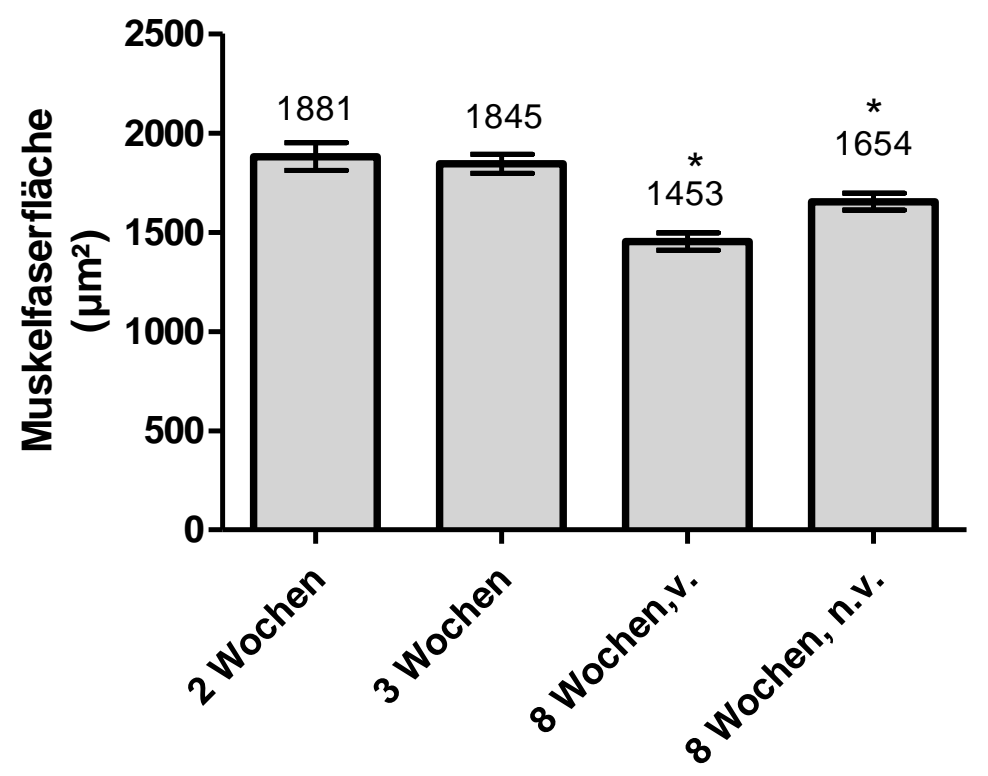

Abb.12: Verlauf der Größe der Muskelfaserfläche des M. gastrocnemius der GenisteinGruppe über acht Wochen v.: vibriert, n.v.: nicht vibriert $*$ p $<0,05$ vs. 2 Wochen

Die Muskelfaserfläche der Genistein-Gruppe nimmt über den gesamten Zeitraum ab. In der zweiten und dritten Woche ist der Wert nahezu gleich. Der stärkste Abfall der Werte ist jedoch in der achten Woche bei den vibrierten Tieren zu beobachten. Im Vergleich zur Muskelfaserfläche in der zweiten Woche reduziert sich die Muskelfläche um $428 \mu \mathrm{m}^{2}$ und ist signifikant. Ebenso reduziert sich die Muskelfaserfläche signifikant in der achten Woche bei den nicht vibrierten Tieren und nimmt um $227 \mu \mathrm{m}^{2} \mathrm{ab}$. 


\subsubsection{Der Verlauf der Größe der Muskelfaserfläche des $M$. gastrocnemius der Equol-Gruppe über einen Zeitraum von 8 Wochen}

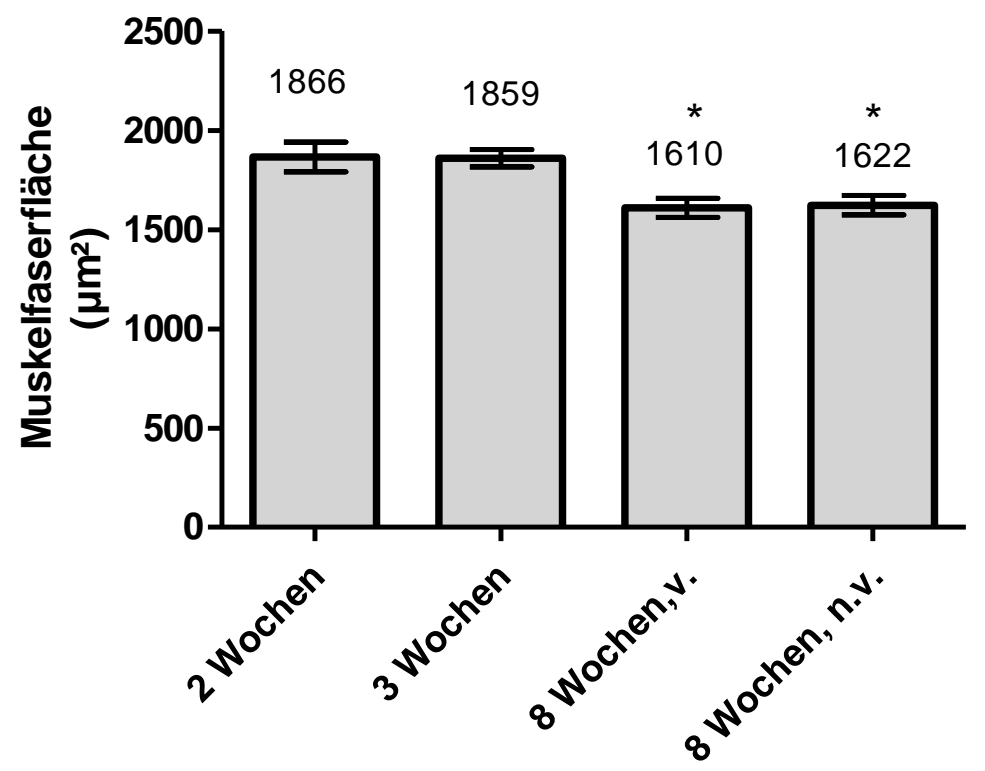

Abb. 13: Verlauf der Größe der Muskelfaserfläche des M. gastrocnemius der EquolGruppe über acht Wochen v.: vibriert, n.v.: nicht vibriert

$*$ p $<0,05$ vs. 2 Wochen

Auch hier reduziert sich die Muskelfaserfläche über den gemessenen Zeitraum. In den ersten drei Wochen verändert sich die Fläche kaum, nimmt aber dann in der achten Woche in beiden Gruppen, vibriert und nicht-vibriert, signifikant ab. Zwischen den vibrierten Tieren und den nicht-vibrierten Tieren gibt es keinen Unterschied.

Verglichen mit den Werten von Genistein nimmt die Muskelfaserfläche unter Equol langsamer ab. Zwischen der dritten und der achten Woche ist der Unterschied am deutlichsten zu sehen. Während die Fläche der Equol-Tiere um durchschnittlich $243 \mu \mathrm{m}^{2}$ abnimmt, findet unter Genistein eine Reduktion um durchschnittlich $292 \mu \mathrm{m}^{2}$ statt. 


\subsubsection{Der Verlauf der Größe der Muskelfaserfläche des $M$. gastrocnemius der E2-Gruppe über einen Zeitraum von 8 Wochen}

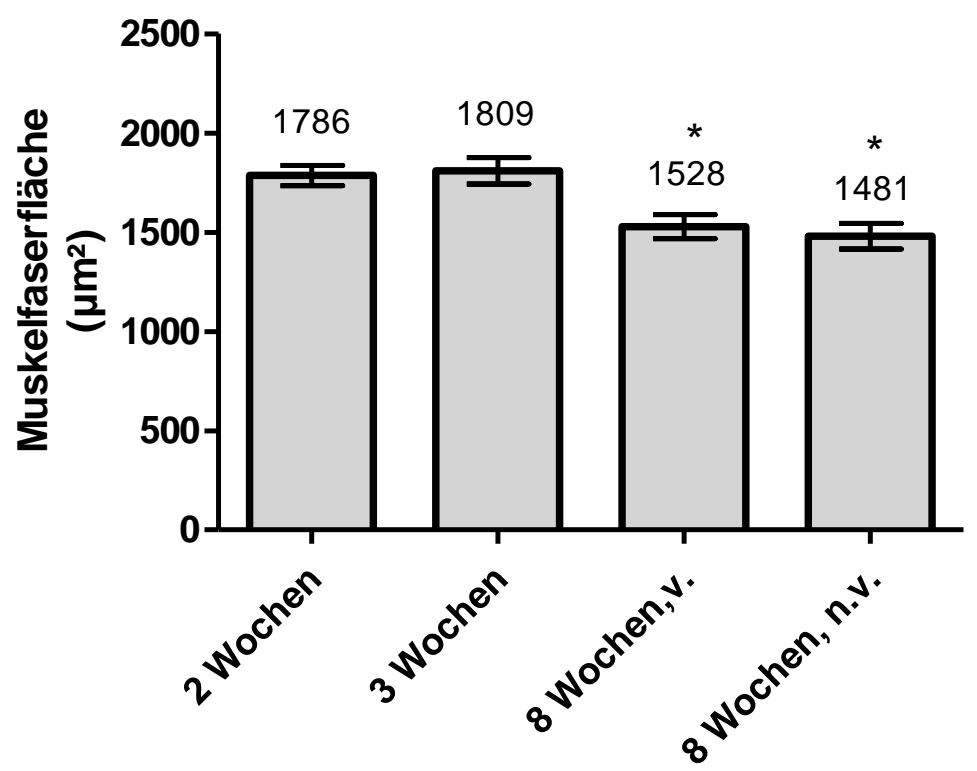

Abb. 14: Verlauf der Größe der Muskelfaserfläche des M. gastrocnemius der E2-Gruppe über acht Wochen v.: vibriert, n.v.: nicht vibriert

$* \mathrm{p}<0,05$ vs. 2 Wochen

Im Ganzen findet auch hier eine Reduktion der Muskelfaserfläche über die acht Wochen statt. In der dritten Woche findet sich eine leichte, nicht signifikante Vergrößerung der Muskelfaserfläche, die jedoch in der achten Woche in beiden Gruppen, vibriert und nichtvibriert, im Vergleich zur zweiten Woche signifikant abfällt. Die Muskelfläche der vibrierten Tiere ist gegenüber den nicht-vibrierten Tieren kaum erhöht. 


\subsubsection{Der Verlauf der Größe der Muskelfaserfläche des $M$. gastrocnemius der DHT-Gruppe über einen Zeitraum von 8 Wochen}

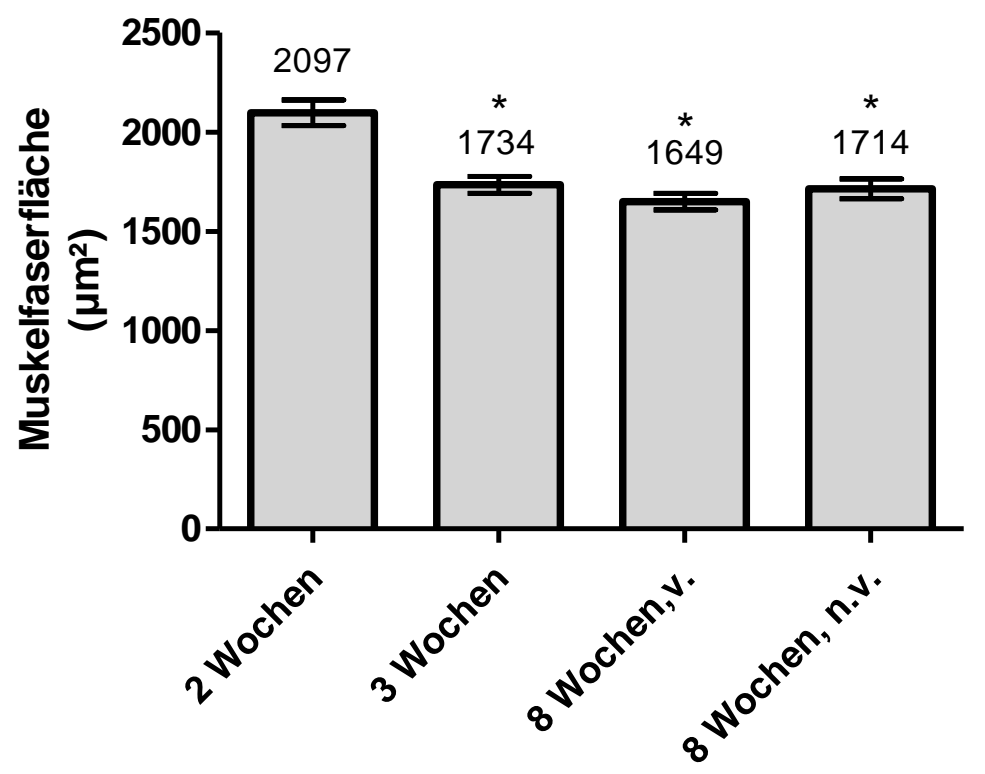

Abb. 15: Verlauf der Größe der Muskelfaserfläche des M. gastrocnemius der E2-Gruppe über acht Wochen v.: vibriert, n.v.: nicht vibriert

$* \mathrm{p}<0,05$ vs. 2 Wochen

Eine Abnahme der Muskelfaserfläche ist auch hier $\mathrm{zu}$ beobachten. Der größte Muskelverlust beträgt $364 \mu \mathrm{m}^{2}$ und findet zwischen der zweiten und dritten Woche statt; er ist im Vergleich zur zweiten Woche signifikant. Nachfolgend stabilisieren sich die Werte in der achten Woche mit einem nur geringen Verlust mit max. $84 \mu^{2}$ im Vergleich zur dritten Woche bei den vibrierten Tieren. Im Vergleich zur 2. Woche sind die Werte der vibrierten wie auch der nicht vibrierten Gruppen der achten Woche signifikant kleiner. 


\subsection{Prostata}

Das HE-gefärbte Prostata-Präparat wurde mittig eingestellt und mit einer Vergrößerung von 12,5x ausgemessen. Hierzu wurde die Breite des Epithels der Ductuli im Übersichtsfeld an verschiedenen Stellen ausgemessen. Pro Präparat wurden 20 Messungen vorgenommen.

\subsubsection{Der Effekt von DHT, E2, Genistein und Equol nach zwei Wochen Futterumstellung auf die Epitheliumdicke der Prostata}

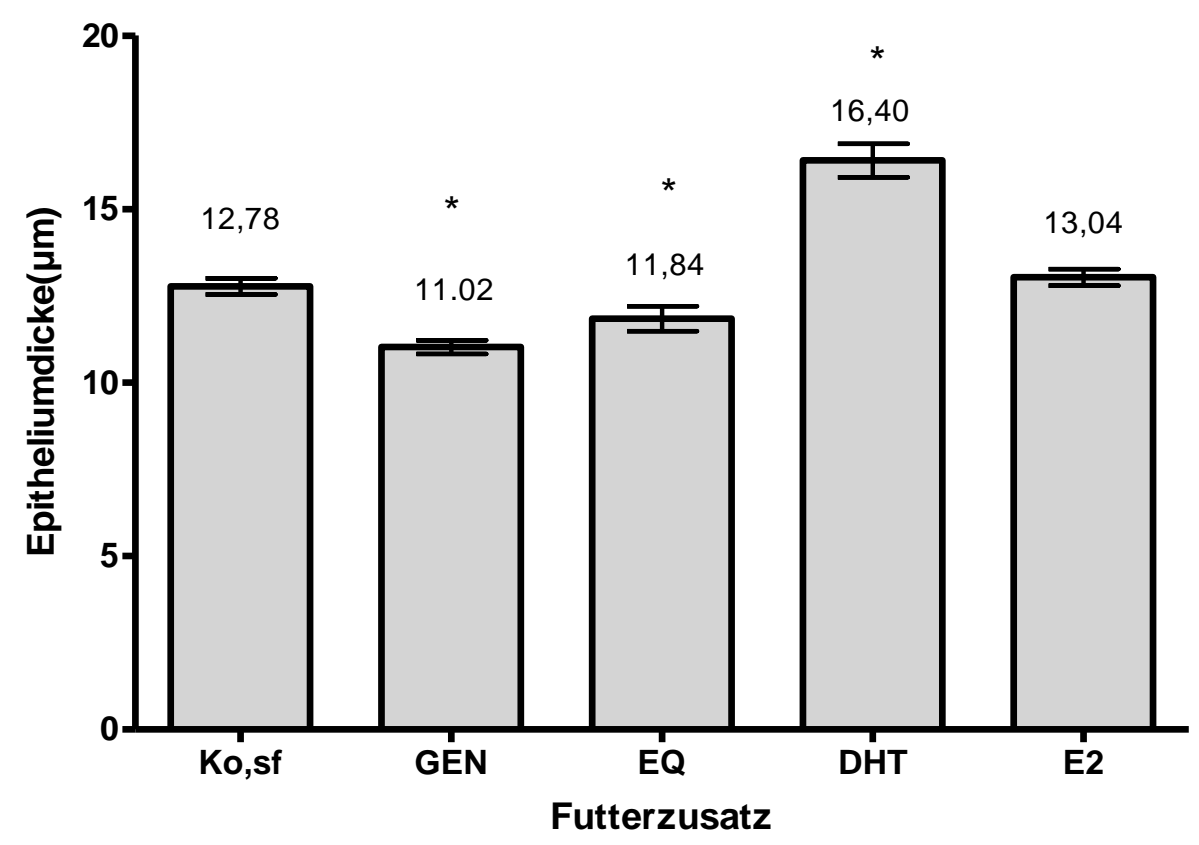

Abb.16: Auswirkung von DHT, E2, Genistein und Equol auf die Epitheliumdicke der Prostata zwei Wochen nach Futterumstellung.

$* \mathrm{p}<0,05$ vs. sf Ko

Im Vergleich zur sojafreien Kontrollgruppe verbreiterte sich die Epitheliumdicke von DHT signifikant um 6,38 $\mu \mathrm{m}$ bzw. um 28 \%. Die Werte von Genistein dagegen sanken signifikant auf 11,02 $\mu \mathrm{m}$, was einem Unterschied zur Kontrollgruppe von 1,76 $\mu \mathrm{m}$ oder $14 \%$ entspricht. Equol nahm ebenfalls signifikant zur Kontrollgruppe ab. Der Wert von E2 änderte sich nicht signifikant zur Kontrollgruppe. 


\subsubsection{Der Effekt von DHT, E2, Genistein und Equol nach drei Wochen Futterumstellung auf die Epitheliumdicke der Prostata}

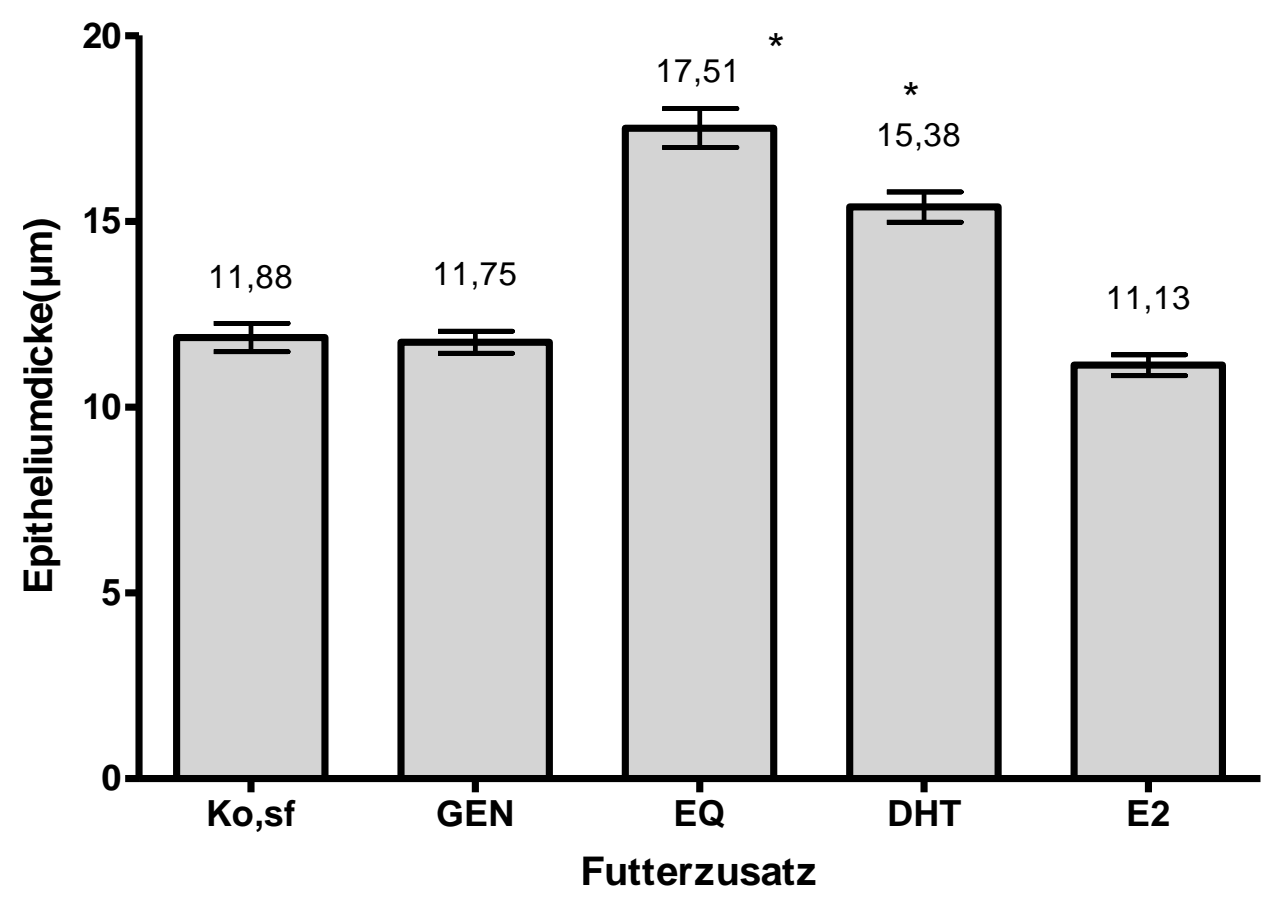

Abb. 17: Auswirkung von DHT, E2, Genistein und Equol auf die Epitheliumdicke der Prostata drei Wochen nach Futterumstellung.

$* \mathrm{p}<0,05$ vs. Kontrollgruppe

Drei Wochen nach Futterumstellung sinken die Werte der Kontrollgruppe um 0,9 $\mu \mathrm{m}$ im Vergleich zur Woche zwei (Abb:16) nach Futterumstellung ab. Bezogen auf die Kontrollgruppe steigt der DHT-Wert signifikant auf 15,38 $\mu \mathrm{m}$, was eine Verbreiterung des Prostata Epithels um $30 \%$ bedeutet. Der Wert von Equol steigt im Vergleich zur Kontrollgruppe ebenfalls signifikant um $48 \%$ auf 17,51 $\mu \mathrm{m}$. Mit den Werten von Genistein und E2 lag kein signifikanter Unterschied zur Kontrollgruppe vor. 


\subsubsection{Der Effekt von DHT, E2, Genistein und Equol nach acht Wochen Futterumstellung auf die Epitheliumdicke der Prostata, in Schnittmitte gemessen}

In der 6.Woche nach der Futterumstellung wurden die Tiere in zwei Gruppen aufgeteilt. Die erste Gruppe erhielt keine Vibrationstherapie, die zweite erhielt für 10 Tage täglich eine Vibrationstherapie.

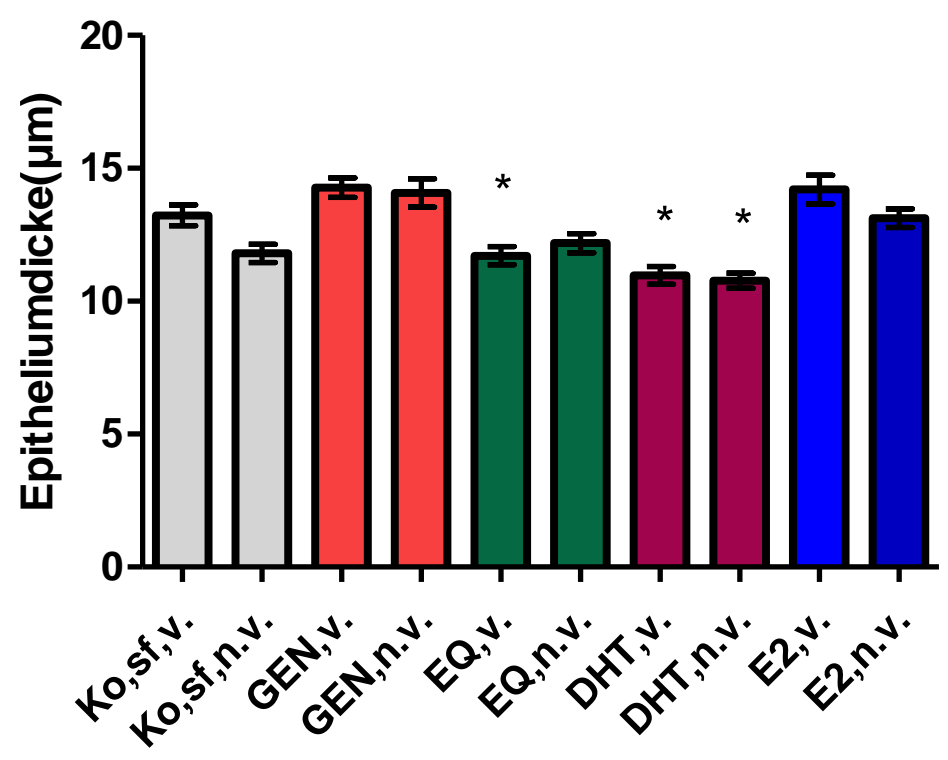

Futterzusatz

Abb. 18: Effekt der Vibrationstherapie auf die Epitheliumdicke der Prostata 8 Wochen nach orx und Futterumstellung, in Schnittmitte gemessen

$*$ p $<0,05$ : vs. Ko,sf; v.: vibriert; n.v.: nicht vibriert

Die Werte der Kontrollgruppe der nicht-vibrierten Tiere sind zu den Werten der dritten Woche in Abb. 17 unverändert geblieben. Genistein und E2 haben in der nicht-vibrierten Tiergruppe an Epitheliumdicke etwas zugenommen, was aber nicht signifikant ist. Equol fällt um 5,3 $\mu \mathrm{m} \mathrm{ab}$, ebenso der DHT-Wert, der um 4,61 absinkt. Die sojafreie Kontrollgruppe der vibrierten Tiere, sowie die Genistein- und die E2-Gruppe haben sich, im Vergleich zu Abb. 17 der dritten Woche leicht, jedoch nicht signifikant, erhöht. Die Werte von Equol und DHT dagegen sind stark gefallen, um 5,8 $\mu \mathrm{m}$ bei Equol und 4,4 $\mu \mathrm{m}$ 
bei DHT. Generell sind die Werte unabhängig von der Vibrationstherapie leicht gestiegen, außer bei den Werten von Equol und DHT, die stark abgefallen sind. Der Wert der nichtvibrierten Kontrollgruppe ist etwas niedriger als der der vibrierten Kontrollgruppe (1,43 $\mu \mathrm{m})$. Beide DHT-Werte sind signifikant niedriger als die Kontrollgruppen und auch Equol ist signifikant verringert.

\subsubsection{Der Effekt von DHT, E2, Genistein und Equol nach acht Wochen Futterumstellung auf die Epitheliumdicke der Prostata, am Schnittrand gemessen}

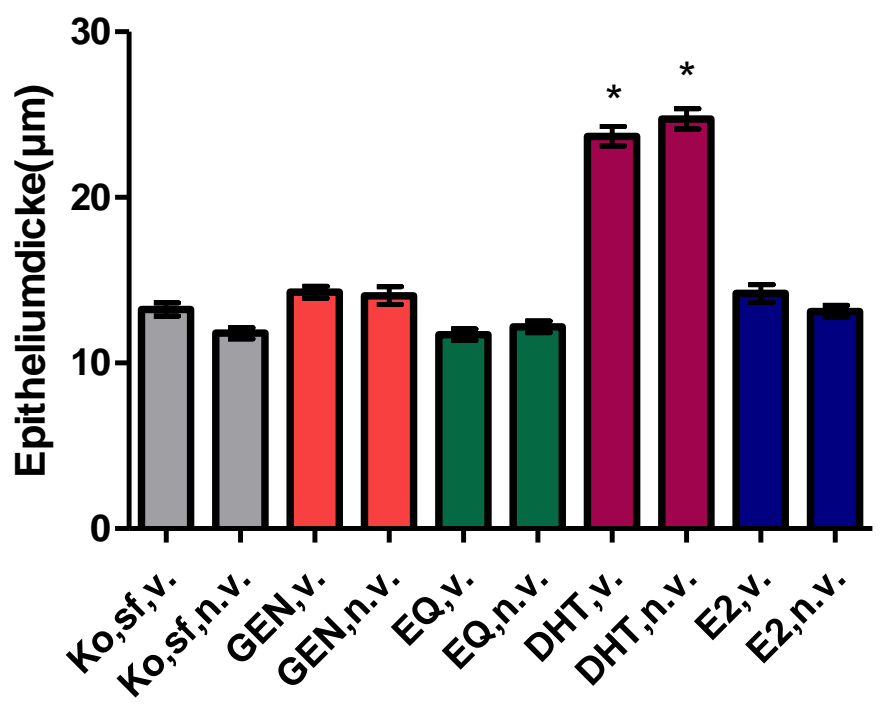

Futterzusatz

Abb.19: Effekt der Vibrationstherapie auf die Epitheliumdicke der Prostata 8 Wochen nach orx und Futterumstellung, am Schnittrand gemessen p<0,05: vs. Ko; v.: vibriert; n.v.: nicht vibriert

Die Werte von DHT (vibriert und nicht-vibriert) sind im Vergleich zu den in der Mitte des Präparates gemessenen Werten in Abb. 17 stark erhöht. So findet sich eine Steigerung der Werte der vibrierten DHT-Tiere um $46 \%$, der nicht-vibrierten Tiere um $44 \%$. Im Vergleich zu der Kontrollgruppe stieg die Epitheliumdicke der vibrierten DHT-Tiere um $56 \%$ an, der Anstieg der nicht-vibrierten DHT-Tiere betrug $48 \%$. In den übrigen 
Gruppen konnte keine Änderung der Werte in Bezug auf das ausgewertete Areal des Präparats festgestellt werden.

\subsubsection{Der Verlauf der Epitheliumdicke der Prostata der sojafreien Kontrollgruppe über acht Wochen}

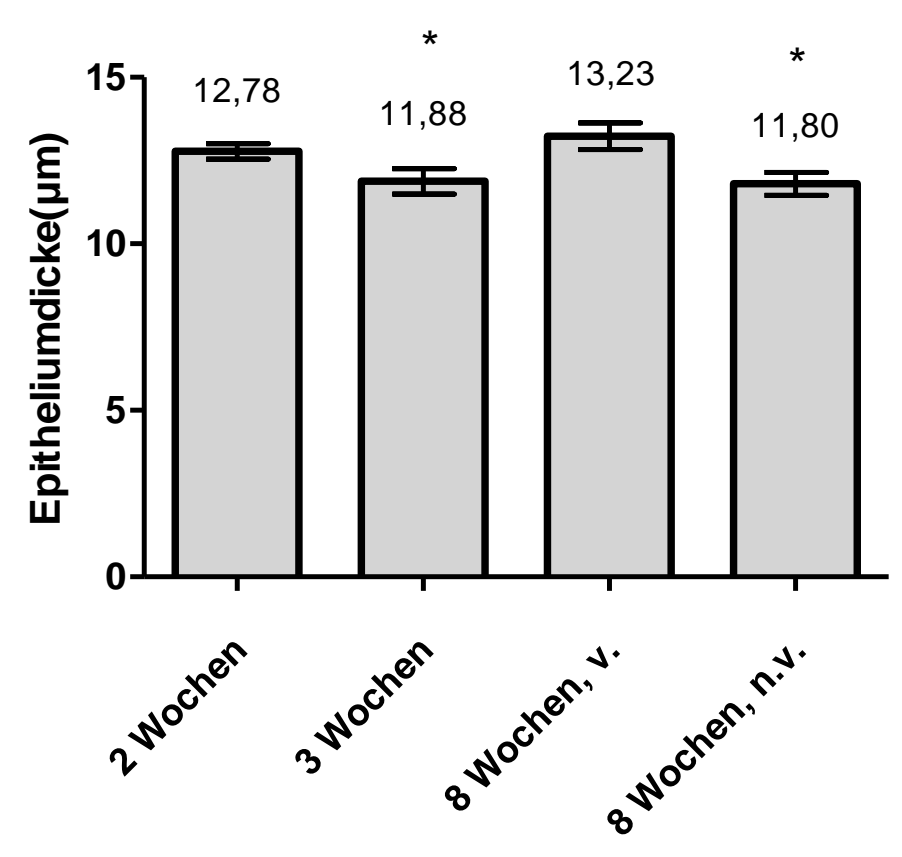

Abb. 20: Verlauf der Epitheliumdicke der Prostata der sojafreien Kontrollgruppe über den Zeitraum von acht Wochen

$* \mathrm{p}<0,05$ vs. 2 Wochen

Im Verlauf der Kontrollgruppe nimmt die Epitheliumdicke von 2 Wochen, über 3 Wochen und bis 8 Wochen nicht-vibriert langsam ab. Wobei die Abnahme zwischen der zweiten Woche und der dritten Woche mit $0.9 \mu \mathrm{m}$ größer ist, als die Abnahme zwischen der dritten Woche und der achten Woche der nicht-vibrierten Tiere, die 0,08 $\mu \mathrm{m}$ betrug. Beide Werte sind signifikant zur zweiten Woche verringert. Bei den vibrierten Tieren konnte ein Zuwachs der Epitheliumdicke beobachtet werden, im Vergleich zu den Werten der zweiten Woche um 0,45 $\mu \mathrm{m}$. 


\subsubsection{Der Verlauf der Epitheliumdicke der Prostata der Genistein- Gruppe über acht Wochen}

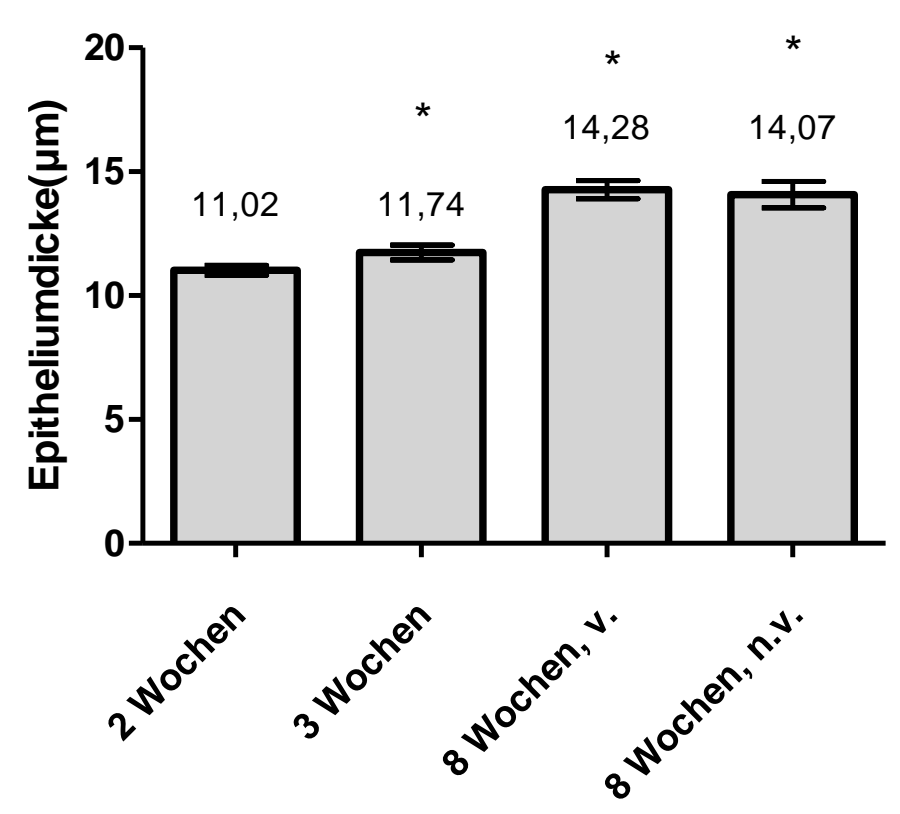

Abb. 21: Verlauf der Epitheliumdicke der Prostata der Genistein-Gruppe über den Zeitraum von acht Wochen

$* \mathrm{p}<0,05$ vs. 2 Wochen

Die Epitheliumdicke der mit Genistein gefütterten Tiere nimmt über den Zeitraum von acht Wochen signifikant zu. Zwischen der zweiten und dritten Woche um 0,72 $\mu \mathrm{m}$, was einem durchschnittlichen täglichen Zuwachs von 0,10 $\mu \mathrm{m}$ entspricht. Zwischen der dritten Woche und der achten Woche findet vibriert eine Zunahme um 2,54 $\mu \mathrm{m}$ statt, was einem Zuwachs von 0,06 $\mu \mathrm{m}$ pro Tag entspricht. Der tägliche Zuwachs ist anfänglich also größer und schwächt sich auf die achte Woche hin ab. Der Wert der vibrierten Tiere unterscheidet sich nicht von den nicht-vibrierten. 


\subsubsection{Der Verlauf der Epitheliumdicke der Prostata der Equol- Gruppe über acht Wochen}

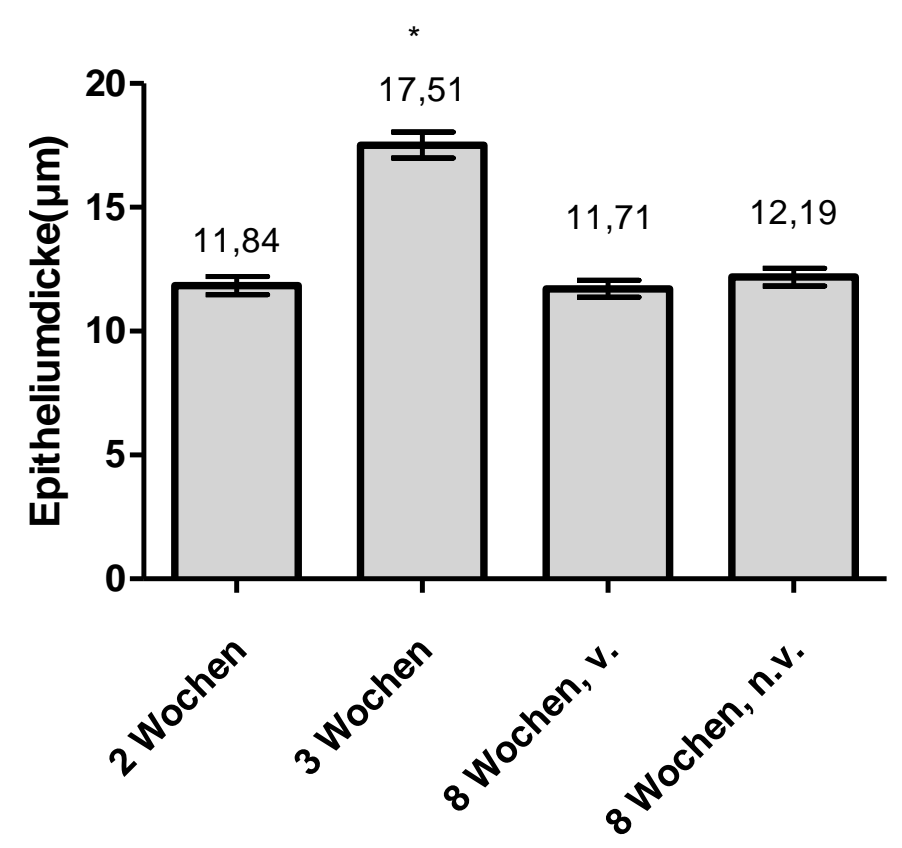

Abb. 22: Verlauf der Epitheliumdicke der Prostata der Equol-Gruppe über den Zeitraum von acht Wochen

$* \mathrm{p}<0,05$ vs. 2 Wochen

In der dritten Woche findet ein signifikanter Anstieg des Equol-Wertes um 5,7 $\mu \mathrm{m}$ zur zweiten Woche statt. Dieser fällt in der achten Woche wieder auf das ursprüngliche Niveau, auf $11,71 \mu \mathrm{m}$ in der vibrierten Gruppe und auf $12,19 \mu \mathrm{m}$ in der nicht-vibrierten Gruppe ab. Die Werte der achten Woche, vibriert und nicht-vibriert, sind nicht signifikant erhöht gegenüber der zweiten Woche. 


\subsubsection{Der Verlauf der Epitheliumdicke der Prostata der E2- Gruppe über acht Wochen}

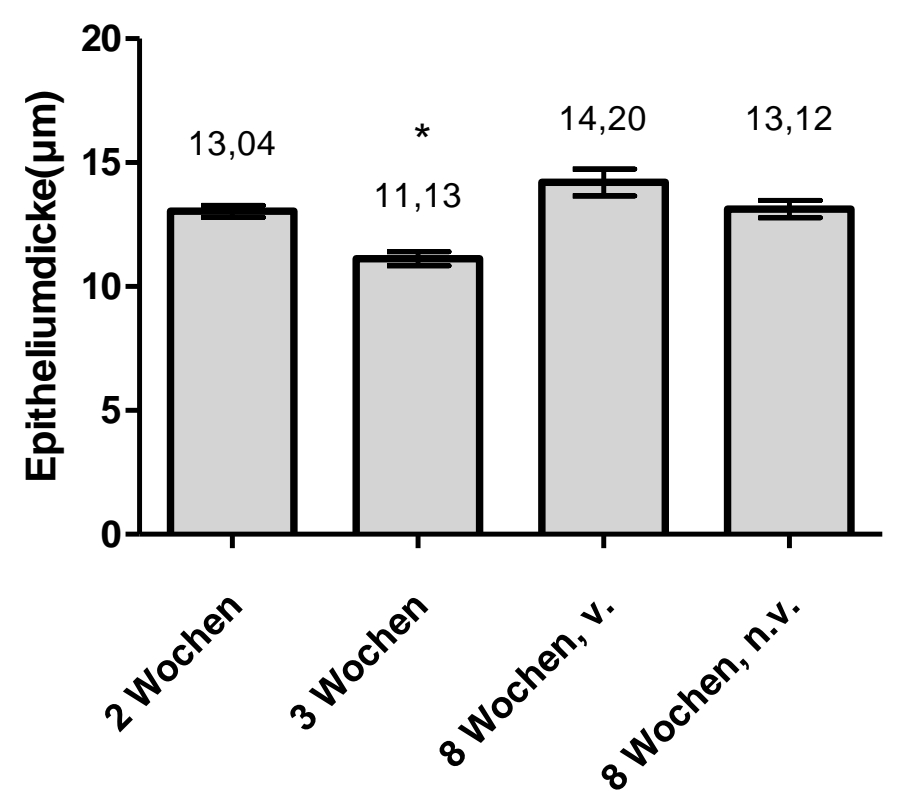

Abb. 23: Verlauf der Epitheliumdicke der Prostata der E2-Gruppe über den Zeitraum von acht Wochen

$* \mathrm{p}<0,05$ vs. 2 Wochen

Im Vergleich zur zweiten Woche nimmt die Epitheliumdicke in der dritten Woche signifikant um 1,91 $\mu \mathrm{m}$ auf $11,13 \mu \mathrm{m}$ ab. In der achten Woche steigt dann der Wert wieder an; in der vibrierten Gruppe auf $14,20 \mu \mathrm{m}$ und in der nicht-vibrierten Gruppe auf 13,12 $\mu \mathrm{m}$. In der nicht-vibrierten Gruppe bleibt der Wert in Bezug auf die zweite Woche also gleich, während in der vibrierten Gruppe ein leichter Anstieg festzustellen ist. 


\subsubsection{Der Verlauf der Epitheliumdicke der Prostata der DHT- Gruppe über acht Wochen}

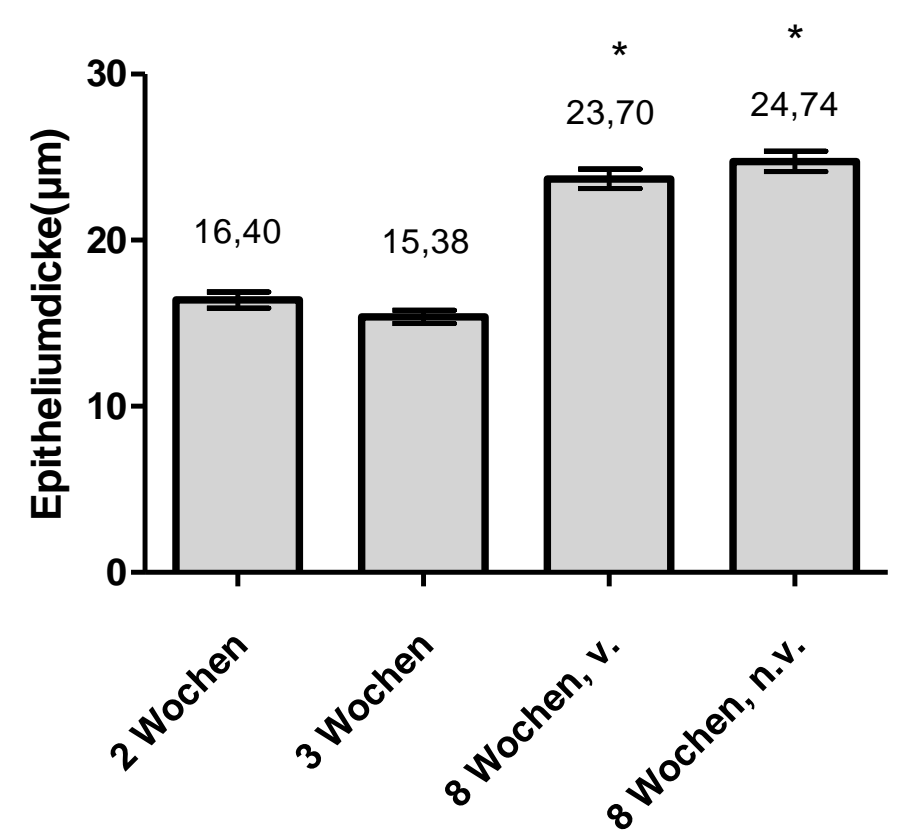

Abb. 24: Verlauf der Epitheliumdicke der Prostata der DHT-Gruppe über den Zeitraum von acht Wochen

$* \mathrm{p}<0,05$ vs. 2 Wochen

Die Epitheliumdicke nimmt in der dritten Woche im Vergleich zur zweiten Woche nicht signifikant ab. In der achten Woche steigen beide Werte, vibriert und nicht-vibriert, signifikant auf 23,70 $\mu \mathrm{m}$, bzw. 24,74 $\mu \mathrm{m}$ an. Zwischen den vibrierten Tieren und den nicht-vibrierten Tieren zeigt sich kaum ein Unterschied, mit 1,04 $\mu \mathrm{m}$ ist die vibrierte Gruppe etwas kleiner als die nicht-vibrierte. Acht Wochen nach Futterumstellung vergrößerte sich die Epitheliumdicke der Prostata in der Gruppe der nicht-vibrierten Tiere um $51 \%$. 


\section{Diskussion}

In der vorliegenden Arbeit wurde anhand eines Tiermodells an orchidektomierten Ratten die Wirkung der Sexualhormone DHT und E2, sowie der Phytoöstrogene Genistein und Equol am muskuloskelettalen-System und der Prostata untersucht. Als Messparameter diente beim Muskelfaszikel die Veränderung der Größe im Muskelquerschnitt; bei der Prostata die Zellproliferation des Epithels der Ductuli und somit die Epitheliumdicke. Darüber hinaus soll zusätzlich der Effekt von körperlicher Betätigung auf die Muskulatur demonstriert werden. Hierzu wurde die Methode der Vibrationstherapie gewählt.

Das Modell der orchidektomierten Ratte wählten wir, um die Vergleichbarkeit der zugegebenen Substanzen durch die Ausschaltung der körpereigenen Hormone zu gewährleisten. Darüber hinaus diente es zur Darstellung der Veränderungen, die durch den Hormonmangel bei älteren Männern entstehen können. Aufgrund dieser Vorteile wählten wir diesen Versuchsansatz.

Als Prophylaxe vor Sarkopenie und Osteoporose wird beim Menschen regelmäßige Bewegung empfohlen. Ist dies nicht ausreichend, werden andere bzw. zusätzliche therapeutische Maßnahmen, wie eine Hormonersatztherapie, eingeleitet. Diese Abstufung wurde in unserem Versuch berücksichtigt und daher wurden zwischen der Orchidektomie und der Futterumstellung alle Versuchstiere vier Wochen lang täglich auf eine Vibrationsplatte gestellt. Anschließend wurden die orchidektomierten Tiere in fünf Gruppen eingeteilt. Je nach Futterzusatz in eine DHT-, E2-, Equol- und Genistein-Gruppe sowie in eine sojafreie Kontrollgruppe. Die Kontrollgruppe erhielt keinen Futterzusatz, um die Entwicklung der Muskulatur und der Prostata ohne hormonellen Einfluss mit den jeweils anderen Futterzusätzen vergleichen zu können.

Ein Teil des körpereigenen $\mathrm{T}$ wird durch das Enzym Aromatase in E2 umgewandelt (Marts et al. 1987; Marks und Petrow 1983; Ellem und Risbridger 2006). E2 hat, wie auch T, einen anabolen Effekt auf die Skelettmuskulatur und wirkt u.a. stimulierend auf die Vorläufer der Muskelzellen, die Satellitenzellen (Dieli-Conwright et al. 2009). Wir verabreichten den Versuchstieren, um die reine T-Wirkung auf die Muskulatur zu zeigen und den E2-Effekt auszuschließen, statt T DHT, da dieses nicht weiter aromatisiert werden kann.

Das durch die Orchidektomie entstandene Hormondefizit verursacht eine katabole Stoffwechsellage, die sich u.a. durch eine verminderte Hämoglobin-Konzentration und 
vermehrten Knochen- und Muskelabbau bemerkbar macht (Hochreiter et al. 2005; Lenk 2005).

Unter Gabe von $\mathrm{T}$ können die Symptome des Testosteronmangels vollständig ausgeglichen werden. Der Effekt von $\mathrm{T}$ auf das Wachstum und die Kraft des Skelettmuskels korreliert dabei linear mit der applizierten Dosis (Herbst und Bhasin 2004).

In einer Studie mit orchidektomierten Ratten überprüften Borst et al. die Wirkung von T auf die Muskulatur, die Knochen und die Prostata (Borst et al. 2007). Hierzu wurden 344 männliche Ratten orchidektomiert und über 56 Tage mit einer supraphysiologischen Dosis von $1 \mathrm{mg}$ T pro Tag subkutan behandelt. Das entspricht einem Äquivalent von $1200 \mathrm{mg} T$ pro Woche für eine $70 \mathrm{~kg}$ schwere Person. Die gebräuchlichen Hormonersatzdosen variieren zwischen 35-100 mg pro Woche. Ein Teil der Tiere bekam zusätzlich einen 5 $\alpha$ Reduktase-Hemmer (MK-439), der die Umwandlung von $\mathrm{T}$ in DHT verhindern sollte. DHT gilt in der Prostata als vorherrschender Androgen-vermittelnder Faktor und kann eine Prostatahyperplasie auslösen. 5a-Reduktase wird hauptsächlich in der Prostata exprimiert, weniger häufig in der Samenblase, sowie in den Haarfollikeln. Keine Expression findet dagegen in der Skelettmuskulatur und den Knochen statt. Die Arbeitshypothese von Borst et al. war, dass ein 5 $\alpha$-Reduktase-Inhibitor die T-induzierte Prostatavergößerung verhindern könnte, ohne die anabole Wirkung auf Muskel und Knochen zu schmälern. Die Wirkung auf die Muskulatur wurde durch den Versuch bestätigt. Die Muskelkraft verstärkte sich und wurde durch den 5 $\alpha$-Reduktase-Hemmer nicht beeinträchtigt, ebenso die Muskelfaserzusammensetzung entsprach den Wirkungen von T. Die Muskelkraft wurde an den Vorderbeinen der Tiere gemessen. Dabei griffen die Tiere auf ein Messgerät und hielten sich daran fest. Die Muskelfaserzusammensetzung der Typen I und II wurde histologisch bestimmt. Durch Zugabe des $5 \alpha$-Reduktase-Hemmers fand keine wesentliche Vergrößerung der Prostata statt, die alleinige Gabe von $\mathrm{T}$ jedoch ging mit einer 12-fachen Vergrößerung der Prostata einher. Durch die Zugabe des $5 \alpha$ Reduktase-Hemmers konnte also eine Organselektivität hergestellt werden und die anabole Wirkung von T auf die Muskulatur nachgewiesen werden, während der Effekt auf die Prostata gering war. Die alleinige Zugabe von T zeigte eine ubiquitäre Wirkung; einen anabolen Effekt auf die Muskulatur, wie auch eine massive Vergrößerung der Prostata. In der vorliegenden Arbeit wurden die orchidektomierten Ratten mit durchschnittlich 21,2mg DHT pro Tag als Futterzusatz behandelt und zeigten nach acht Wochen im 
Vergleich zur Kontrollgruppe eine geringere Reduktion der Muskelfaszikelfläche um 132 $\mu \mathrm{m}^{2}$, also um 7,7 \%. Am Ende des substituierten Zeitraums verlor die DHT-Gruppe im Vergleich zu allen übrigen Gruppen am wenigsten Faszikelfläche und diese war damit also am größten aller substituierten Tiere. Durch die DHT-Therapie konnte der Muskelsubstanzverlust vermindert werden, eine anabole Wirkung auf die Muskelfaszikelfläche blieb jedoch aus. Dies könnte allerdings auch an der angewandten Messmethode liegen, die, im Gegensatz zur Methodik von Borst et al. ausschließlich morphologisch die Fläche der Muskelfaszikel bestimmt und nicht auf die Muskelzusammensetzung und die Muskelkraft eingeht. Borst et al. untersuchten auch die Muskelmasse, die sich bei den orchidektomierten Tieren weder unter Zugabe von DHT noch ohne DHT unterschied. Die Vergrößerung der Prostata unter alleiniger Zugabe von $\mathrm{T}$, die Borst in seinem Versuch beschreibt, können wir ebenfalls bestätigen. Die Epitheliumdicke der Prostata acht Wochen nach Futterumstellung vergrößerte sich in diesem Versuch um 51\%.

Die beiden Östrogenrezeptoren ER $\alpha$ und ER $\beta$ konnten in der Skelettmuskulatur von Frauen, wie auch in der von Männern, nachgewiesen werden (Lemoine et al. 2003; Wiik et al. 2009). Die Wirkung von Östrogenen in der Muskulatur ist nicht vollständig geklärt; $\mathrm{ER} \alpha$ hat eine proliferative Funktion, während $\operatorname{ER} \beta$ eine modulierende Wirkung hat und die Aktivität von ER $\alpha$ unterdrücken kann (Glenmark et al. 2004; Pettersson et al. 2000; Weihua et al. 2000). Dieli-Conwright et al. konnten auf zellulärer Ebene zeigen, dass E2 den Muskelzellstoffwechsel durch Einbau von Glukosetransportern anregt und zur Differenzierung der Satellitenzellen beiträgt (Dieli-Conwright et al. 2009). Darüber hinaus scheint es einen Zusammenhang von Östrogenen und Bewegung zu geben. Wiik et al. konnten nachweisen, dass die Expression von mRNA beider Östrogenrezeptoren bei Ausdauer-trainierten Personen höher war, als bei untrainierten, was den Schluss zulässt, dass die Östrogenrezeptoren durch körperliche Aktivität reguliert werden (Wiik et al. 2005). Die Auswirkung körperlichen Trainings auf die Muskulatur nach Gabe von Östrogenen untersuchten auch Enns et al. (Enns et al. 2008). Dazu wurde ovariektomierten Ratten Östrogen gegeben und die Tiere wurden auf ein Laufband gesetzt. Die Auswertung der Muskulatur ergab eine direkte Östrogenrezeptor-vermittelte Steigerung der Anzahl der Muskelvorläuferzellen, den Satellitenzellen. Durch diese Aktivierung kann Östrogen direkt in den Muskelstoffwechsel eingreifen und anabol wirken. Diese neuen Erkenntnisse und Wirkungsweisen bilden die Grundlage der 
Untersuchung von Östrogenen und Phytoöstrogenen im Hinblick auf die Behandlung der Sarkopenie und möglicher Nebenwirkungen an der Prostata in der vorliegenden Arbeit. Tiidus et al. (2005) konnten zeigen, dass sich die Anzahl von Satellitenzellen in der Skelettmuskulatur bei männlichen, nicht-orchidektomierten Ratten nach körperlichem Training und der zusätzlichen Gabe von Östrogenen vergrößerte. Hierzu wurden die Tiere in zwei Gruppen unterteilt (E2/nicht-E2), die wiederum zur Hälfte mithilfe eines Laufrades körperlich aktiv waren. Drei Tage später wurden Muskelproben entnommen und mithilfe von Satellitenzell-spezifischen PAX-7-Antikörpern die Satellitenzellzahl bestimmt. PAX-7-Antikörper detektieren ein Satellitenzell-spezifisches Gen, welches in aktiviertem, wie auch in nicht-aktiviertem Zustand erkannt werden kann. Die detektierten Zellen waren unter E2- Gabe und Laufband-Training signifikant erhöht verglichen zur E2freien- und der nicht-trainierten Gruppe. Dies deutet auf einen Einfluss von Östrogenen auf den Muskelstoffwechsel hin, der sich unter körperlicher Aktivität verstärkt. Der genaue Mechanismus liegt jedoch im Dunkeln, diskutiert wird unter anderem, dass Östrogen indirekt über die Aktivierung von Makrophagen die Satellitenzellanzahl erhöhen kann (Tiidus et al. 2005).

In unserem Versuchsansatz wurde im Gegensatz zur Arbeit von Tiidus et al. die Wirkung von E2 nicht auf molekularer Ebene dargestellt, sondern anhand der Faszikeldicke der quer geschnittenen Muskulatur morphologisch gemessen.

Es findet in der E2-Gruppe ein Muskelfaserflächenverlust über acht Wochen statt, der signifikant ist zum Ausgangswert zwei Wochen nach Futterumstellung, wie auch zur Kontrollgruppe. Der gesamte Faszikelflächenverlust der nicht-vibrierten E2-Gruppe über den Zeitraum von acht Wochen war mit $305 \mu \mathrm{m}^{2}$ kleiner als der Verlust der Kontrollgruppe mit $365 \mu \mathrm{m}^{2}$. Beide, Kontrollgruppe wie auch nicht-vibrierte E2-Gruppe, zeigen acht Wochen nach Futterumstellung eine signifikante Reduktion der Muskelfaserfläche. Ebenso signifikant ist der Muskelfaserflächenverlust der vibrierten E2-Tiere acht Wochen nach Futterumstellung. Zwischen der vibrierten und der nichtvibrierten E2-Gruppe lässt sich nach acht Wochen kaum ein Unterschied messen. Die Muskelfaserfläche der vibrierten Tiere ist um $47 \mu \mathrm{m}^{2}$ nicht signifikant größer gemessen worden, als die Muskelfaserfläche der nicht-vibrierten.

Die Genistein-Tiere, wie auch die Equol-Gruppe, haben konstant an Faszikelfläche verloren: zu Beginn der Futterumstellung, in der zweiten und dritten Woche leicht mehr als die sojafreie Kontrollgruppe; in der achten Woche flacht die Abnahme leicht ab und die Faszikelfläche ist etwas größer als die der Kontrollgruppe. Die verminderte Abnahme 
der Faszikelfläche könnte auf die partielle ER $\alpha$-Wirkung zurückzuführen sein, die proliferativ und stimulierend auf die Muskulatur wirkt (Dieli-Conwright et al. 2009). Der Muskelmassenverlust konnte aber durch die Gabe von Östrogenen und Phytoöstrogenen nicht verhindert werden. Der Verlust der E2-Tiere ist jedoch größer, als der der Phytoöstrogen-Gruppen. Dieses Ergebnis war nicht zu erwarten, denn die Affinität von E2 an den Östrogenrezeptoren ER $\alpha$ und ER $\beta$ ist gleich, ebenso wie die Expression beider Östrogenrezeptoren in der Skelettmuskulatur gleich ist (Wiik et al. 2009). Im Gegensatz dazu binden Phytoöstrogene überwiegend an ER $\beta$ und üben nur eine eingeschränkte Gewebeprolifertion über die Aktivierung von ER $\alpha$ aus. Eine Erklärung hierfür könnte in der Dosierung der substituierten Substanzen liegen. Die Tiere bekamen durchschnittlich 20,7 mg Genistein und 8,2 mg Equol pro Tag. Im Gegenzug dazu wurde eine 48-fach geringere durchschnittliche Dosis an E2, nämlich 0,17 mg pro Tag, den Tieren verfüttert, sodass die zu erwartende Wirkung, nämlich eine verminderte Reduktion der Muskelmasse durch eine zu geringe Dosierung, ausgeblieben sein könnte. Die Affinität von Genistein an ERa ist zwar geringer als die von E2, dennoch könnte es durch die erhöhte Dosierung zu einer verminderten Abnahme der Muskulatur gekommen sein (Kuiper et al. 1998).

Sarkopenie ist ein altersabhängiger Muskelverlust (Evans 2010), verursacht durch eine Protein-Dysbalance, wobei weniger Proteine synthetisiert als abgebaut werden. Dies führt $\mathrm{zu}$ einem Verlust an Muskelmasse und -kraft was wiederum mit einer erhöhten Mortalität verbunden ist (Newman et al. 2006). Darüber hinaus kommt es zu einer eingeschränkten Mobilität und Funktion der Muskeln wie auch zu einer deutlich erhöhten Muskelermüdung.

Der Abbau der Skelettmuskulatur beginnt recht früh; zwischen dem 20. und 80. Lebensjahr werden $40 \%$ der Muskeln abgebaut, mit einer deutlichen Steigerung nach dem 60. Lebensjahr (Adamo und Farrar 2006).

Neben dem Abbau der Muskulatur findet auch ein Umbau dieser statt. Das Verhältnis von schnellen Muskelfasern (Typ II) zu langsamen Muskelfasern (Typ I) verlagert sich zugunsten der langsamen Muskelfasern (Lang et al. 2009). Diese sind hauptsächlich für Haltefunktionen zuständig. Die schnellen Muskelfasern degenerieren durch den hormonellen Mangel oder werden überwiegend in die langsamen Typ-I-Fasern umgewandelt. Ebenso finden neurodegenerative Abbau- und Umbauprozesse statt. Hierbei verringert sich die Anzahl der $\alpha$-Motoneurone, sodass bestehende Motoneurone 
eine größere Anzahl an Muskelfasern mitinnervieren müssen (Silbernagel und Klinke 2003). Durch die Abnahme der Feinmotorik vergröbert sich das allgemeine Bewegungsmuster (Adamo und Farrar 2006; Jones et al. 2009; Lang et al. 2009; Silbernagel und Klinke 2003). Durch die Degeneration der schnellen Muskelfasern und der Vergröberung des Bewegungsmusters durch $\mathrm{Ab}$ - und Umbau der Motoneurone entstehen Probleme, wie beispielsweise beim Treppensteigen oder Aufstehen von einem Stuhl.

Die Ätiologie der Sarkopenie ist multifaktoriell und komplex. Neben der hormonellen Dysbalance sind eine Proteinmangelernährung und Faktoren wie chronische Entzündungen und Insulin-Resistenz für die Entstehung einer Sarkopenie mitverantwortlich (Evans 2010). Ein wichtiger Aspekt ist auch die körperliche Aktivität, die sich im Alter zunehmend reduziert. Durch die mangelnde Aktivität verändert sich die Körperbeschaffenheit; die Muskulatur wird abgebaut, während Fett aufgebaut wird (Evans 2010). Entsprechend hat regelmäßiges Muskeltraining einen positiven Effekt auf die Muskelstärke, die Schnelligkeit und letztlich auch die Muskelmasse (Frontera et al. 1988). Neben diesen Resultaten verbessert sich durch den gesteigerten Fitnessgrad auch das Körpergefühl, die Körperbalance und die Gefahr von Stürzen wird vermindert. Das regelmäßige körperliche Training ist allerdings häufig mit einer geringen Compliance verbunden (Russo et al. 2003; Verschueren et al. 2004). Eine alternative Möglichkeit, Bewegung effektiv und attraktiv zu gestalten, ist die Ganzkörper-Vibrationstherapie. Hierbei stellt sich der Patient in statischer Position auf eine Platte, die vibriert. Die Frequenz und die Amplitude der Vibration kann variabel eingestellt werden und ermöglicht so ein individuelles Training (Rauch 2009). Die Vibrationstherapie wurde von den Probanden gut vertragen (Cardinale et al. 2008; Russo et al. 2003) und verbessert langfristig die Körperbalance, reduziert das Körperfett und steigert die Muskelkraft sowie die Knochendichte (Cochrane et al. 2008; Maddalozzo et al. 2008; Rauch 2009; Verschueren et al. 2004).

Da Sarkopenie und Osteoporose nicht selten gemeinsam vorkommen, hat regelmäßiges Training auch auf die Knochendichte, hauptsächlich von Wirbelkörpern und Hüfte, eine positive Wirkung (Lang et al. 2009).

Gegen Ende des Versuchs wurden die Tiere in zwei Gruppen unterteilt, in denen sich alle substituierten Futtergruppen und die Kontrollgruppe wiederfanden. Die eine Gruppe wurde für 10 Tage vibriert, die andere nicht. In der vibrierten Kontrollgruppe konnte im 
Vergleich zur nicht-vibrierten Kontrollgruppe eine Zunahme der Muskelfaszikelfläche um 8,6 \% festgestellt werden. Damit haben wir den positiven Effekt der Vibrationstherapie auf die Muskulatur nachgewiesen. Innerhalb der substituierten Gruppen ließ sich allerdings keine signifikante Änderung der Faszikelfläche feststellen. Die Kombination von anabolen Steroiden und körperlichem Training für den Aufbau von Muskelmasse wurde in anderen Studien nachgewiesen (Brower 2009). Der Grund dieser fehlenden Änderung in der DHT-Gruppe in der vorliegenden Arbeit kann daran liegen, dass die Dauer der Vibrationstherapie zu kurz war, um einen messbaren Effekt auf die Muskelmasse aufzuzeigen. Es kann dennoch zu einer Auswirkung der Vibrationstherapie gekommen sein, die jedoch mit der von uns verwendeten morphologischen Faszikelmessung nicht nachweisbar ist. Cardinale et al. konnten nach einer Vibrationstherapie-Einheit auf hormonaler Ebene eine kurzfristige Veränderung messen, die einen proliferativen Einfluss auf das Wachstum der Muskulatur hat (Cardinale et al. 2008). Der langfristige Effekt der Vibrationstherapie ist hauptsächlich die Stärkung der Muskelkraft, die in unserer morphologischen Muskelfaszikelmessung allerdings nicht ermittelt wurde.

Das Hauptanliegen unserer Arbeit war es, die proliferative Wirkung der Sexualhormone DHT und E2 sowie die der Phytoöstrogene Genistein und Equol auf die Muskulatur und die Prostata zu untersuchen. Die festgestellte proliferative Wirkung von DHT auf die Muskulatur geht mit einer massiven Zunahme des Prostatavolumens einher, dies haben wir in unserer Arbeit bestätigen können.

Die Prostata-protektiven Phytoöstrogene haben dagegen kaum einen Effekt auf die Muskulatur. In der Literatur ist die Auswirkung von Phytoöstrogenen auf die Skelettmuskulatur kaum beschrieben. In einem Versuch an Ferkeln untersuchten Mau et al. die Wirkung von Genistein und Daidzein, dem Vorläufer von Equol, in vitro an Satellitenzellen und konnten feststellen, dass die beiden Isoflavone eine Wirkung auf die Muskulatur haben (Mau et al. 2008). In supraphysiologischen Dosen übermittelten Isoflavone einen toxischen und einen Wachstums-hemmenden Effekt, in physiologischen Dosen dagegen konnte eine verringerte Proteinabbaurate beobachtet werden. Die Ergebnisse dieser Studie sind schwer mit unseren Ergebnissen zu vergleichen, da die gewählten Methoden sehr unterschiedlich sind.

E2 hat auf molekularer und hormoneller Ebene einen proliferativen Effekt auf die Muskulatur (Dieli-Conwright et al. 2009; Enns et al. 2008; Tiidus et al. 2005; Wiik et al. 
2005); in der Prostata ist die Gefahr der Entzündung und das Risiko für die Entstehung eines Karzinoms dagegen erhöht (Bonkhoff et al. 1999; Prins et al. 2001). Auf morphologischer Ebene konnte keine signifikante Veränderung der Muskelmasse, wie auch der Epitheliumdicke der Prostata in unserem Versuch festgestellt werden.

Die Bedeutung der Bewegung für die Muskulatur bzw. die Sarkopenie ist bewiesen (Cardinale et al. 2008; Cochrane et al. 2008; Maddalozzo et al. 2008; Russo et al. 2003). In unserer Arbeit war die morphologische Messung der Muskelmasse nicht die richtige Methode, um den kurzfristigen Effekt der Vibrationstherapie auf die Muskulatur aufzuzeigen. Die Messung der Muskelstärke durch, z.B. die zusätzliche Messung der Greifstärke, wäre sicherlich aussagekräftiger gewesen.

Die Bedeutung der Sarkopenie in einer immer älter werdenden Gesellschaft nimmt weiterhin zu und so sind weitere langfristige Studien über die Wirksamkeit und die Sicherheit von Sexualhormonen und Phytoöstrogenen als mögliche Therapeutika wichtig und erforderlich. Interessant ist hierbei die Entwicklung von SARMs. Analog zu den SERMs könnten sie in Zukunft eine selektive Androgenwirkung hervorrufen und die Vorteile, wie beispielsweise die anabole Wirkung auf die Muskulatur, ausschöpfen ohne die negativen Nebenwirkungen, wie eine massive Prostatavergrößerung, auftreten zu lassen.

Kürzlich veröffentlichte Studien konnten zeigen, dass das Prinzip der selektiven Androgenrezeptor-Modulatoren an Ratten möglich ist und die gewünschten Ergebnisse bringen kann (Gao et al. 2005; Mohler et al. 2009).

Derzeit befindet sich die Entwicklung der SARMs noch in der Überprüfung des Therapiekonzeptes. Die präklinischen Daten sind vielversprechend, müssen aber noch in weiteren klinischen Studien überprüft werden (Bhasin und Jasuja 2009; Mohler et al. 2009). 


\section{Zusammenfassung}

In einer immer älter werdenden Gesellschaft werden sich auch die Anzahl alterbedingter Krankheiten und deren Folgen erheblich erhöhen. Durch den schleichenden Abfall von T beim Mann kann es zu einem Androgenmangel und mit begleitenden Symptomen zu einem „late-onset hypogonadism“ (LOH) kommen (Hochreiter et al. 2005; Zitzmann 2008). Dieser zeichnet sich durch verschiedene, individuell unterschiedlich ausgeprägte Symptome aus. So kann es unter anderem zu einer veränderten Körperbeschaffenheit mit Abnahme von Muskelmasse (Sarkopenie) und Osteoporose, sowie benignen und malignen Veränderungen der Prostata kommen (Hochreiter et al. 2005).

Die Sarkopenie ist ein altersabhängiger Muskelverlust, der durch einen vermehrten Abbau von Proteinen verursacht wird (Evans 2010) und nicht nur mit einem Muskelsubstanzverlust einhergeht, sondern auch den Verlust von Muskelkraft beinhaltet (Newman et al. 2006). Daneben findet auch ein Umbau der Muskulatur statt. Das Verhältnis von langsamen Muskelfasern (Typ I) zu schnellen Muskelfasern (Typ II) verlagert sich zugunsten der langsamen, die hauptsächlich für Haltefunktionen zuständig sind. Darüberhinaus vergröbert sich das Bewegungsmuster zusätzlich durch neurodegenerative Abbau- und Umbauprozesse (Lang et al. 2009). Die Ätiologie der Sarkopenie ist multifaktoriell und komplex. Ein wichtiger Aspekt in der Prävention und Therapie dieser ist körperliches Training. Ist dies nicht ausreichend zur Therapie, so können zusätzliche therapeutische Maßnahmen wie eine Hormonersatztherapie eingeleitet werden. Anabol wirkende Hormone wie T und DHT können den Muskelsubstanzverlust verhindern, aber gleichzeitig, da sie ubiquitär wirken, schwere Nebenwirkungen haben. Hormonsensible Organe wie die Prostata können durch eine Hormonersatztherapie hypertrophieren oder entzündliche Reaktionen zeigen, bis hin zur Ausbildung eines Karzinoms.

Anhand eines Tiermodells an orchidektomierten Ratten wurden die Sexualhormone DHT und E2, sowie die Phytoöstrogene Genistein und Equol in ihre Wirkung auf die Skelettmuskulatur und die Prostata untersucht. Die Muskelfaszikel, ebenso wie die Epitheliumdicke der Prostata wurden histologisch-morphologisch ausgewertet. Die Auswirkung der Bewegungstherapie auf die Muskulatur wurde bei einem Teil der Tiere durch eine Ganzkörper-Vibrationsplatte realisiert.

Die Ergebnisse besagen, dass unter Zugabe von DHT die Muskulatur proliferiert, aber ebenso die Größe der Prostata erheblich zunimmt. Auf morphologischer Ebene hat E2 
keinen Einfluss auf die Muskelmasse sowie die Epitheliumdicke der Prostata, auf molekularer Ebene konnten andere Studien aber einen proliferativen Effekt auf die Muskulatur feststellen (Dieli-Conwright et al. 2009). Auch in der Gruppe der Prostataprotektiven Phytoöstrogene konnte auf morphologischer Ebene kaum ein Effekt auf die Muskulatur nachgewiesen werden. Die Bedeutung der Bewegung für die Muskulatur ist in vielen Studien nachgewiesen (Cardinale et al. 2008; Cochrane et al. 2008; Maddalozzo et al. 2008). Die Muskelmasse änderte sich in unserem Versuch nicht, was jedoch an der Methodik gelegen haben könnte, da die Muskelkraft nicht erfasst wurde.

Zusammenfassend lässt sich sagen, dass Sexualhormone einen proliferativen Einfluss auf den Stoffwechsel der Muskulatur haben, allerdings besteht auch ein hohes Risiko für Nebenwirkungen, da die Hormone ubiquitär im Körper vorkommen und in vielen verschiedenen Organsystemen wirken. Die Entscheidung für eine Hormonersatztherapie zur Behandlung einer Sarkopenie sollte daher in Hinblick auf mögliche Nebenwirkungen genau abgewogen werden. Weitere langfristige Studien über die Sicherheit und Dosierung der Hormonersatztherapie sind hierzu sicherlich nötig. Eine interessante Entwicklung auf diesem Gebiet ist, analog zu den SERMs, die Entdeckung der SARMs. Durch sie kann die anabole Wirkung der Androgene selektiv ausgeschöpft werden, ohne dass Nebenwirkungen wie beispielsweise eine Hypertrophie der Prostata auftreten. Dieses vielversprechende Therapiekonzept befindet sich gerade noch in der präklinischen Phase und wird in weiteren Studien überprüft. 


\section{Anhang}

\subsection{Histologische Abbildungen}

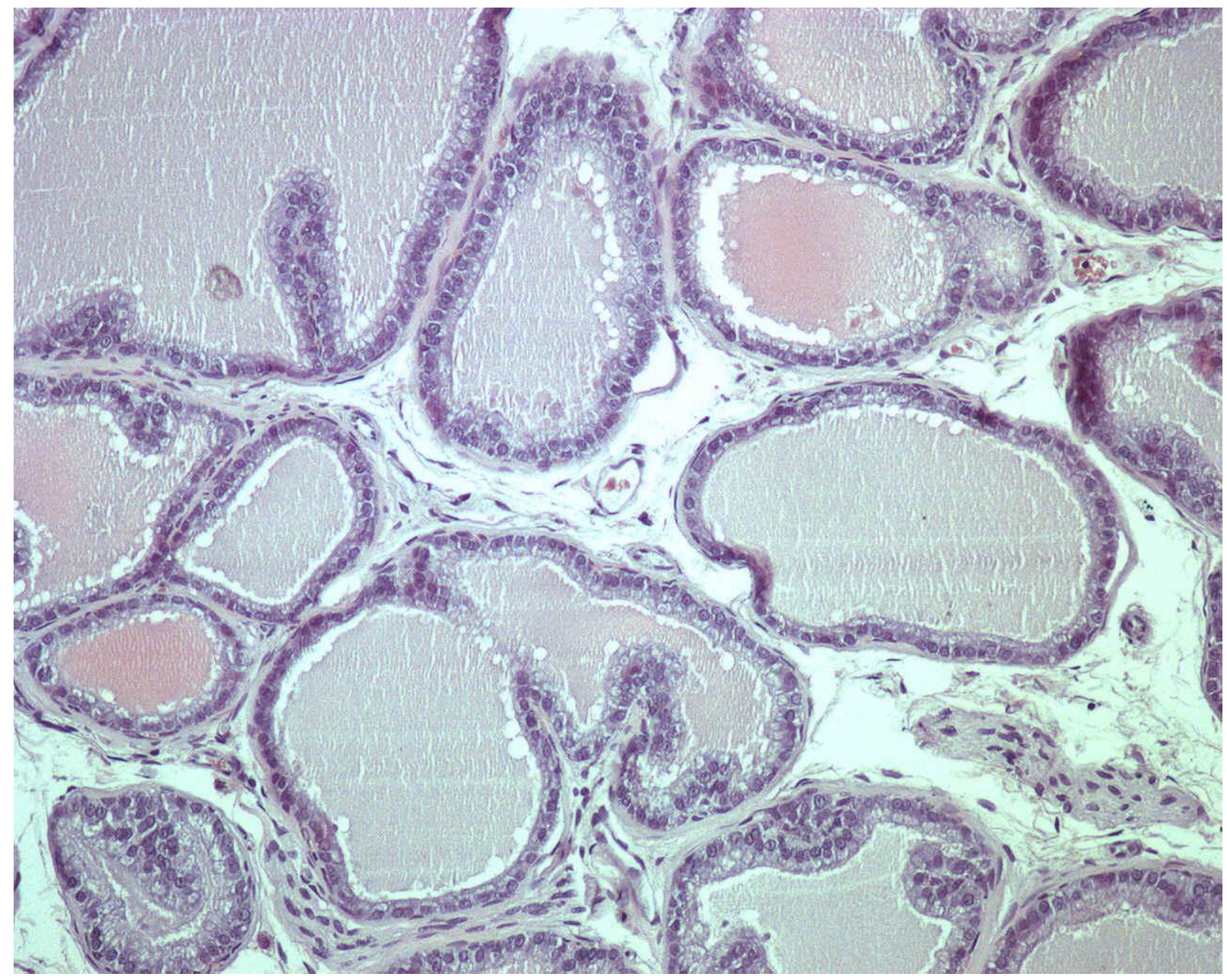

Abb. 25: Prostata, 12,5x Vergrößerung, DHT-substituiert, in Präparatmitte gemessen 


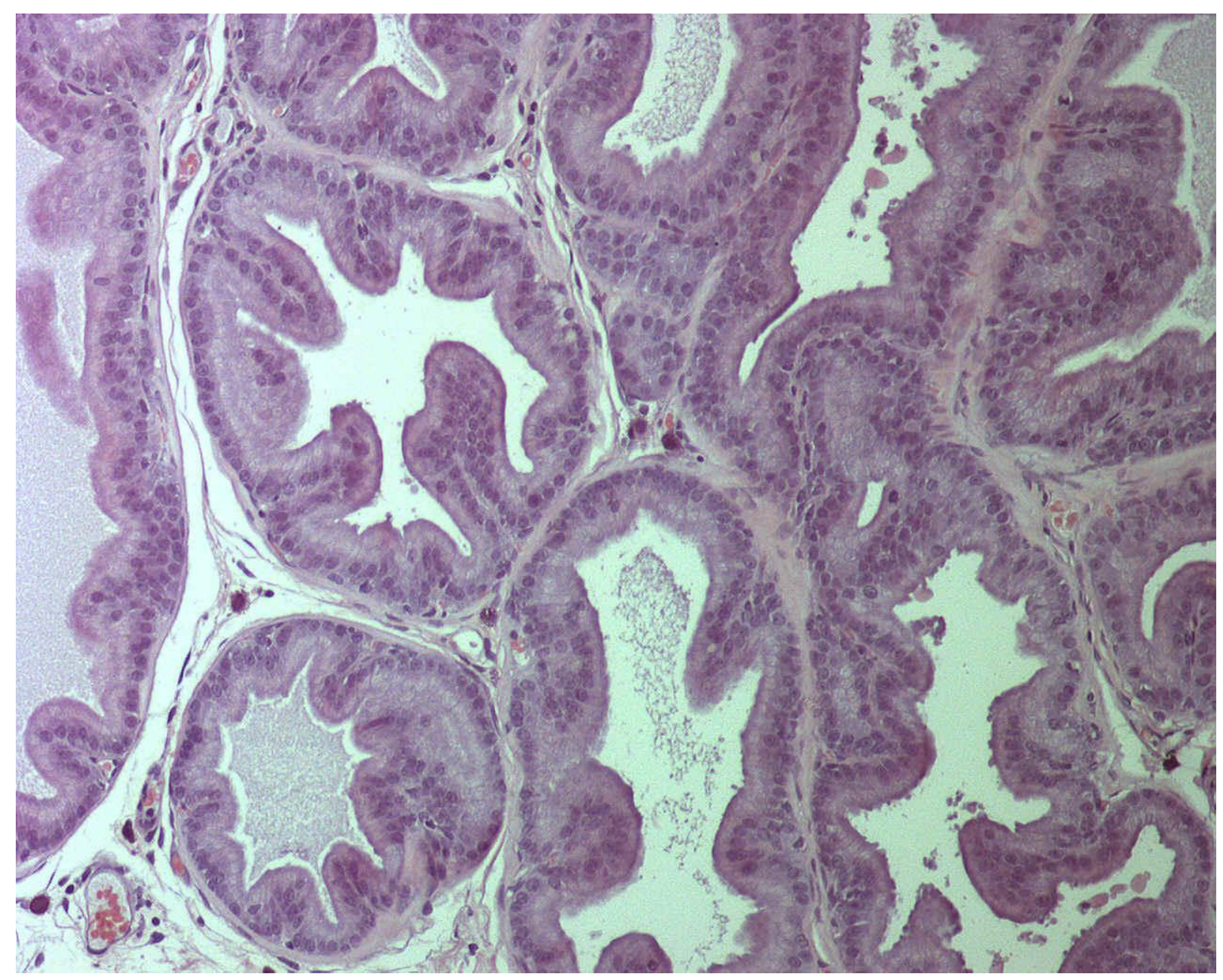

Abb. 26: Prostata, 12,5x Vergrößerung, dasselbe Präparat wie in Abb. 25, am äußeren Rand des Präparates gemessen 


\subsection{Standardprotokoll der Hämatoxylin- und Eosinfärbung}

1. Xylol

2. Xylol

3. Xylol

4. $100 \%$ Alkohol (ETOH)

5. $100 \% \mathrm{ETOH}$

6. $100 \% \mathrm{ETOH}$

7. $96 \% \mathrm{ETOH}$

$8.96 \% \mathrm{ETOH}$

9. $75 \% \mathrm{ETOH}$

10. Aqua bidest.

11. Hämatoxylin

12. Wässern unter lauwarmen, fließenden Wasser

13. Aqua bidest.

14. Eosin

15. $75 \% \mathrm{ETOH}$

16. $96 \% \mathrm{ETOH}$

17. $96 \% \mathrm{ETOH}$

18. $100 \% \mathrm{ETOH}$

19. $100 \% \mathrm{ETOH}$

20. $100 \% \mathrm{ETOH}$

21. Xylol

22. Xylol

23. Xylol

24. Eindecken der Schnitte mit DePex.
10 Minuten

10 Minuten

10 Minuten

2 Minuten

2 Minuten

2 Minuten

2 Minuten

2 Minuten

2 Minuten

2 Minuten

zwischen 30 -50Sekunden, je

nach Färbeintensität und Alter der Lösung

10 Minuten

$15 \mathrm{x}$ eintauchen

zwischen 1,5 und 2 Minuten, je

nach Färbeintensität und Alter der Lösung

30 Sekunden

30 Sekunden

30 Sekunden

1 Minute

1 Minute

1 Minute

5 Minuten

5 Minuten

5 Minuten 


\subsection{Lösungen}

Hämatoxylin von Mayers Hämalaunlösung für die Mikroskopie, Merck KgaA

Verdünnung 1:2 mit Aqua bidest

Eosin Eosin G, Merck KGgA

-Herstellung der Stocklösung von 1\% Eosin (1 $\mathrm{g} / 100 \mathrm{ml}$ 80\% ETOH):

$1 \mathrm{~g}$ Eosin

$80 \mathrm{ml} \mathrm{96 \%} \mathrm{ETOH}$

$20 \mathrm{ml}$ Aqua bidest

-Herstellung der Arbeitslösung:

Verdünnung mit Aqua bidest auf 1:5 oder 1:6

Xylol jtbaker, Mallinckrodt Baker, Griesheim, Bestell-Nr.: 8118

Alkohole $\quad 75 \%$ ETOH vergällt und abgefüllt durch das UKG

96\% ETOH vergällt und abgefüllt durch das UKG

$100 \%$ ETOH vergällt und abgefüllt durch das UKG

Aqua bidest abgefüllt durch das UKG

DePex SERVA Electrophoresis $\mathrm{GmbH}$, Heidelberg 


\subsection{Gebrauchsgüter}

\begin{tabular}{|c|c|}
\hline & $\begin{array}{l}\text { Leica TP 1020, Leica Mikrosysteme Vertrieb GmbH, } \\
\text { Wetzlar }\end{array}$ \\
\hline \multirow{2}{*}{ Einbettautomat } & $\begin{array}{l}\text { Wetzlar } \\
\text { Leica EG } 1140 \text { H, Leica Mikrosysteme }\end{array}$ \\
\hline & Vertrieb GmbH, Wetzlar \\
\hline \multirow[t]{2}{*}{ Objektträger } & SuperFrost $\AA^{8}$ Plus 26x76x1mm, Fa. Menzel-Gläser \\
\hline & GmbH \& Co KG, Braunschweig, Bestell-Nr.: J1800AMNZ \\
\hline Rotationsmikrotom & $\begin{array}{l}\text { RM 2135, Fa. Leica Mikrosysteme Vertrieb GmbH, } \\
\text { Wetzlar }\end{array}$ \\
\hline Mikrotomklingen & $\begin{array}{l}\text { Mikrotomeinwegklingen Feather, Safety Razor Co.Ltd. } \\
\text { Osaka, Japan Typ S } 35 \text { "High Profile" bezogen über pfm- } \\
\text { Produkte für die } \\
\text { Medizin AG, Köln, Bestell-Nr.: 2.075.00.010 }\end{array}$ \\
\hline Paraffinstreckbad & $\begin{array}{l}\text { Paraffinstreckbad } 400 \text { Watt, MEDAX GmbH \& Co KG, } \\
\text { Rendsburg, Bestell-Nr.: } 25900\end{array}$ \\
\hline Trockenschrank & Heraeus Holding GmbH, Hanau \\
\hline Färbetröge & $\begin{array}{l}\text { Typ Hellendah 57x57x90mm, bezogen über Schütt } \\
\text { Labortechnik, Göttingen, Bestell-Nr.: } 9.161350 \\
\text { Färbetrog 80x100x70mm, bezogen über Schütt Labortechnik, } \\
\text { Göttingen, Bestell-Nr.: } 9.161340\end{array}$ \\
\hline Deckgläser & $\begin{array}{l}\text { Fa. Menzel-Gläser GmbH \& Co KG, Braunschweig } \\
\text { Deckgläser 24x40mm, Bestell-Nr.: BB024040A1 }\end{array}$ \\
\hline Lichtmikroskop & $\begin{array}{l}\text { Zeiss Axiophot@ Fotomikroskop, Fa. Zeiss, Carl Zeiss AG, } \\
\text { Oberkochen }\end{array}$ \\
\hline Kamera & $\begin{array}{l}\text { ColorView, Soft Imaging System, Olympus Soft Imaging } \\
\text { Solutions GmbH, Münster }\end{array}$ \\
\hline $\begin{array}{l}\text { Digitale Bildanalyse } \\
\text { und digitale }\end{array}$ & $\begin{array}{l}\text { analySIS®, Soft Imaging System, Olympus Soft Imaging } \\
\text { Solutions, Münster }\end{array}$ \\
\hline \multicolumn{2}{|l|}{ Bildmanagement- } \\
\hline \multicolumn{2}{|l|}{ Software } \\
\hline Software & $\begin{array}{l}\text { GraphPad Prism } 4 \AA \text { Software, Fa. GraphPad Software, } \\
\text { Inc. San Diego, USA }\end{array}$ \\
\hline trukturformel Softwa & Advanced Chemistry Development Software, \\
\hline
\end{tabular}




\subsection{Verzeichnis der Abbildungen und Tabellen}

\subsubsection{Abbildungen}

Abb.1: Strukturformeln von Testosteron und Östradiol

Auswertung durch Umfahrung der einzelnen Muskelfaszikel

Abb.5: Prostata, HE-Färbung,12,5fach, Messung der Breite des Epithels der verschiedenen Ductuli

Abb.6: Der Effekt von DHT, E2, Genistein und Equol zwei Wochen nach Futterumstellung auf die Muskelfaserfläche des M. gastrocnemius

Abb.7: Der Effekt von DHT, E2, Genistein und Equol drei Wochen nach Futterumstellung auf die Muskelfaserfläche des M. gastrocnemius

Abb. 8: Der Effekt von DHT, E2, Genistein und Equol nach 8 Wochen 
Abb.11: Der Verlauf der Größe der Muskelfaserfläche des M. gastrocnemius der sojafreien Kontrollgruppe über einen Zeitraum von 8 Wochen

Abb.12: Der Verlauf der Größe der Muskelfaserfläche des M. gastrocnemius der Genistein-Gruppe über einen Zeitraum von 8 Wochen

Abb. 13: Der Verlauf der Größe der Muskelfaserfläche des M. gastrocnemius der Equol-Gruppe über einen Zeitraum von 8 Wochen

Abb. 14: Der Verlauf der Größe der Muskelfaserfläche des M. gastrocnemius der E2-Gruppe über einen Zeitraum von 8 Wochen

Abb. 15: Der Verlauf der Größe der Muskelfaserfläche des M. gastrocnemius der DHT-Gruppe über einen Zeitraum von 8 Wochen

Abb.16: Der Effekt von DHT, E2, Genistein, und Equol nach zwei Wochen Futterumstellung auf die Epitheliumdicke der Prostata

Abb. 17: Der Effekt von DHT, E2, Genistein, und Equol nach drei Wochen Futterumstellung auf die Epitheliumdicke der Prostata

Abb. 18: Der Effekt von DHT, E2, Genistein und Equol nach acht Wochen 38 Futterumstellung auf die Epitheliumdicke der Prostata, in Schnittmitte gemessen

Abb.19: Der Effekt von DHT, E2, Genistein und Equol nach acht Wochen Futterumstellung auf die Epitheliumdicke der Prostata, am Schnittrand gemessen

Abb. 20: Verlauf der Epitheliumdicke der Prostata der sojafreien Kontrollgruppe 40 über den Zeitraum von acht Wochen

Abb. 21: Verlauf der Epitheliumdicke der Prostata der Genistein-Gruppe über den Zeitraum von acht Wochen 
Abb. 22: Verlauf der Epitheliumdicke der Prostata der Equol-Gruppe über den Zeitraum von acht Wochen

Abb. 23: Verlauf der Epitheliumdicke der Prostata der E2-Gruppe über den Zeitraum von acht Wochen

Abb. 24: Verlauf der Epitheliumdicke der Prostata der DHT-Gruppe über den Zeitraum von acht Wochen

Abb. 25: Prostata, 12,5x Vergrößerung, DHT-substituiert, 55 in Präparatmitte gemessen

Abb. 26: Prostata, 12,5 x Vergrößerung, dasselbe Präparat wie in Abb. 25, am äußeren Rand des Präparates gemessen

\subsubsection{Tabellen}

Tab.1: Wirkung von Östrogenen und Androgenen beim Mann

Tab.2: Futteraufnahme der Ratten

Tab.3: Gesamtübersicht der geschnittenen und ausgewerteten Tiere für je Muskel und Prostata 


\section{Literatur}

Adamo ML Farrar RP (2006): "Resistance training, and IGF involvement in the maintenance of muscle mass during the aging process." Ageing Res Rev $\underline{5}(3)$ : $310-331$.

An J, Tzagarakis-Foster C, Scharschmidt TC, Lomri N Leitman DC (2001): "Estrogen receptor beta-selective transcriptional activity and recruitment of coregulators by phytoestrogens." J Biol Chem 276(21): 17808-17814.

Antonio J, Wilson JD \& George FW (1999): "Effects of castration and androgen treatment on androgen-receptor levels in rat skeletal muscles." J Appl Physiol $\underline{87}$ 2016-2019.

Bartl R (2008): "[Treatment of osteoporosis according to the "European Guidance 2008". Fracture-oriented--economical--cost-effective]." Internist (Berl) $\underline{49}(9)$ : 11261136.

Bhasin S Jasuja R (2009): "Selective androgen receptor modulators as function promoting therapies." Curr Opin Clin Nutr Metab Care 12(3): 232-240.

Bhasin S, Woodhouse L Storer TW (2001): "Proof of the effect of testosterone on skeletal muscle." J Endocrinol 170(1): 27-38.

Bonkhoff H, Fixemer T, Hunsicker I Remberger K (1999): "Estrogen receptor expression in prostate cancer and premalignant prostatic lesions." Am J Pathol 155(2): 641647.

Borst SE, Conover CF, Carter CS, Gregory CM, Marzetti E, Leeuwenburgh C, Vandenborne K Wronski TJ (2007): "Anabolic effects of testosterone are preserved during inhibition of 5alpha-reductase." Am J Physiol Endocrinol Metab 293(2): E507-514.

Brossner C, Petritsch K, Fink K, Auprich M, Madersbacher S, Adlercreutz H, Rehak P Petritsch P (2004): "Phytoestrogen tissue levels in benign prostatic hyperplasia and prostate cancer and their association with prostatic diseases." Urology 64(4): 707-711.

Brower KJ (2009): "Anabolic steroid abuse and dependence in clinical practice." Phys Sportsmed 37(4): 131-140.

Cardinale M, Soiza RL, Leiper JB, Gibson A Primrose WR (2008): "Hormonal responses to a single session of whole body vibration exercise in elderly individuals." $\mathrm{Br} \mathrm{J}$ Sports Med 44(4):284-8

Carlson S, Peng N, Prasain JK Wyss JM (2008): "Effects of botanical dietary supplements on cardiovascular, cognitive, and metabolic function in males and females." Gend Med 5 Suppl A: S76-90. 
Chen Y, Zajac JD, MacLean HE (2005): "Androgen regulation of satellite cell function" J Endocrinol 186, 21-31

Clarke BL Khosla S (2009): "New selective estrogen and androgen receptor modulators." Curr Opin Rheumatol 21(4): 374-379.

Cochrane DJ, Stannard SR, Sargeant AJ Rittweger J (2008): "The rate of muscle temperature increase during acute whole-body vibration exercise." Eur J Appl Physiol 103(4): 441-448.

Dieli-Conwright CM, Spektor TM, Rice JC Todd Schroeder E (2009): "Oestradiol and SERM treatments influence oestrogen receptor coregulator gene expression in human skeletal muscle cells." Acta Physiol (Oxf) 197(3): 187-196.

Diemer T, Hauck EW, Rohde V Weidner W (2005): "[Therapy of the "aging male"]." Urologe A $\underline{44}(10):$ 1173-1178.

Dixon RA (2004): "Phytoestrogens." Annu Rev Plant Biol 55: 225-261.

Drewa T Chlosta P (2010): "Testosterone supplementation and prostate cancer, controversies still exist." Acta Pol Pharm 67(5): 543-546.

Ellem SJ, Risbridger GP.(2006): "Aromatase and prostate cancer." Minerva Endocrinol $\underline{31}(1): 1-12$.

Ellem SJ Risbridger GP (2009a): "Aromatase and regulating the estrogen:androgen ratio in the prostate gland." J Steroid Biochem Mol Biol 118(4-5):246-51

Ellem SJ Risbridger GP (2009b): "The dual, opposing roles of estrogen in the prostate." Ann N Y Acad Sci 1155: 174-186.

Enns DL, Iqbal S Tiidus PM (2008): "Oestrogen receptors mediate oestrogen-induced increases in post-exercise rat skeletal muscle satellite cells." Acta Physiol (Oxf) 194(1): 81-93.

Evans WJ (2010) "Skeletal muscle loss: cachexia, sarcopenia, and inactivity." Am J Clin Nutr $\underline{91} 1123 \mathrm{~S}-1127 \mathrm{~S}$

Falkenstein E, Tillmann HC, Christ M, Feuring M Wehling M (2000): "Multiple actions of steroid hormones--a focus on rapid, nongenomic effects." Pharmacol Rev 52(4): 513-556.

Fallon JB, Macefield VG (2007): "Vibration sensitivity of human muscle spindles and Golgi tendon organs." Muscle Nerve 36(1):21-9.

Flieger J, Karachalios T, Khaldi L, Raptou P, Lyritis G (1998): "Mechanical stimulation in the form of vibration prevents postmenopausal bone loss in ovariectomized rats" Calcif Tissue Int $\underline{63: 510-4}$ 
Frontera WR, Meredith CN, O'Reilly KP, Knuttgen HG Evans WJ (1988): "Strength conditioning in older men: skeletal muscle hypertrophy and improved function." J Appl Physiol 64(3): 1038-1044.

Gao W, Reiser PJ, Coss CC, Phelps MA, Kearbey JD, Miller DD Dalton JT (2005): "Selective androgen receptor modulator treatment improves muscle strength and body composition and prevents bone loss in orchidectomized rats." Endocrinology 146(11): 4887-4897.

Glenmark B, Nilsson M, Gao H, Gustafsson JA, Dahlman-Wright K Westerblad H (2004): "Difference in skeletal muscle function in males vs. females: role of estrogen receptor-beta." Am J Physiol Endocrinol Metab 287(6): E1125-1131.

Hedlund TE, Johannes WU Miller GJ (2003): "Soy isoflavonoid equol modulates the growth of benign and malignant prostatic epithelial cells in vitro." Prostate 54(1): 68-78.

Heinlein CA Chang C (2002): "Androgen receptor (AR) coregulators: an overview." Endocr Rev 23(2): 175-200.

Herbst KL Bhasin S (2004): "Testosterone action on skeletal muscle." Curr Opin Clin Nutr Metab Care 7(3): 271-277.

Hochreiter WW, Ackermann DK Brutsch HP (2005): "[Andropause]." Ther Umsch 62(12): 821-826.

Hoffman MA, DeWolf WC Morgentaler A (2000): "Is low serum free testosterone a marker for high grade prostate cancer?" J Urol 163(3): 824-827.

Holzbeierlein JM, McLaughlin MD Thrasher JB (2004): "Complications of androgen deprivation therapy for prostate cancer." Curr Opin Urol 14(3): 177-183.

Icks A, Haastert B, Wildner M, Becker C Meyer G (2008): "Trend of hip fracture incidence in Germany 1995-2004: a population-based study." Osteoporos Int 19(8): 1139-1145.

Jankovich JP. (1972): "The effects of mechanical vibration on bone development in the rat." J Biomech 5(3):241-50.

Jones TE, Stephenson KW, King JG, Knight KR, Marshall TL Scott WB (2009): "Sarcopenia--mechanisms and treatments." J Geriatr Phys Ther 32(2): 39-45.

Kanis JA, Oden A, Johnell O, De Laet C, Jonsson B Oglesby AK (2003): "The components of excess mortality after hip fracture." Bone 32(5): 468-473.

Kaushik MC, Misro MM, Sehgal N Nandan D (2010): "Effect of chronic oestrogen administration on androgen receptor expression in reproductive organs and pituitary of adult male rat." Andrologia 42(3): 193-205.

Kerr JF Searle J (1973): "Deletion of cells by apoptosis during castration-induced involution of the rat prostate." Virchows Arch B Cell Pathol 13(2): 87-102. 
Kim J (2008): "Protective effects of Asian dietary items on cancers - soy and ginseng." Asian Pac J Cancer Prev 9(4): 543-548.

Kuiper GG, Lemmen JG, Carlsson B, Corton JC, Safe SH, van der Saag PT, van der Burg B, Gustafsson JA. (1998):"Interaction of estrogenic chemicals and phytoestrogens with estrogen receptor beta." Endocrinology 139(10):4252-63.

Lampe JW, Karr SC, Hutchins AM Slavin JL (1998): "Urinary equol excretion with a soy challenge: influence of habitual diet." Proc Soc Exp Biol Med 217(3): 335-339.

Lang T, Streeper T, Cawthon P, Baldwin K, Taaffe DR Harris TB (2009): "Sarcopenia: etiology, clinical consequences, intervention, and assessment." Osteoporos Int 21 (4):543-59

Lau KM, LaSpina M, Long J Ho SM (2000): "Expression of estrogen receptor (ER)alpha and ER-beta in normal and malignant prostatic epithelial cells: regulation by methylation and involvement in growth regulation." Cancer Res $\underline{60}$ (12): 31753182 .

Leitlinien Arbeitsmedizin (2003): "Arbeit unter Einwirkung von mechanischen Schwingungen (Arbeitsbedingte Gesundheitsschäden durch mechanische Schwingungen)"

http://www.dgaum.de/index.php/publikationen/leitlinien/leitlinienarbeitsmedizin/ 86-mechanischeschwingungen

Lekas E, Johansson M, Widmark A, Bergh A Damber JE (1997): "Decrement of blood flow precedes the involution of the ventral prostate in the rat after castration." Urol Res 25(5): 309-314.

Lemoine S, Granier P, Tiffoche C, Rannou-Bekono F, Thieulant ML Delamarche P (2003): "Estrogen receptor alpha mRNA in human skeletal muscles." Med Sci Sports Exerc 35(3): 439-443.

Lenk VS (2005): "[Diagnosis of the "aging male"--what is recommended?]." Urologe A 44(10): 1167-1172.

Li X Rahman N (2009): "Estrogens and bladder outlet obstruction." J Steroid Biochem Mol Biol 118(4-5):257-63

Lund TD, Munson DJ, Haldy ME, Setchell KD, Lephart ED Handa RJ (2004): "Equol is a novel anti-androgen that inhibits prostate growth and hormone feedback." Biol Reprod 70(4): 1188-1195.

Maddalozzo GF, Iwaniec UT, Turner RT, Rosen CJ Widrick JJ (2008): "Whole-body vibration slows the acquisition of fat in mature female rats." Int $\mathrm{J}$ Obes (Lond) 32(9): 1348-1354.

Mau M, Kalbe C, Wollenhaupt K, Nürnberg G, Rehfeldt C. (2008): "IGF-I- and EGFdependent DNA synthesis of porcine myoblasts is influenced by the dietary isoflavones genistein and daidzein." Domest Anim Endocrinol 35(3):281-9 
Marks LS, Mazer NA, Mostaghel E, Hess DL, Dorey FJ, Epstein JI, Veltri RW, Makarov DV, Partin AW, Bostwick DG, et al. (2006): "Effect of testosterone replacement therapy on prostate tissue in men with late-onset hypogonadism: a randomized controlled trial." JAMA 296(19): 2351-2361.

Marks TA, Petrow V.(1983): "Effect of the preestrogen 4-androstene-3,17-dion-19-al on the Dunning R3327 prostatic adenocarcinoma." Cancer Res 43(8):3687-90.

Marrian GF Haslewood GA (1932): "Equol, a new inactive phenol isolated from the ketohydroxyoestrin fraction of mares' urine." Biochem J 26(4): 1227-1232.

Marts SA, Padilla GM, Petrow V. (1987):" Aromatase activity in microsomes from rat ventral prostate and Dunning R3327H rat prostatic adenocarcinoma." J Steroid Biochem 26(1):25-9.

McPherson SJ, Ellem SJ, Simpson ER, Patchev V, Fritzemeier KH Risbridger GP (2007): "Essential role for estrogen receptor beta in stromal-epithelial regulation of prostatic hyperplasia." Endocrinology 148(2): 566-574.

Michel G, Baulieu EE. (1976): "An approach to the anabolic action of androgens by an experimental system." Environ Qual Saf Suppl 1976(5):54-9.

Michel G, Baulieu EE. (1980): " Androgen receptor in rat skeletal muscle: characterization and physiological variations." Endocrinology 107(6):2088-98.

Mohler ML, Bohl CE, Jones A, Coss CC, Narayanan R, He Y, Hwang DJ, Dalton JT Miller DD (2009): "Nonsteroidal selective androgen receptor modulators (SARMs): dissociating the anabolic and androgenic activities of the androgen receptor for therapeutic benefit." J Med Chem 52(12): 3597-3617.

Morales A (2004): "Testosterone treatment for the aging man: the controversy." Curr Urol Rep 5(6): 472-477.

Morgentaler A (2009): "Rapidly shifting concepts regarding androgens and prostate cancer." ScientificWorldJournal 9: 685-690.

Muthyala RS, Ju YH, Sheng S, Williams LD, Doerge DR, Katzenellenbogen BS, Helferich WG Katzenellenbogen JA (2004): "Equol, a natural estrogenic metabolite from soy isoflavones: convenient preparation and resolution of R- and S-equols and their differing binding and biological activity through estrogen receptors alpha and beta." Bioorg Med Chem 12(6): 1559-1567.

Negro-Vilar A (1999): "Selective androgen receptor modulators (SARMs): a novel approach to androgen therapy for the new millennium." J Clin Endocrinol Metab 84(10): 3459-3462.

Newman AB, Kupelian V, Visser M, Simonsick EM, Goodpaster BH, Kritchevsky SB, Tylavsky FA, Rubin SM Harris TB (2006): "Strength, but not muscle mass, is 
associated with mortality in the health, aging and body composition study cohort." J Gerontol A Biol Sci Med Sci 61(1): 72-77.

Nikolic M, Bajek S, Bobinac D, Vranic TS Jerkovic R (2005): "Aging of human skeletal muscles." Coll Antropol 29(1): 67-70.

Ohlsson C Vandenput L (2009): "The role of estrogens for male bone health." Eur J Endocrinol 160(6): 883-889.

Orgaard A Jensen L (2008): "The effects of soy isoflavones on obesity." Exp Biol Med (Maywood) 233(9): 1066-1080.

Oxlund BS, Ørtoft G, Andreassen TT, Oxlund H. (2003):" Low-intensity, high-frequency vibration appears to prevent the decrease in strength of the femur and tibia associated with ovariectomy of adult rats." Bone $\underline{32}$ (1):69-77

Page ST, Amory JK, Bowman FD, Anawalt BD, Matsumoto AM, Bremner WJ Tenover JL (2005): "Exogenous testosterone (T) alone or with finasteride increases physical performance, grip strength, and lean body mass in older men with low serum T." J Clin Endocrinol Metab 90(3): 1502-1510.

Pelletier G (2002): "Effects of estradiol on prostate epithelial cells in the castrated rat." J Histochem Cytochem 50(11): 1517-1524.

Pettersson K, Delaunay F Gustafsson JA (2000): "Estrogen receptor beta acts as a dominant regulator of estrogen signaling." Oncogene 19(43): 4970-4978.

Preisinger E (2009): "[Physiotherapy and exercise in osteoporosis and its complications]." Z Rheumatol 68(7): 534-536, 538.

Prins GS, Birch L, Couse JF, Choi I, Katzenellenbogen B Korach KS (2001): "Estrogen imprinting of the developing prostate gland is mediated through stromal estrogen receptor alpha: studies with alphaERKO and betaERKO mice." Cancer Res 61(16): 6089-6097.

Rafii F, Davis C, Park M, Heinze TM Beger RD (2003): "Variations in metabolism of the soy isoflavonoid daidzein by human intestinal microfloras from different individuals." Arch Microbiol 180(1): 11-16.

Rauch F (2009): "Vibration therapy." Dev Med Child Neurol 51 Suppl 4: 166-168.

Riggs BL, Khosla S Melton LJ, 3rd (2002): "Sex steroids and the construction and conservation of the adult skeleton." Endocr Rev 23(3): 279-302.

Royuela M, de Miguel MP, Bethencourt FR, Sanchez-Chapado M, Fraile B, Arenas MI Paniagua R (2001): "Estrogen receptors alpha and beta in the normal, hyperplastic and carcinomatous human prostate." J Endocrinol 168(3): 447-454.

Russo CR, Lauretani F, Bandinelli S, Bartali B, Cavazzini C, Guralnik JM Ferrucci L (2003): "High-frequency vibration training increases muscle power in postmenopausal women." Arch Phys Med Rehabil 84(12): 1854-1857. 
Sadeh M (1988): "Effects of aging on skeletal muscle regeneration." J Neurol Sci $\underline{\text { 77(1): }}$ $67-74$.

Sandford NL, Searle JW Kerr JF (1984): "Successive waves of apoptosis in the rat prostate after repeated withdrawal of testosterone stimulation." Pathology 16(4): 406-410.

Sandhu E, Miles JD, Dahners LE, Keller BV, Weinhold PS. (2011): " Whole body vibration increases area and stiffness of the flexor carpi ulnaris tendon in the rat." J Biomech 444(6):1189-91.

Sarkar FH Li Y (2002): "Mechanisms of cancer chemoprevention by soy isoflavone genistein." Cancer Metastasis Rev 21(3-4): 265-280.

Schatzl G, Madersbacher S, Thurridl T, Waldmuller J, Kramer G, Haitel A Marberger M (2001): "High-grade prostate cancer is associated with low serum testosterone levels." Prostate 47(1): 52-58.

Schill WB (2001): "Fertility and sexual life of men after their forties and in older age." Asian J Androl $\underline{3}(1):$ 1-7.

Setchell KD Cole SJ (2006): "Method of defining equol-producer status and its frequency among vegetarians." J Nutr 136(8): 2188-2193.

Setchell KD, Brown NM, Desai P, Zimmer-Nechemias L, Wolfe BE, Brashear WT, Kirschner AS, Cassidy A Heubi JE (2001): "Bioavailability of pure isoflavones in healthy humans and analysis of commercial soy isoflavone supplements." J Nutr 131(4 Suppl): 1362S-1375S.

Setchell KD, Brown NM Lydeking-Olsen E (2002): "The clinical importance of the metabolite equol-a clue to the effectiveness of soy and its isoflavones." J Nutr 132(12): 3577-3584.

Shabsigh A, Chang DT, Heitjan DF, Kiss A, Olsson CA, Puchner PJ Buttyan R (1998): "Rapid reduction in blood flow to the rat ventral prostate gland after castration: preliminary evidence that androgens influence prostate size by regulating blood flow to the prostate gland and prostatic endothelial cell survival." Prostate $\underline{36}(3)$ : 201-206.

Silbernagel S und Klinke R: Lehrbuch der Physiologie, 4. Korrig. Auflage: Georg Thieme Verlag Stuttgart 2003, S.82-105

Statistisches Bundesamt (2009): "Bevölkerungsentwicklung in Deutschland bis 2060" http://www.destatis.de/jetspeed/portal/cms/Sites/destatis/Internet/DE/Content/Stat istiken/Bevoelkerung/VorausberechnungBevoelkerung/InteraktiveDarstellung/Int eraktiveDarstellung,templateId=renderPrint.psml 
Taylor CK, Levy RM, Elliott JC Burnett BP (2009): "The effect of genistein aglycone on cancer and cancer risk: a review of in vitro, preclinical, and clinical studies." Nutr Rev 67(7): 398-415.

Thomas A, Bunyan K Tiidus PM "Oestrogen receptor-alpha activation augments postexercise myoblast proliferation." Acta Physiol (Oxf) 198(1): 81-89.

Tiidus PM, Deller M Liu XL (2005): "Oestrogen influence on myogenic satellite cells following downhill running in male rats: a preliminary study." Acta Physiol Scand 184(1): 67-72.

Travis RC, Spencer EA, Allen NE, Appleby PN, Roddam AW, Overvad K, Johnsen NF, Olsen A, Kaaks R, Linseisen J, et al. (2009): "Plasma phyto-oestrogens and prostate cancer in the European Prospective Investigation into Cancer and Nutrition." Br J Cancer 100(11): 1817-1823.

Vasan S (2006): "Ageing male and testosterone: Current status and treatment guidelines" Indian J Urol 22: 15-22

Verschueren SM, Roelants M, Delecluse C, Swinnen S, Vanderschueren D Boonen S (2004): "Effect of 6-month whole body vibration training on hip density, muscle strength, and postural control in postmenopausal women: a randomized controlled pilot study." J Bone Miner Res 19(3): 352-359.

Wang J, Eltoum IE, Carpenter M Lamartiniere CA (2009): "Genistein mechanisms and timing of prostate cancer chemoprevention in lobund-wistar rats." Asian Pac J Cancer Prev 10(1): 143-150.

Warden SJ, Hurst JA, Sanders MS, Turner CH, Burr DB Li J (2005): "Bone adaptation to a mechanical loading program significantly increases skeletal fatigue resistance." J Bone Miner Res 20(5): 809-816.

Weidner W (2000): "[The aging man]." Urologe A $\underline{39(6): ~ 576-577 . ~}$

Weihua Z, Saji S, Makinen S, Cheng G, Jensen EV, Warner M Gustafsson JA (2000): "Estrogen receptor (ER) beta, a modulator of ERalpha in the uterus." Proc Natl Acad Sci U S A 97(11): 5936-5941.

White JW (1895): "I. The Results of Double Castration in Hypertrophy of the Prostate." Ann Surg 22(1): 1-80.

Wiik A, Gustafsson T, Esbjornsson M, Johansson O, Ekman M, Sundberg CJ Jansson E (2005): "Expression of oestrogen receptor alpha and beta is higher in skeletal muscle of highly endurance-trained than of moderately active men." Acta Physiol Scand 184(2): 105-112.

Wiik A, Ekman M, Johansson O, Jansson E Esbjornsson M (2009): "Expression of both oestrogen receptor alpha and beta in human skeletal muscle tissue." Histochem Cell Biol 131(2): 181-189. 
Xie L, Rubin C, Judex S. (2008): "Enhancement of the adolescent murine musculoskeletal system using low-level mechanical vibrations." J Appl Physiol 104(4):1056-62. Epub 2008 Feb 7.

Zhu YS (2005): "Molecular Basis of Steroid Action in the Prostate." Cellscience 1(4): 2755.

Zhu YS Imperato-McGinley JL (2009): "5alpha-reductase isozymes and androgen actions in the prostate." Ann N Y Acad Sci 1155: 43-56.

Zitzmann M (2008): "[Therapy of male hypogonadism]." Internist (Berl) 49(5): 559-560, 562-554, 566-559. 


\section{Danksagung}

An dieser Stelle möchte ich mich bei Herrn Prof. Dr. Wuttke für die Überlassung des interessanten Themas sowie für die großzügige Bereitstellung der Laborräume und die freundliche und unkomplizierte Betreuung während des Schreibens der Arbeit bedanken.

Meiner wissenschaftlichen Betreuerin, Frau PD Dr. med. D. Seidlová-Wuttke, möchte ich für ihr großes Interesse und die vielen praktischen Hinweise im Rahmen der labortechnischen Arbeit und des Schreibens der Arbeit danken.

Bei Frau Brüggemann-Meyer möchte ich mich ebenfalls sehr herzlich für die praktische Einführung in die Labormethoden sowie die sehr gute Zusammenarbeit und die vielen Hilfestellungen bedanken. 


\section{Lebenslauf}

Ich wurde am 07.05.1980 als Kind des Versicherungskaufmanns Hans-Joachim Scharff und der medizinisch-technischen Assistentin Doris Scharff, geb. Lieb, in Freudenstadt geboren.

In Freudenstadt verbrachte ich auch meine Kindheit und besuchte von 1987 bis 1991 die dortige Hartranft-Grundschule. Nachfolgend besuchte ich das Kepler-Gymnasium und beendete meine schulische Laufbahn an der Luise-Büchner-Schule mit der allgemeinen Hochschulreife im Jahr 2000. Anschließend folgte eine Ausbildung zur biologischtechnischen Assistentin an der Jörg-Zürn-Gewerbeschule in Überlingen am Bodensee. Diese schloss ich erfolgreich im Jahr $2002 \mathrm{ab}$.

Im Sommersemester 2002 begann ich mein Studium der Humanmedizin an der GeorgAugust-Universität Göttingen. Während meines Studiums famulierte ich innerhalb verschiedenster Bereiche der Medizin in Göttingen, Freudenstadt und Ho-Chi-minh-City/Vietnam.

Das Praktische Jahr folgte 2008 mit Tertialen in Budapest (Allgemeinchirurgie), Sanderbusch (Innere Medizin) und dem Kantonsspital Sarnen in der Schweiz (Wahlfach Gynäkologie). Im Frühjahr 2009 schloss ich mein Studium der Humanmedizin mit der Zweiten Ärztlichen Prüfung erfolgreich ab.

Im Herbst 2009 begann ich meine Dissertationsarbeit unter der Leitung von Herrn Prof. Dr. med. Wuttke, Leiter der Arbeitsgruppe Endokrinologie der Universität Göttingen. 